\title{
Migration/mobility and vulnerability to HIV among male migrant workers: Karnataka 2007-08
}

Shiva S. Halli

Raluca Buzdugan

Niranjan Saggurti

Population Council

Ravi K. Verma

Stephen Moses

See next page for additional authors

Follow this and additional works at: https://knowledgecommons.popcouncil.org/departments_sbsr-hiv

Part of the Demography, Population, and Ecology Commons, Family, Life Course, and Society

Commons, International Public Health Commons, and the Migration Studies Commons

How does access to this work benefit you? Let us know!

\section{Recommended Citation}

Halli, Shiva S., Raluca Buzdugan, Niranjan Saggurti, Ravi K. Verma, Stephen Moses, James Blanchard, Anrudh K. Jain, Saumya RamaRao, Ajay Kumar Singh, and Suvakanta N. Swain. 2008. "Migration/mobility and vulnerability to HIV among male migrant workers: Karnataka 2007-08." New Delhi: Karnataka Health Promotion Trust (KHPT) and Population Council. 


\section{Authors}

Shiva S. Halli, Raluca Buzdugan, Niranjan Saggurti, Ravi K. Verma, Stephen Moses, James Blanchard, Anrudh K. Jain, Saumya RamaRao, Ajay Kumar Singh, and Suvakanta N. Swain 
Migration/mobility of at-risk individuals, particularly their relocation or frequent visits to other areas for economic opportunity, has been viewed as a strong cofactor in accelerating HIV prevalence in India. However, little is known in India about the patterns of mobility of at-risk populations, the nature and extent of the interaction among them, and the implications of such migration on the HIV pandemic. This lack of understanding has been an impediment in planning effective HIVprevention programmes for these vulnerable populations.

A research study designed to determine the patterns and drivers of migration and mobility of at-risk populations of male migrant workers and sex workers and to examine the links of migration and mobility with HIV risk was conducted in four states with high HIV prevalence in India, namely Andhra Pradesh, Karnataka, Tamil Nadu, and Maharashtra. This report presents the findings from the male migrant workers study on volume and patterns of migration and their linkages with HIV risk. The study among male migrant workers in Karnataka was implemented by the Karnataka Health Promotion Trust in Bangalore and the Population Council in New Delhi. The report was reviewed by the team at the International Center for Research on Women (ICRW) in New Delhi.

For additional information on the study, please contact:

Dr. Saggurti Niranjan

HIV \& AIDS program

Population Council

Zone 5A, India Habitat Centre Lodi Road

New Delhi 110003

Telephone: 011- 24651314

Fax: 011 - 24645060

Email: nsaggurti@popcouncil.org website: www.popcouncil.org
For additional copies of this report, please contact:

South and East Asia Regional Office Zone 5A, India Habitat Centre Lodi Road

New Delhi 110003

Tel: +91 $1124642901 / 02$

Fax: +911124642903

Email:vthomas@popcouncil.org website: www.popcouncil.org 


\section{八 KHT $^{\text {KARNATAKA HEALTH PROMOTION TRUST }}$}

The Karnataka Health Promotion Trust (KHPT) was set up as a partnership between the Karnataka State AIDS Prevention Society (KSAPS) and the University of Manitoba, Canada in the year 2003. KHPT focuses on supporting and implementing initiatives related to HIV/AIDS and reproductive health.

\section{(P. Population Council}

The Population Council seeks to improve the well-being and reproductive health of current and future generations around the world. The Council's biomedical, public health, and social scientists identify and evaluate responses to the most important population, health, and development issues. Work is focused on three programme areas: HIV and AIDS; Poverty, Gender, and Youth; and Reproductive Health.

\section{(c) 2008 The Population Council, Inc.}

This document may be reproduced in whole or part without permission of the Population Council, provided that full source citation is given and reproduction is not for commercial purposes.

Suggested citation: Karnataka Health Promotion Trust (KHPT) and Population Council. 2008. Migration/Mobility and Vulnerability to HIV among Male Migrant Workers: Karnataka. Bangalore: KHPT. 


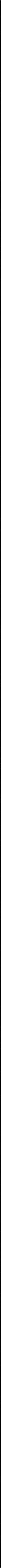




\title{
CONTRIBUTORS
}

\author{
Shiva S. Halli ${ }^{1}$ \\ Raluca Buzdugan ${ }^{1}$ \\ Niranjan Saggurti ${ }^{2}$ \\ Ravi K.Verma ${ }^{3}$ \\ Stephen Moses ${ }^{1}$ \\ James Blanchard ${ }^{1}$ \\ Anrudh Jain ${ }^{4}$ \\ Saumya RamaRao ${ }^{4}$ \\ Ajay K.Singh ${ }^{3}$ \\ Suvakanta N. Swain ${ }^{2}$
}

${ }^{1}$ Karnataka Health Promotion Trust, Bangalore, India

${ }^{2}$ Population Council, New Delhi, India

${ }^{3}$ International Center for Research on Women (ICRW), New Delhi, India

${ }^{4}$ Population Council, New York, USA 


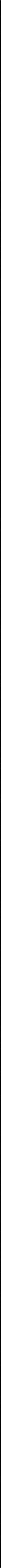




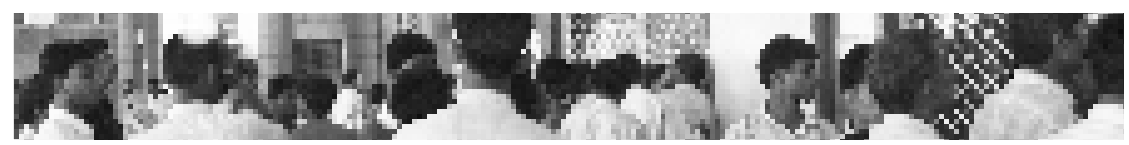

There is a growing recognition of the importance of migration in the spread of HIV infection. However, empirical FOREWORD research in this area has been negligible. Although intrastate and inter-state migration of men is common in India, little is known about their patterns of migration and the links of such mobility to HIV infection. Consequently, it has not been possible to design programs to prevent the spread of HIV infection in this vulnerable population group.

During November, 2006 - November, 2007, the Population Council undertook a study to examine the patterns of male migration and its links with HIV risk. The goal was to provide evidence to inform the design and implementation of HIV interventions for male migrant workers. The study was undertaken in collaboration with the Tata Institute of Social Sciences, Karnataka Health Promotion Trust, the Annamalai University and TNS India Pvt Ltd. It was conducted in 21 destination districts of four high HIV prevalence states namely Maharashtra, Karnataka, Tamil Nadu and Andhra Pradesh.

Ethnographic and survey research methods were employed to collect data on the volume, patterns, and routes of migration, and sexual risk behaviors. Data were collected from over 12,000 male migrant workers. Support provided by Avahan, Avahan's partner NGOs, the National AIDS Control Organisation, State AIDS Control Societies, other international and national organizations, and most importantly from the study participants themselves, was invaluable in conducting this study.

The study documents the volume and patterns of mobility of male migrants within and across districts and across states. It examines the social dynamics within the contract system that employs these men as laborers with the objective of exploring opportunities for implementing programs for the prevention of HIV infection in this vulnerable population. It documents the sexual risk behaviors and addictive behaviors of male migrants. The study shows that there is a clear need for implementing interventions to prevent HIV infection in migrant workers. A majority of these men report symptoms of sexually transmitted infections. They have multiple sexual partners. They report having sex with sex workers and with other women. A notable proportion 


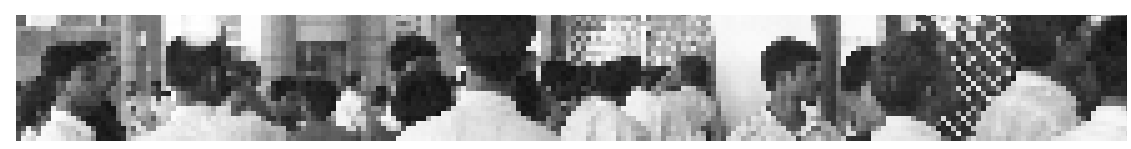

report the use of alcohol in conjunction with risky sexual behaviors. Furthermore, their self perception of HIV risk is low and few use condoms. A significant proportion of the men report having sex with women at the worksite indicating the need to provide HIV prevention interventions at the worksite for both men and women. They also report having sex with non-marital partners in the place of origin indicating the need for implementing interventions to prevent HIV infection before they migrate.

The study shows that in a majority of male workers, movement is facilitated by contractors in various occupations. These workers often move within the contract systems along with their male peers. The patterns of mobility within contract systems vary by state. However, there is a hierarchical structure within the system that connects individual workers to the industrial establishments at the state and national levels via groups of contractors. These findings signify that the contract system could provide an important entry-point for implementing HIV prevention interventions for male migrant workers.

This pioneering research study provides important evidence that should be used at both the national and state levels for the design and implementation of program strategies for the prevention of HIV infection in male migrant workers and their partners at the place of origin as well as at the place of destination. This important research-based evidence is valuable for the national and state-level AIDS control organizations of the government to inform the design of policies and implementation of programs. The research findings are also relevant for NGOs and others engaged in programs for the prevention and control of HIV and AIDS.

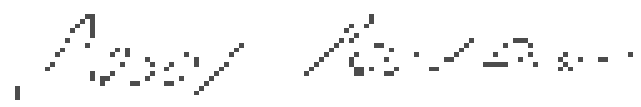

Dr. Saroj Pachauri MD, PhD.

Regional Director

South and East Asia

Population Council 


\section{Table of Contents}

\section{Acknowledgments}

Executive Summary

I. INTRODUCTION

II. STUDY DESIGN AND METHODS
2.1 Identification of study areas
2.2 Characterization of study districts
2.3 Quantitative data-collection procedure
2.4 Sample size
2.5 Sampling design
2.6 Degree of mobility
2.7 Definitions of other key variables

III. PATTERNS OF MIGRATION/MOBILITY

3.1 The extent of male workers' mobility

3.2 Mobility routes of recent male migrant workers

3.3 Characteristics of recent male migrants' mobility

3.4 What drives workers' migration

IV. PROFILE OF RECENT MALE MIGRANTS

4.1 Socio-economic and demographic characteristics of recent male migrants

4.2 Occupations of recent male migrant workers

4.3 Exposure to mass media, sex-related materials, and substance use

V. PATTERNS OF SEXUAL BEHAVIOUR AND VULNERABILITY TO HIV

5.1 Sexual behaviour of recent male migrants

5.2 Migration/mobility characteristics and sexual behaviour

5.3 Migrants' nonuse or inconsistent use of condoms with different sex partners

5.4 Symptoms of STIs and perception of HIV risk

5.5 Sexual behaviour along migration routes

5.6 Knowledge of HIV transmission and prevention

VI. IMPLICATIONS FOR THE HIV-PREVENTION PROGRAMME

6.1 Role of contractors/facilitators

6.2 Focus on places of origin 


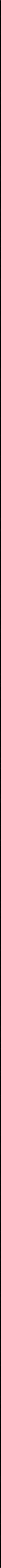




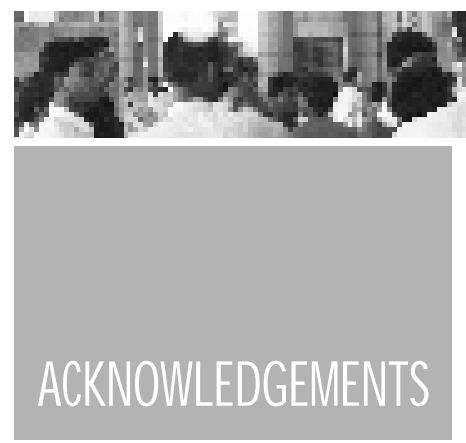

The study of Migration/Mobility and Vulnerability to HIV among Male Migrant Workers was successfully completed during 2007-08. The efforts of a number of individuals who were involved in the study are acknowledged.

First of all, the authors are grateful to the Bill \& Melinda Gates Foundation for its support for the study through Avahan, it's India AIDS Initiative. We are thankful to Mr. Ashok Alexander, Dr. Gina Dallabetta, Dr. Aparajita Bhalla, Mr. Hari Menon from the Avahan, it's India AIDS initiative of the Bill \& Melinda Gates Foundation for their active support and involvement at all stages of the project. However, the views expressed herein are those of the authors and do not necessarily reflect the official policy or position of the Bill \& Melinda Gates Foundation and Avahan.

We would like to acknowledge the support of the members of the Technical Advisory Committee (TAC) for their overall guidance in the smooth conduct of the study. The contributions of the members, Dr. Prem Saxena, Dr. P.M. Kulkarni, Dr. Tarun K. Roy, Dr. R.R.

Gangakhedkar, Dr. Rohini Pande, Dr. Gurumurthy Rangaiyan, Dr. Arvind Pandey, Dr. Rajatashuvra Adhikary, Dr. Shiva S. Halli, Dr. Tobi Saidel, and Dr. Shalini Bharat, were helpful both through their direct involvement in TAC meetings and through interactions with individual members during the various stages of the project. Special thanks are due to Dr. Saroj Pachauri for chairing the Technical Advisory Committee and for guiding us at each stage of the project.

We also would like to acknowledge the contribution and support of the research team at the International Center for Research on Women (ICRW), New Delhi, in the preparation of this report.

We thank all the experts who participated in a series of workshops that were organized to prepare qualitative research tools, to undertake training of the research teams, to plan qualitative data analysis, and to prepare questionnaires, the sample design, and the tabulation plan for the report. 


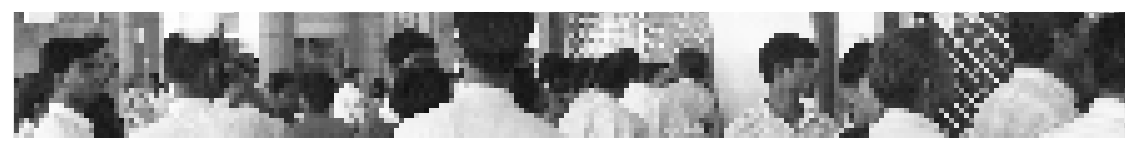

We are thankful to our consultants Dr. Pertti J. Pelto, Senior Anthropologist, Dr. Laxmi Ramchander and Mr. Zaheer Ahmad Khan for their assistance. Special thanks to Mr. V. L. Thomas, Executive Assistant at the Population Council for his excellent administrative support throughout the study as well as expert assistance in creating the tables, graphs, and formatting the report.

We would like to convey our special thanks to Dr. Ajay K. Khera, Mr. Aslam Naved, and Ms. Lakshmi Murthy from the National AIDS Control Organization (NACO) and the authorities from Karnataka State AIDS Prevention Society (KSAPS) for their help in facilitating data collection and interpretation and dissemination of findings.

We thank the Population Research Center, Dharwad, for their support and help, especially Mr. Channakki and Dr. Purnima for help with supervision of the fieldwork. We appreciate and acknowledge the untiring efforts of our field research team. We also would like to thank the KHPT NGO partners and the agencies for their cooperation in data collection. Of course, we are also thankful to our colleagues in KHPT: Mr. Raghavendra, Dr. B.M. Ramesh, Mrs. Vandana Gurnani, Dr. Reynold Washington, and other support staff.

Most importantly, we are immensely grateful to the participants of this study who have, without hesitation, given their time and narrated their experiences and views regarding mobility and HIV risk.

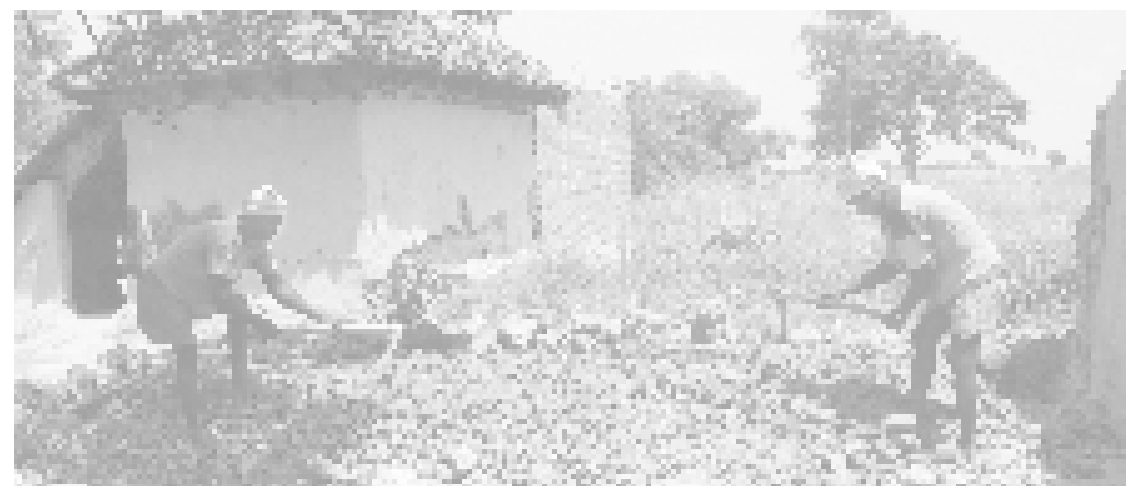




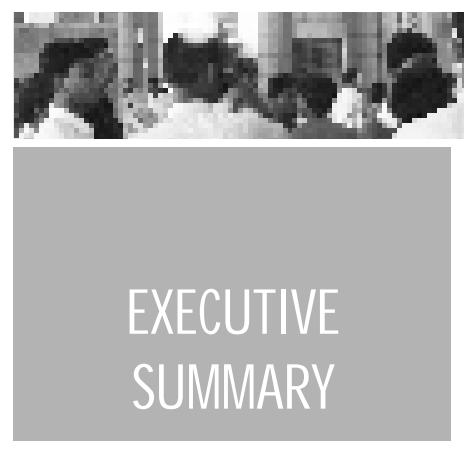

Karnataka, a South Indian state, is known to have a high prevalence of HIV infection. This situation may be related to the increasing volume of in-migration at the state and interdistrict levels. Little is known, however, about the patterns and causes driving male migration. This gap in understanding is particularly important in the context of the spread of HIV in Karnataka. Without sufficient knowledge about the patterns of movements of migrant men and their HIV vulnerability, designing intervention programmes to reduce the risky behaviour of this subpopulation is not possible.

The present study was undertaken by the Population Council and the Karnataka Health Promotion Trust (KHPT) to study the patterns and factors driving migration among men and the extent to which they engage in high-risk activities associated with HIV.

The specific objectives of the study are:

- $\quad$ to understand the patterns and factors driving the migration of men seeking work in the state of Karnataka;

- $\quad$ to describe the characteristics of vulnerable subpopulations among migrant men; and

- to examine the determinants of high-risk sexual behaviour among the subpopulations of migrant men, with an emphasis on their mobility as one possible factor.

The study was conducted in 2007 in five districts of Karnataka that experience in-migration of men from within and outside the state: Bangalore Urban, Dakshina Kannada, Bellary, Mandya, and Uttara Kannada. In each of the selected districts, characterization mapping was conducted in order to identify the areas where male migrant workers are found, to estimate the number of these workers, and to determine their occupations. This information was used to select the study sites in each district. Both qualitative and quantitative research methods were employed. For the qualitative phase of the study, a 


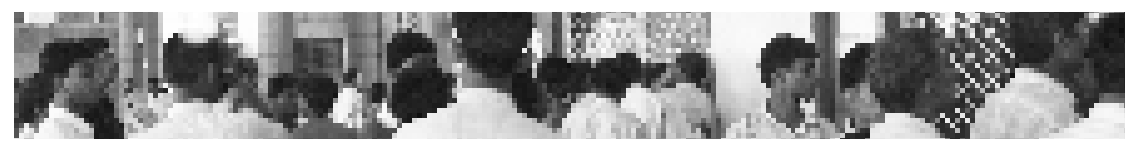

variety of methods were used: key-informant interviews, geographical and route mapping for mobile and migrant populations, and in-depth interviews. From the five selected districts for the qualitative phase, 109 key-informant interviews and 292 in-depth interviews were conducted. Mobility maps were drawn for all those selected for the in-depth interviews. In the quantitative phase, a total of 4,951 male migrants from the selected sites were contacted, of whom 2,640 eligible migrants were selected for comprehensive interviews using a structured survey instrument. The sample-selection criteria were chosen to ensure that the focus is on men who were recently mobile and migrating within the selected districts.

The male migrants interviewed were engaged in various occupations, including construction, mining, factory work, daily wage work, brickindustry work, fishing, garment making, port/factory loading, sugarcane cutting, and farm-produce warehouse work.

According to the survey, an estimated 50 percent of migrant men from the destination districts are recently migrating workers who have been living at their current residence for less than two years and have moved to at least two other places in the past two years to seek work. The proportion of such migrants is comparatively higher in Bangalore Urban and Mandya and lower in Uttara Kannada and Dakshina Kannada districts.

Male migrants mention several reasons for moving to their current locations, reporting both "push factors" at their place of origin and "pull factors" at their current workplaces. The most important of these reasons are to seek better income and better work opportunities and to escape poverty and unemployment in their home areas.

Most of these migrants are younger than 30, have little education, and are overrepresented among the scheduled classes/scheduled tribes/other backward classes (SC/ST/OBC). Half of them are currently married, and one-third of the married men are currently living without their wives.

Two-thirds of the men interviewed report that they have been exposed to pornographic materials, and 70 percent have consumed alcohol in 


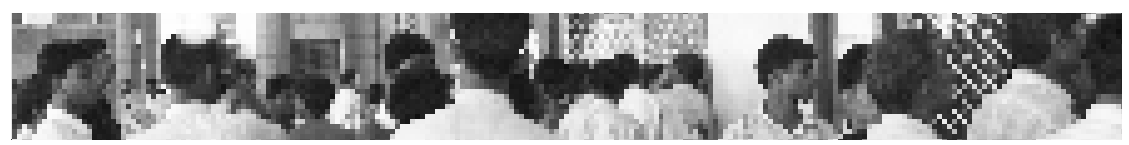

the past month. These proportions are important because men who engage in these practices tend to have pre- and extramarital sex in larger numbers than those who do not. Their marital status and whether they are accompanied by their spouse are also important factors in understanding their sexual behaviour. Single male migrants report engaging more frequently in sexual activities than do currently married men. Married men living without their wives are at highest risk of engaging in sex with sex workers, compared with other men.

Condom use differs among these men depending on the type of sex partners they have. Although the proportion of men who use condoms with sex workers is high, their low condom use with casual partners is of particular concern in light of the prevalence of casual sex among unmarried and married men alike.

Results suggest no relationship between degree of mobility and risky sexual behaviours among the migrants surveyed in the study districts in Karnataka. Moreover, no systematic pattern of a relationship is found between condom use with the various types of sex partners and degree of mobility.

Information about the sexual behaviour of recent male migrants in different places suggests that men are consistent in their sexual behaviour as they move along their migration route, a point of concern for HIV-prevention programmes. One-fourth of the migrants surveyed had pre- and extramarital sex in their places of origin, and half of them also had sex in one of the last three places to which they moved for work in the past two years. These findings indicate the need for HIVintervention initiatives in their home areas as well as in their work destinations. Based on the results of the present study, the main source districts in Karnataka are in the north: Koppal, Bellary, and Bagalkot. In the south, the main source district is Tumkur. Other districts that experience substantial male out-migration are Davanagere, Gadag, and Haveri.

From a programmatic point of view, HIV interventions could be implemented by means of the contract system, because most men in specific occupations work under contract. The data suggest that 30 


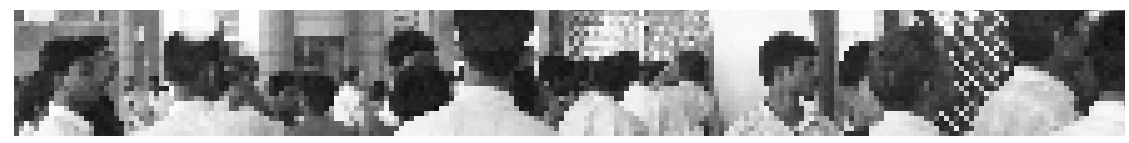

percent of men are currently under contract and that most of them work in the sugarcane-cutting industry, in road and other construction jobs, in mining, and in other high-risk occupations.

HIV-intervention programmes intended for recent male migrants should focus their efforts among subgroups of migrants, such as high-risk occupational groups, younger men, those who are married and living without their wives, and those who are unmarried. Future research is needed to improve understanding of the behaviour of men working in specific occupational groups, such as fishermen in Mangalore, mining workers in Bellary District, and sugarcane cutters in Mandya District (most of them from tribal hamlets), in terms of their sexual networks and HIV-prevention needs.

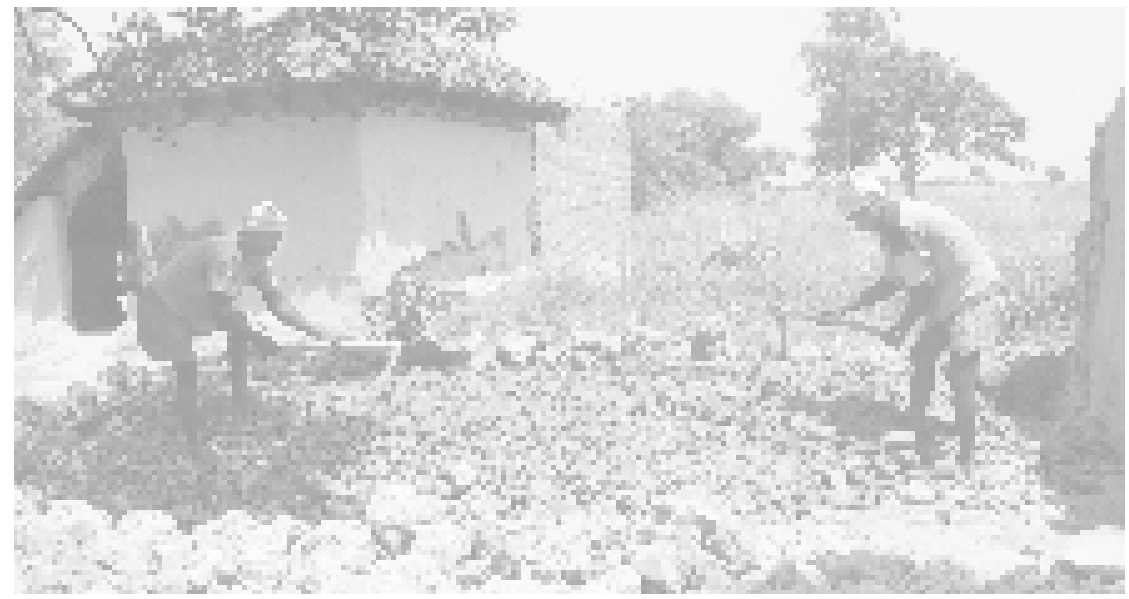




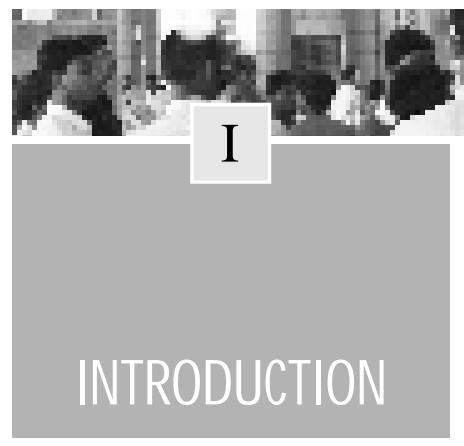

According to the 2001 Census of India, the number of males in Karnataka counted as migrants that is, enumerated in places other than their place of birth or previous residence increased from 4.6 million in 1991 to 5.7 million in 2001. A little more than half (53 percent) of the total number of male migrants moved within their districts, 30 percent moved across districts but within their state, and 17 percent moved across states (Saggurti et al. 2008). This evidence suggests that a large majority of men moves within districts and that a significant proportion moves across districts for work purposes. Similarly, a recent study conducted in northern Karnataka reveals that almost every village experiences 40 to 50 percent seasonal migration of men aged 20 to 35 (Halli et al 2007). Some 50 percent of the villages in at least some districts in northern Karnataka include tribal-group hamlets. Historically, these tribal peoples are landless labourers, and nearly 80 percent of the men in most of these hamlets are seasonal migrants (Halli et al. 2007). Such extensive migration, together with considerable mobility has significant implications for the spread of HIV among districts that are destinations for male migrant workers and also within the migrants' places of origin.

HIV infection is prevalent in Karnataka State. Results from the National Family and Health Survey III (NFHS-3) indicate that in 2005-06, 0.69 percent of the adult general population aged 15 to 49 were infected with HIV (IIPS and Macro International 2007). According to India's surveillance systems, 18 of 27 districts experienced HIV prevalence rates of more than 1 percent among pregnant women attending antenatal clinics. Prevalence among patients receiving treatment for sexually transmitted diseases (STDs) increased from 10 percent in 2003 to 14 percent in 2005 (NIHFW and NACO 2007).

Some reports suggest that migration to and from the neighbouring states of Maharashtra, Tamil Nadu, and Andhra Pradesh is one of the factors that contribute to some selected districts' vulnerability to the HIV pandemic in Karnataka (KHPT 2007², Menon 2004).

\footnotetext{
${ }^{1}<$ www.khpt.org/hivaids.htm>. Accessed 14 December 2007.
} 


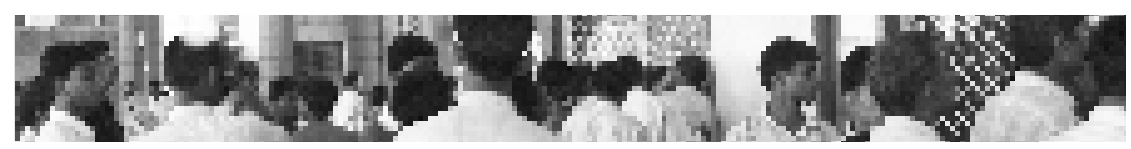

The India AIDS Initiative, Avahan, supported by the Bill \& Melinda Gates Foundation, has placed special emphasis on high-risk populations, including female sex workers, to check the spread of the HIV/AIDS pandemic. As part of this effort, the initiative proposed a study on male migrant workers, who are considered as a "bridge population" for HIV transmission from urban to rural communities (Decosas et al. 1995; Chandrasekaran et al. 2006). Examination of the district-level malemigration data of the 2001 census showed that levels of migration have a weak but positive association with HIV prevalence among antenatalclinic attendees (Saggurti et al. 2008). Without sufficient knowledge of the migration patterns of male workers and their HIV vulnerability, designing appropriate intervention programmes to reduce their risky behaviour is not possible. This study was undertaken by the Population Council in partnership with the Karnataka Health Promotion Trust (KHPT) to answer questions about migration and mobility patterns and their links to male migrant workers' vulnerability to HIV.

Some of the questions that the study addresses are:

- What types of occupations are migrant men engaged in within the high in-migration districts?

- Which are the districts and states of origin of male migrant workers?

- What are the men's routes of mobility/migration, and how long do they stay in each place.

- What is their connection to their places of origin? What are the reasons that they move/migrate?

- How do they behave sexually where they are living now, and how did they behave along their migration route?

- What are their condom-use patterns?

- How do their degree of mobility and other factors relate to their HIV vulnerability and risk? 


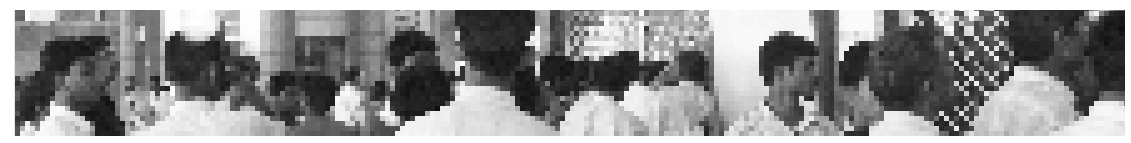

- What are the structures and dynamics of the migration of male workers (especially in terms of labour contractors)?

The specific objectives of the study are:

(1) to understand the patterns of and factors driving the migration/mobility of men who move from their places of origin for the purpose of work in the state of Karnataka;

(2) to describe the characteristics of vulnerable sub-populations among migrant men; and

(3) to examine the determinants of high-risk sexual behaviour among the subpopulations of migrant men, with emphasis on their mobility as a possible factor associated with their risky sexual behaviour.

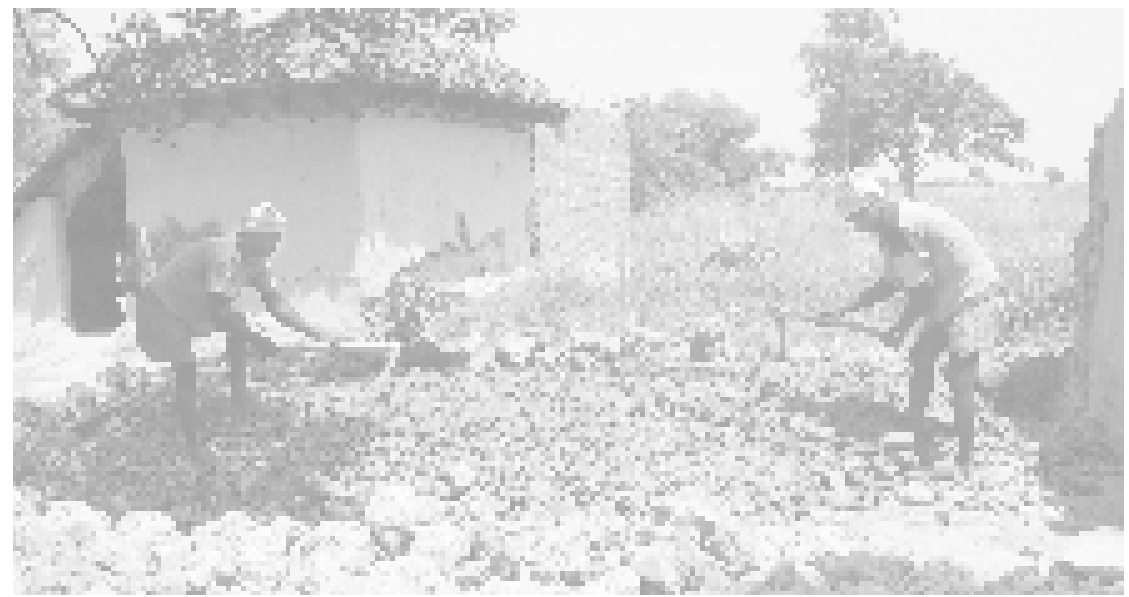




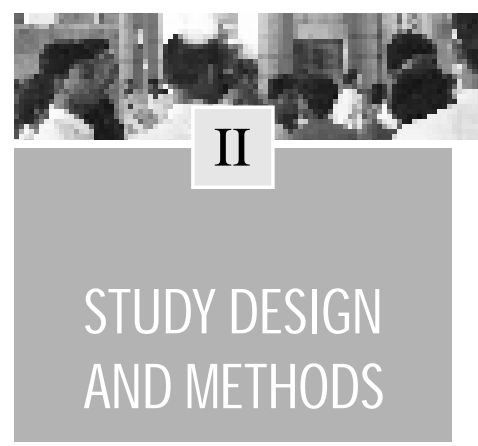

The cross-sectional study design involved the following major steps and engaged both qualitative and quantitative methods as outlined below:

(1) identification of major destination points, including intermediate destination points, of concentrations of male migrant workers (MMWs);

(2) profiling of destination sites, including intermediate destination sites within each selected district, using qualitative research methods; and

(3) gathering of quantitative data at the destination points and at the intermediate destination points.

The fieldwork was carried out from January to July 2007 in two phases: qualitative and quantitative. Before the initiation of the fieldwork, data from the 2001 census were analyzed to identify the districts (also referred to here as "study areas") that attracted migrant workers between 1991 and 2001. Migrant men from three foremost study districts identified in the census-data analysis were characterized using primarily qualitative data followed by a quantitative survey. Two additional districts with a substantial male in-migrant population engaged in skilled occupations were also selected for the study.

\subsection{Identification of study areas}

Primary destination and intermediate points were identified using the analysis of 2001 census data together with reports from key informants and anecdotal evidence. Selected districts cover a diversity of industrial sectors and occupational groups within a varied geography. The three districts of Bangalore Urban, Bellary, and Dakshina Kannada were among the five primary destination districts for men from outside and within the state. A large intradistrict movement of men also occurs in these three districts. Although they were among the five principal destination districts in Karnataka, Belgaum and Bagalkot Districts were not selected because a parallel study is being conducted in these 


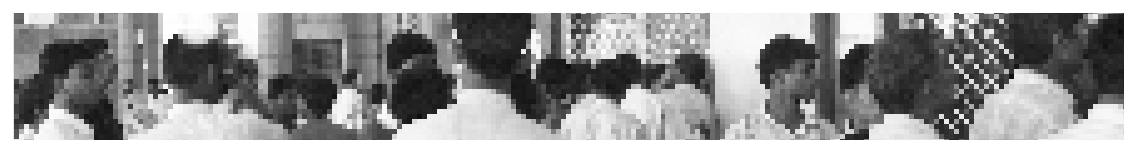

districts by KHPT with the support of Avahan. The other two destination districts selected were Uttara Kannada and Mandya, where male migrants work in agriculture and at the port. The five selected districts are shown in Map 1.

\section{Map 1 : Study districts in Karnataka State, India, 2007}

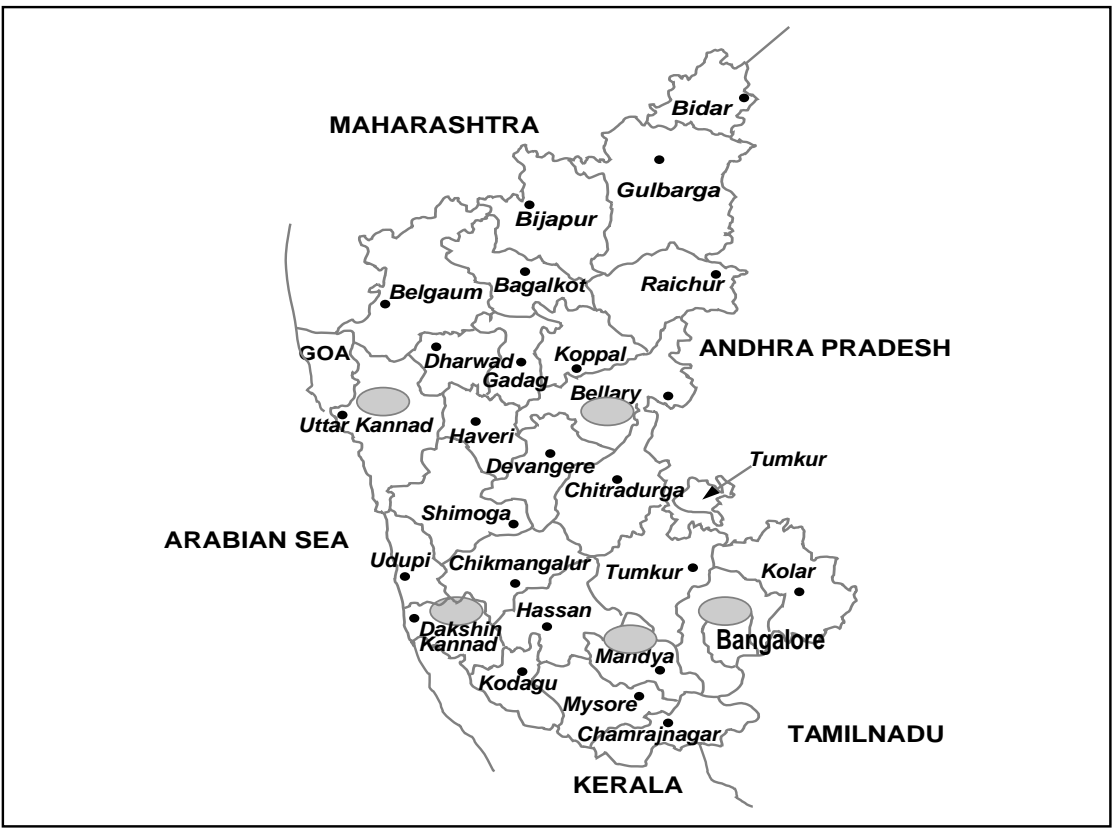

Bellary is located in the northeast of Karnataka and borders Andhra Pradesh in the east. The district is notable for its hot, dry climate. Bellary is ranked high in terms of income per capita (mainly as a result of its large-scale industries, including iron-ore mining and steel manufacturing) and low in terms of social development.

Uttara Kannada is also situated in northern Karnataka. A coastal district, it experiences heavy rains during the monsoon season and hosts the Karwar port. It borders Goa in the northwest. Uttara Kannada attracts 


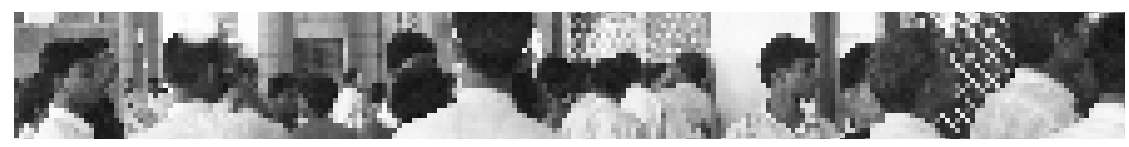

large number of men to work in fishing and other port activities (including loading and unloading), and in construction/infrastructure work.

South of Uttara Kannada is the district of Dakshina Kannada, which borders Kerala in the south. It is a developed coastal district where the Mangalore port area attracts men to work in fishing, related port activities, and construction.

Southeast of Dakshina Kannada is Mandya District, where the main work for migrants is sugarcane cutting. Mandya District enjoys a close association with the neighbouring districts, including Bangalore, Mysore, Hassan, and others, which affects its economy positively.

Bangalore Urban District, the capital of Karnataka State, lies northeast of Mandya District. It is one of India's booming hubs. Bangalore borders Tamil Nadu in the south and is close to Andhra Pradesh in the east. It is home to millions of people working in a variety of industrial occupations. As a consequence of the city's continuous growth, great demand exists for labour, particularly in construction/infrastructure.

\subsection{Characterization of study districts}

After the census data were analyzed and the study districts were selected, the characteristics of the selected districts were profiled. Sites were mapped within each district where MMWs either work or reside, the number of men working at each site was estimated, the types of occupations they are engaged in recorded, their places of origin listed, the existence of HIV programmes operating in the district was noted, and the local economy was described. To obtain this information, discussions were held with officials from revenue departments, districtlevel administrators, heads of nongovernmental organizations (NGOs), police officials, and heads of professional associations. Moreover, at each identified site interviews were conducted with individuals who were knowledgeable about male migrant workers, such as labour union leaders, local association leaders, contractors, industry security men, and NGO staff.

These characterizations helped identify a multitude of male migrant worker sites. The lists of sites were used to prepare a list of primary 


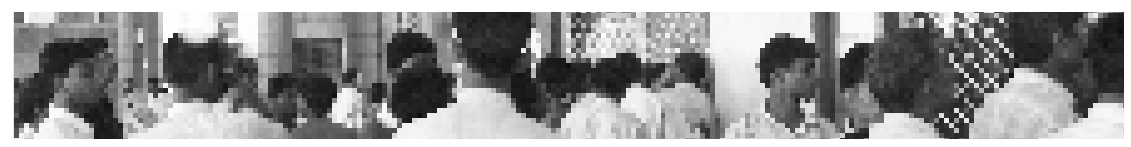

sampling units (PSUs). PSUs were formed by combining small areas or by segmenting the large areas so that each PSU would include approximately 5,000 male migrant workers. A total of 36 PSUs were formed, of which 19 PSUs (referred to as "study sites") were selected for detailed qualitative and quantitative study.

The qualitative data were collected in three stages. First, a description of study sites within each selected district was generated through interviews with local key informants, including migrant men, to map the physical locations of migrants, along with the locations where men have access to video parlours and sex workers, to develop a profile of migrant men working or residing in different locations and to identify their mobility patterns. Second, in-depth interviews were conducted with selected migrant men to generate individual mobility maps and to gather information about their lifestyles and sexual behaviours. During the indepth interview, the respondent identified his place of origin, and his intermediate and current locations, the duration of stay in each place, the contractor he worked under (if any), and his reason for each move. This information was used to create an individual mobility map. Third, in order to analyze the dynamics of group mobility, interviews were held with groups of migrant men who were selected according to their occupational category and/or place of origin.

This detailed research approach was designed to identify individual, community, and structural factors that influence male workers to migrate and that affect their sexual-risk behaviour and vulnerability, and to inform the sampling frame for the quantitative survey. A total of 401 interviews (109 key-informant interviews and 292 in-depth interviews) were conducted in the five study districts. For these interviews, the respondents were purposively selected to include individuals from a range of occupations. All interviews were conducted after taking written or verbal informed consent from study participants.

The qualitative data were gathered by a team of ten trained and experienced male investigators. The information gathered from keyinformant interviews, in-depth interviews, and mobility maps was collected in Kannada (the state language of Karnataka). The interviews were translated into English and analyzed with the help of Atlas.ti, a computer-based text-search programme (Muhr 2004). 


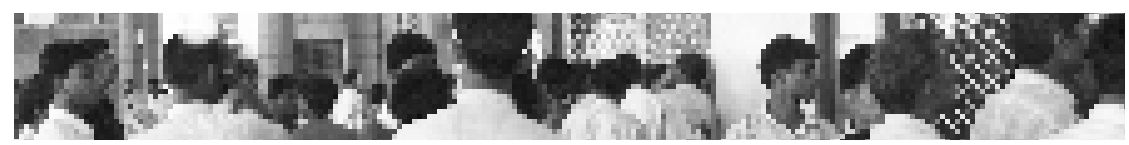

In the second phase, a quantitative survey was conducted among selected male migrants to understand the factors leading to their migration and to gather information about their sexual behaviour along the migration routes.

\subsection{Quantitative data-collection procedure}

For the purpose of the survey, a male migrant worker was defined as an "eligible respondent" and included in the study if he

(a) had moved to his current location to obtain work in the previous two years, and

(b) had lived in two or more places for the purpose of work in the previous two years.

The study sample included only consenting male migrant workers aged 18 or older.

\subsection{Sample size}

To examine the relationship between the men's degree of mobility and their sexual risk behaviour, 2,500 interviews were planned to be conducted at the selected districts of Karnataka. A total of 4,951 men were approached at selected PSUs and screened for eligibility. Fiftythree percent $(2,640)$ of the men contacted at the study sites arrived at their current location in the past two years and had moved from their places of origin to at least two places in order to work in the past two years.

\subsection{Sampling design}

In each PSU, the study adopted two types of sampling procedures for selecting migrant men. The workers from residential colonies (either organized labour colonies or illegally occupied land where small hutments were made for living) were selected using a two-stage systematic sampling procedure, and the migrant men from workplaces were selected using a facility-based sampling procedure. 


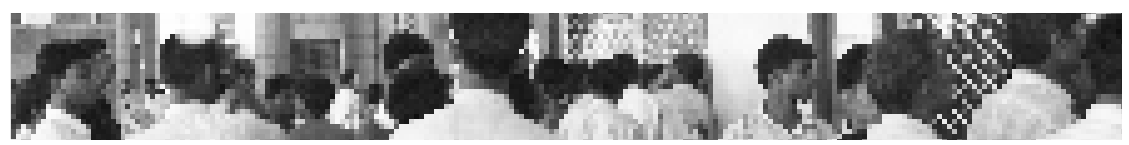

Male migrant workers who could be located in residential colonies were selected using a two-stage systematic sampling procedure. First, a sketch of the area was drawn on paper and the lanes, small pockets, and areas within each larger area were listed. The sub-lanes or small areas were selected systematically from the lists in the first stage. In the second stage, the required number of houses was systematically selected after the number of intervals was determined.

For the selection of migrants at the workplace, a facility-based procedure was used. If the facility listed their male migrant workers, the lists were used to select the men for interview systematically. Otherwise, men were selected from the areas where they work or loiter (nakkas where they wait to be hired).

The selected men were screened to collect information on age, place of birth, duration of residence at the current location, number of places to which they had moved for work in their lifetime, and number of places to which they had moved for work in the past two years. This information was used to estimate the extent of male migration in each district.

The survey instrument included: a socioeconomic and demographic profile, questions concerning each man's living conditions, media exposure, lifestyle, support services, migration/mobility history, his connection to his place of origin, his sexual behaviour, including sexual activities with sex workers, with a regular or casual partner, and with his spouse if he was married, his current and past condom use, sexually transmitted infections, and knowledge of and risk perception concerning HIV/AIDS.

Quantitative surveys in all the study areas were carried out by ten experienced male interviewers using a paper questionnaire. These men were trained in the ethical conduct of interviews. Informed consent was obtained from each respondent. Data quality was ensured by means of a supervisory structure that provided regular feedback in the field and data cleaning in the office. Data-processing operations included data editing in the field, feedback to the team, data-quality checks, cleaning, and tabulation. Statistical Package for Social Sciences (SPSS) was used for data-consistency checks and analysis. 


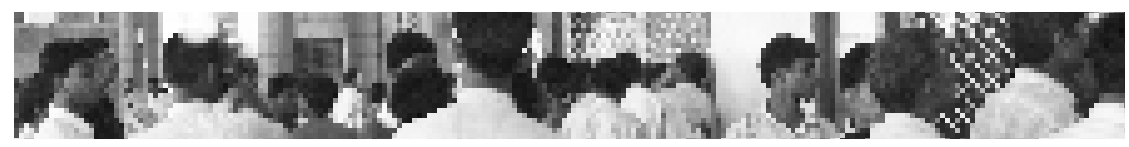

\subsection{Degree of mobility}

Because this study did not compare migrant and nonmigrant men, a variable "degree of mobility" was constructed with two categories: migration to two locations or to three or more locations. The other indicators of mobility used in the study are: respondent stayed overnight away from home while at current location in the past month (no, yes); respondent commutes between the workplace and his residence, but has not stayed overnight away from home in the past month (no, yes); respondent moved to current location under contract (no, yes).

\subsection{Definitions of other key variables}

Measures of sexual risk behaviours were derived from responses to questionnaire items. Respondents were asked to indicate their experience of specific sexual behaviours in their lifetime (ever) and in the past 12 months (present). The types of sexual behaviour asked about included sex with a sex worker and sex with either a regular or casual unpaid sex partner in the past 12 months. In addition, respondents were asked to indicate the number of their sex partners in the past 12 months, and the response was coded as one or more preand extramarital sex partners or no partner in the past 12 months. Questions were asked about whether the respondent had had sex with sex workers or with other partners in each of the places they had moved to in the past two years and in their place of origin. This response provided a count of the number of places where men had had sex in the past two years and was tabulated by respondents' type of occupation and contractual system.

In order to measure potential HIV-prevention-programme coverage if the contract systems were to be targeted, the questions about respondents' working under contract for the first time or currently were divided into groups: men who were never under contract; men who were under contract for their first move but are not now under contract, men who are under contract currently but who were not under contract for their 


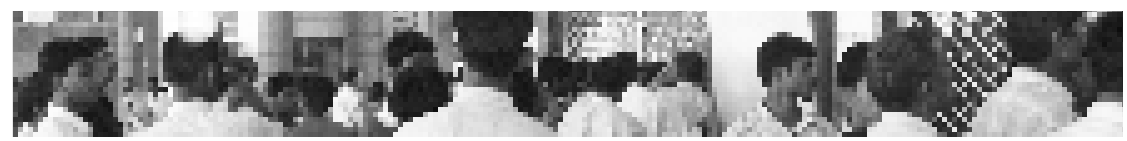

first move; and men who were under contract on both occasions ${ }^{2}$. The last three categories for this variable were combined (ever contracted, never contracted) to determine the proportion of men who might be covered by the HIV-prevention programme if the contract systems were to be targeted, and the respondents were cross-tabulated by their sociodemographic and economic characteristics.

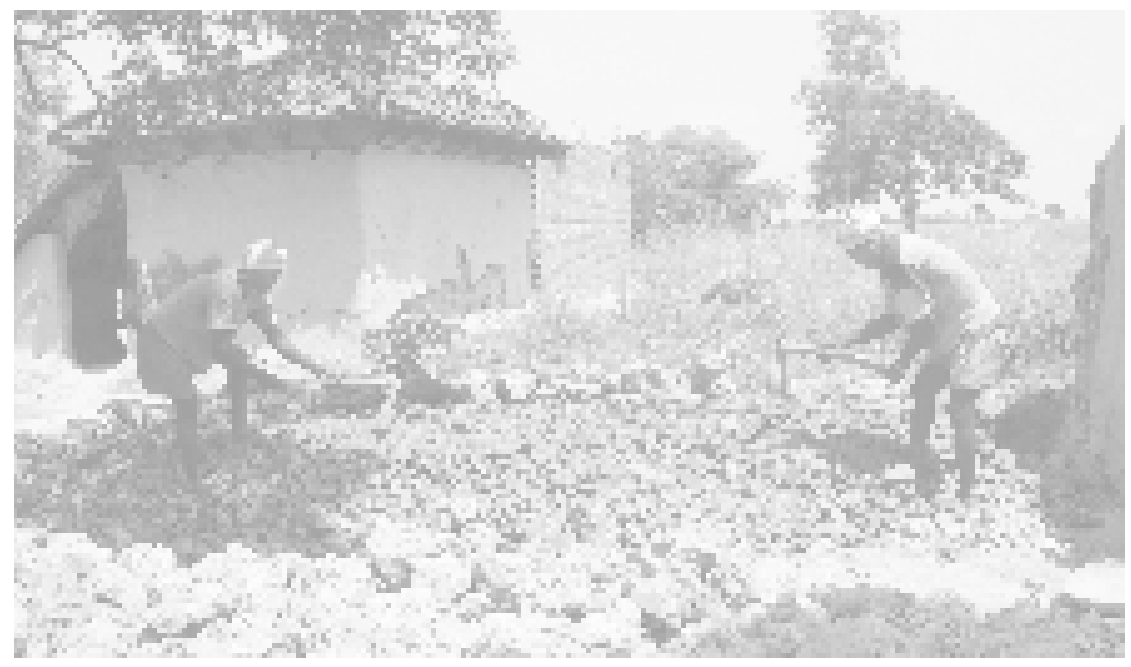

${ }^{2}$ Data on this variable was limited to information about men working under a contract either during their first move or at the time of the survey. 


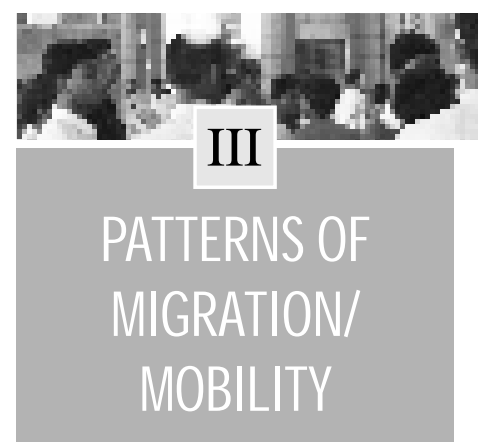

Responses to the screening questionnaire from the men recruited for the study $(\mathrm{N}=4,951)$ generated an estimate of the number of recent male migrants in each district.

\subsection{The extent of male workers' mobility}

Slightly more than half of the men interviewed using the screening tool were found to be living in their current location for less than two years and had moved from their place of origin to at least two different locations in the past two years (see Table 1). This subpopulation, referred to as "recent male migrants" in the report, is larger in Bangalore Urban and Mandya than in Uttara Kannada and Dakshina Kannada Districts. Most of these men are 20 to 29 years old. Men in this age group tend to be more mobile than others.

Following the administration of the screening schedule, men who moved to at least two locations in the past two years for work and whose current location is not their native district were selected for a comprehensive interview on mobility and HIV vulnerability. Of the 4,951 men screened during the sampling procedure, 2,640 were found eligible for the in-depth survey questionnaire. The information presented hereinafter refers to this subpopulation of recent male migrants.

\subsection{Mobility routes of recent male migrant workers}

Responses of recent male migrants $(\mathrm{N}=2,640)$ who participated in the survey provided the data for determining the patterns of their mobility. Data on the men's current location and previous two workplaces were used to construct common mobility routes for migrant men that are presented in the map below. The thickness of the lines represents the varying number of migrants using the different routes, and the arrows indicate the direction of the routes. We distinguish between interstate (dotted line arrows), interdistrict (grey arrows) and intradistrict (black arrows) routes. Maps 2 through 6 show the routes of MMWs currently residing and working in Bellary, Bangalore Urban, Mandya, Uttara Kannada, and Dakshina Kannada Districts. 


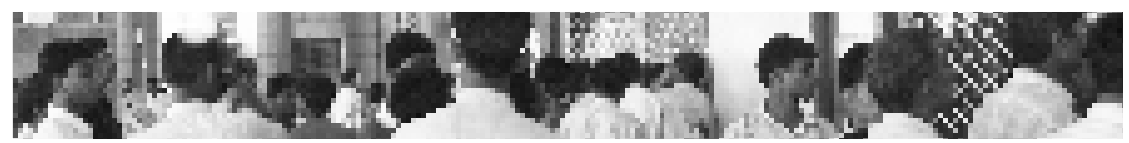

Recent male migrants in Bellary District moved in the previous two years mainly within the district (see Map 2). Other MMWs move to other districts in Karnataka, mainly Bangalore and Uttara Kannada. Some were working in Andhra Pradesh and came to Bellary either directly or through Bangalore.

Map 2 : Routes of recent male migrants in Bellary District, Karnataka State, India, 2007

Note: Thickness of the line represents the volume of migration and arrow indicates the direction.

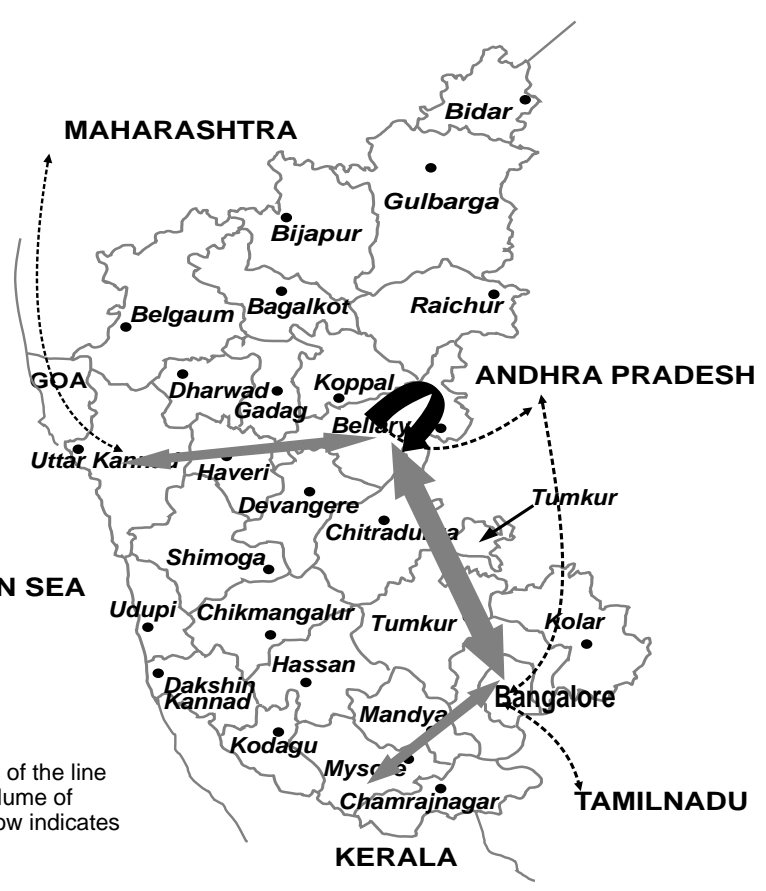




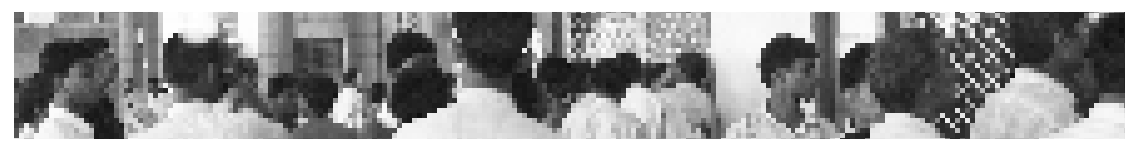

The majority of recent MMWs in Bangalore Urban moved within the district (as shown in Map 3). Other MMWs worked previously in Tumkur and before that in neighbouring districts, including Shimoga, Bellary, Chitradurga, and Hassan. Interstate mobility for this group is weak; their main destination state was Andhra Pradesh.

\section{Map 3 : Routes of recent male migrants in Bangalore Urban} District, Karnataka State, India, 2007

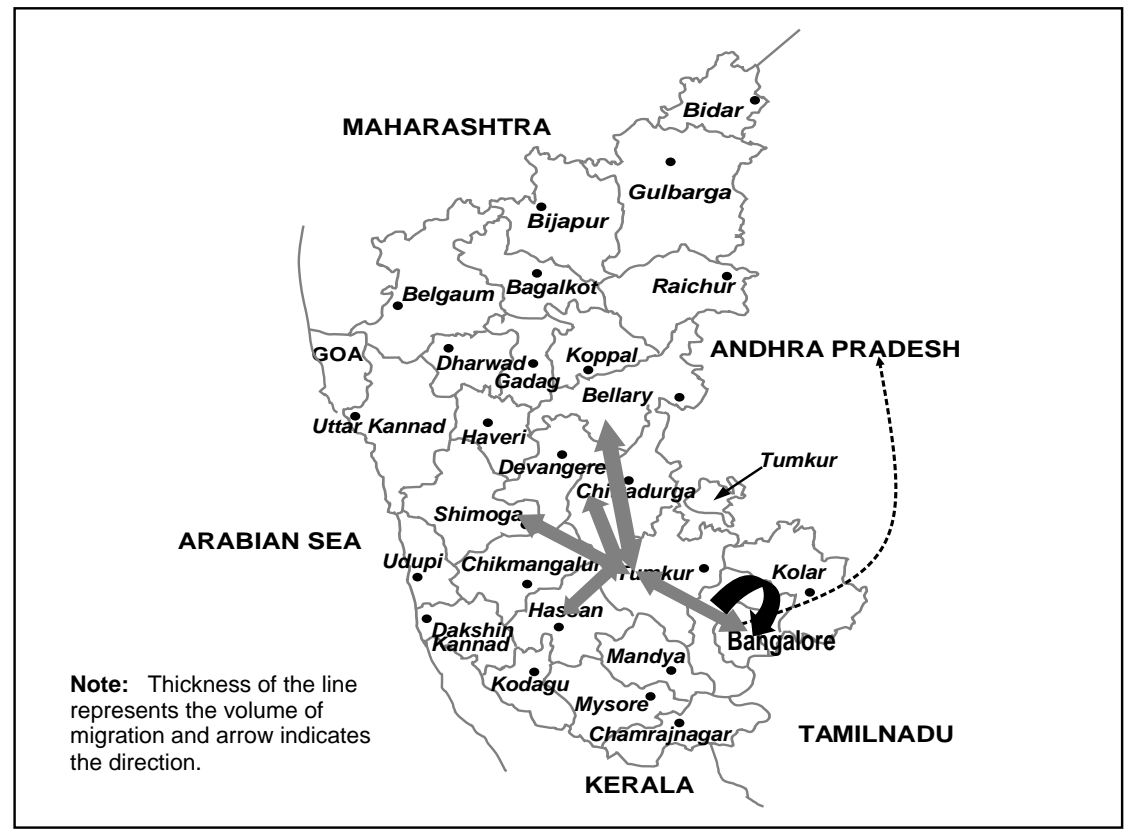




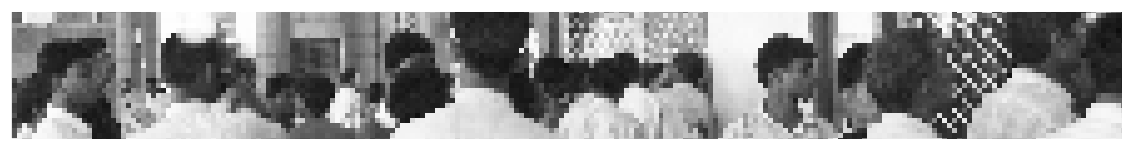

The majority of MMWs working in Mandya also worked previously in other places in the same district (see Map 4). Many workers move from the neighbouring districts of Mysore, Bangalore Urban, and Tumkur.

\section{Map 4 : Routes of recent male migrants in Mandya District,} Karnataka State, India, 2007

Note: Thickness of the line represents the volume of migration and arrow indicates the direction.

ARABIAN SEA

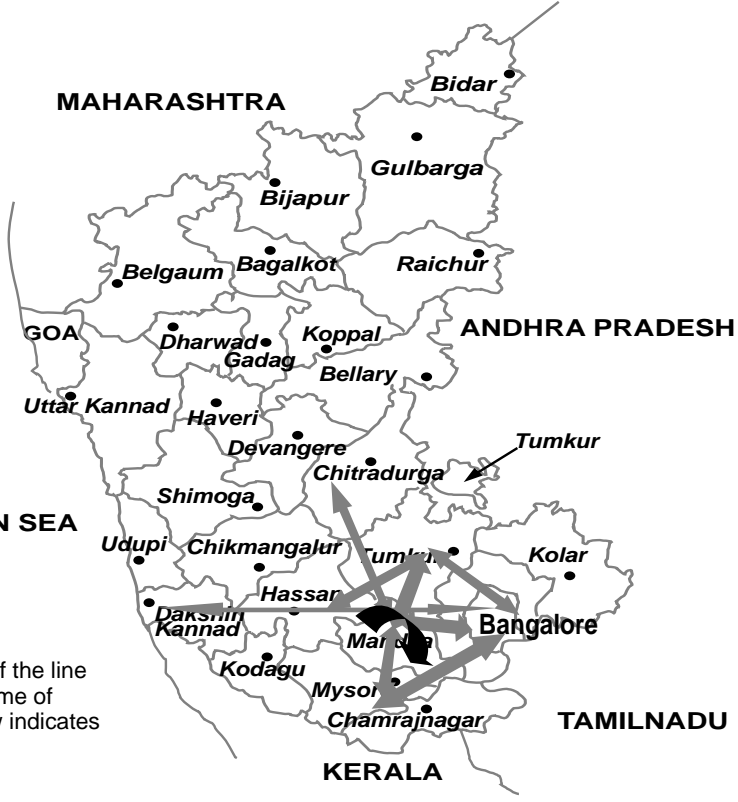




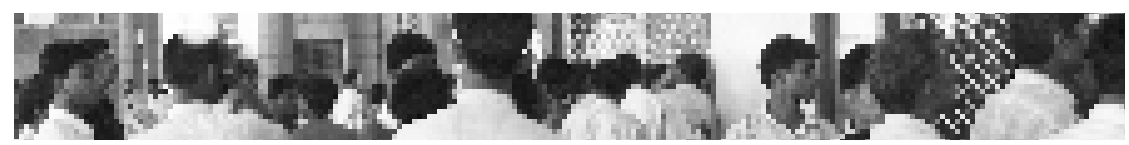

A substantial number of recent MMWs in Uttara Kannada have moved to their current place of work from other locations in the district (see Map 5). Some MMWs worked in other coastal districts in Karnataka, namely in Dakshina Kannada and Udupi, and some have worked in other districts in Karnataka, including Bellary and Bangalore. Some MMWs come to Uttara Kannada from Andhra Pradesh through Bangalore.

Map 5 : Routes of recent male migrants in Uttara Kannada District, Karnataka State, India, 2007

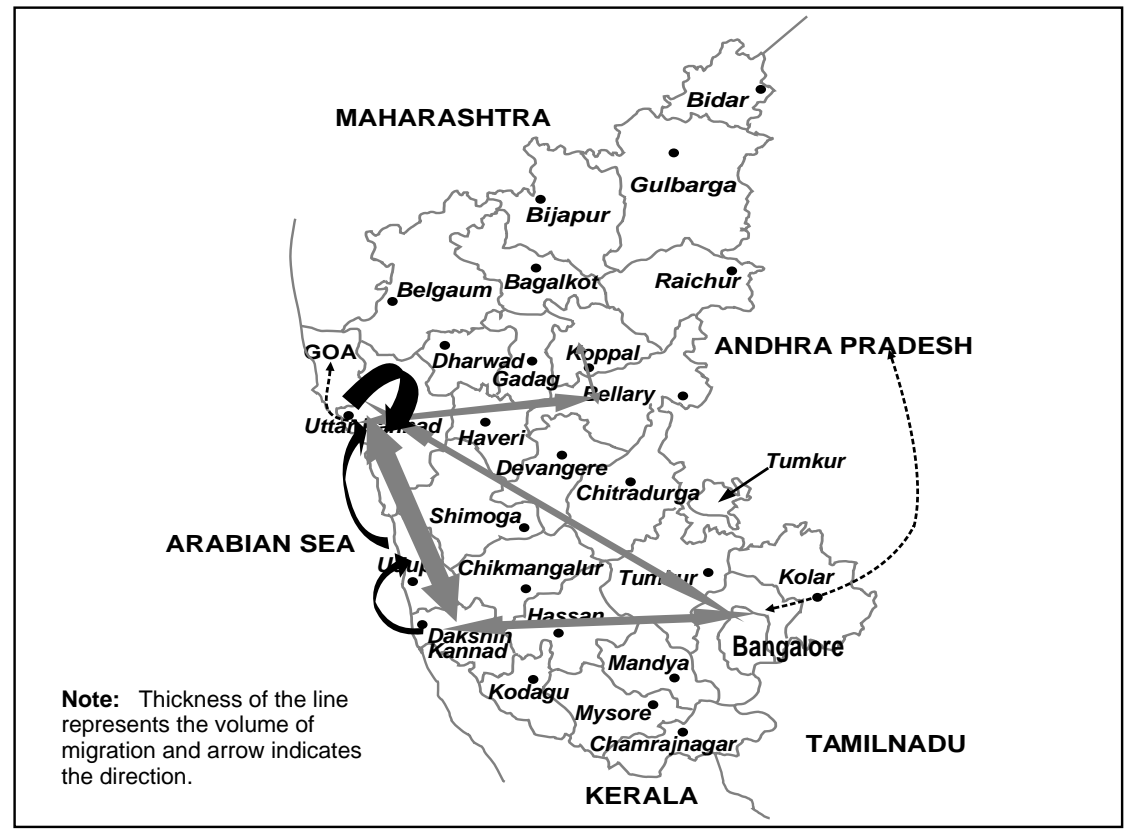




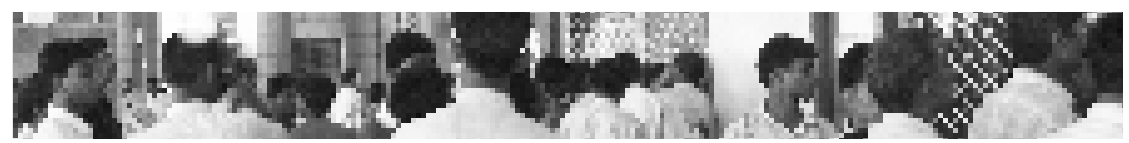

Compared with the other study districts, considerable intradistrict mobility is found in Dakshina Kannada, as shown in Map 6. Strong connectivity is evident with the coastal districts of Udupi and Uttara Kannada. MMWs in Dakshina Kannada have also worked previously in other districts in Karnataka, particularly in Bagalkot and Bangalore. Dakshina Kannada is connected by the migrants' route to Goa and to a smaller extent to Tamil Nadu and Kerala.

\section{Map 6 : Routes of recent male migrants in Dakshina Kannada} District, Karnataka State, India, 2007

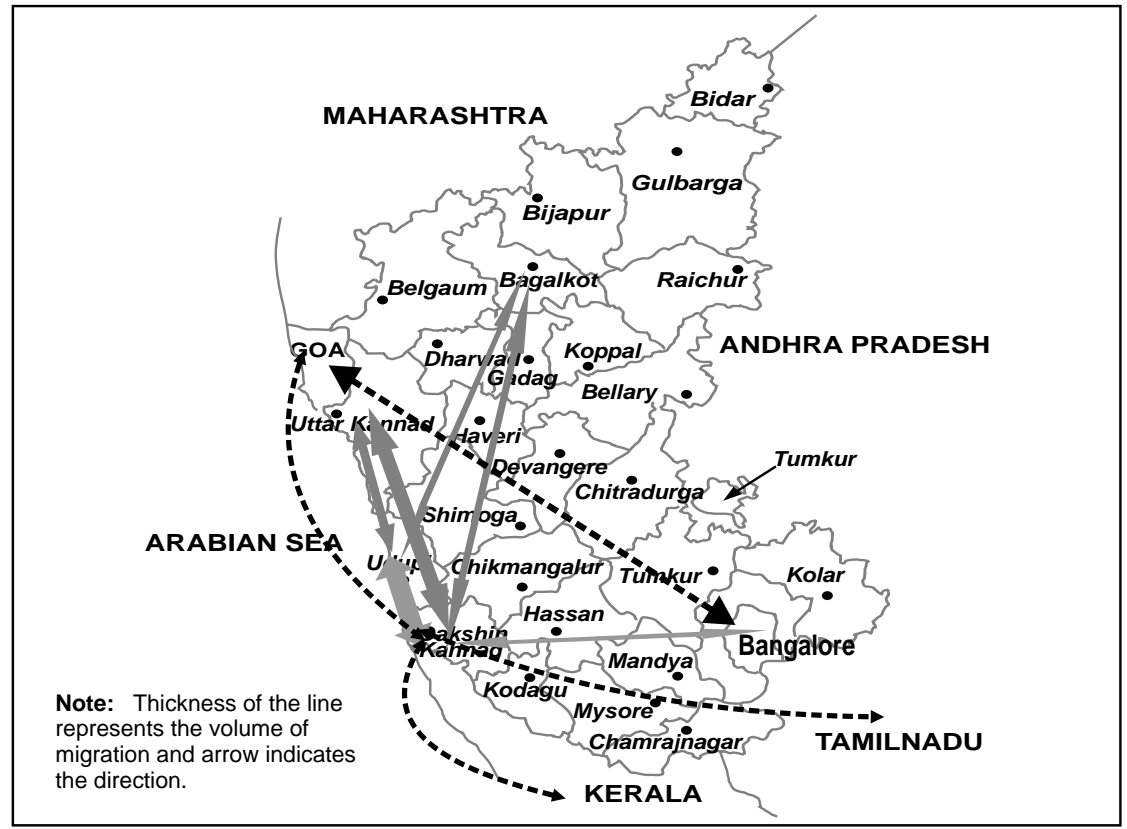




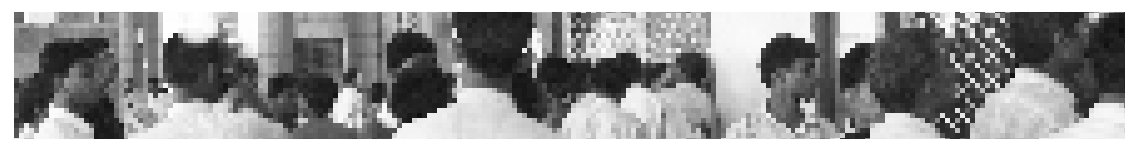

Respondents' home districts are shown in table $2 a$ according to the districts to which they migrated. The intradistrict, interdistrict, and interstate patterns of mobility are also revealed by the qualitative data. For example, miners in Bellary District usually moved from other places in the same district:

"They have come from our neighbouring taluks like Kudalgi, Hagri Bommanhalli, Kottaru, Harppanhalli, Hadgalli, and Mundargi, and also from places in other districts, like Gangavati, Kopal, Davangeri, Ron, Dharwad, and Bagalkot." (KI, mining supervisor, Bellary District)

Sugarcane cutters in Mandya District usually come from Bellary District on a seasonal basis during the cane-cutting season:
"Most of them are from Bellary. H.B.Halli taluk, Huvenhadagali, Hospet, Kamalapur, Koppal taluk, and "Lambani" [tribal] people come here. Those tandas are Raral tanda, Komaranahalli tanda, Sogi tanda, Nagalapur tanda, Kogali tanda, Timalapur tanda, and Maremanhalli tanda. They are coming here yearly in sugarcane- cutting season. They are staying here from J uly to March and are going back to the village." (KI, sugar-industry field officer, Mandya District)

At one of the construction sites in Bellary District, in part of a power plant, many migrants come from other states, particularly from North India:

"Migrants come mainly from Rajasthan, Andhra Pradesh, Bihar, Orissa, Gujarat, Tamil Nadu, Uttar P radesh, West Bengal, Kerala, and Punjab. A part from this, people come from different places in Karnataka, that is, Bagalkot, Raichur, Koppal, and Ilkal. Especially from Raichur (S indhagi and Manvi) the maximum [number] of migrants can be seen." (KI, fitter, Bellary District, skilled construction work)

\subsection{Characteristics of recent male migrants ' mobility}

The survey collected information from 2,640 recent male migrant workers about their movements from one place to another, their connection to their places of origin, and patterns, motivations, and facilitators of their migration. Their patterns of mobility are varied. Some 


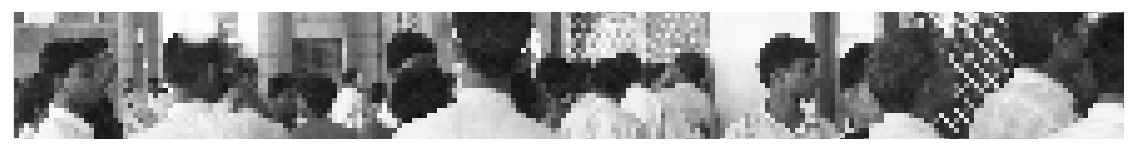

change their workplace every few months; others stay in one place for years. Moreover, some spend only a few nights per month away from their residence in order to work, and others commute on a regular basis between their residences and their workplaces.

Survey results suggest that two-thirds of respondents moved to three or more places in the past two years (see Table 2b). By comparison, more of the recent male migrants in Dakshina Kannada and Mandya than those in any other study district had moved to three or more locations in the past two years. Nine percent of the recent male migrants surveyed stayed overnight away from home for work purposes at least once in the month prior to the survey. Staying away from home overnight for work is more common among male workers in Dakshina Kannada district than in the other study districts. The majority of the men (90 percent) did not commute between residence and work. The proportion of commuters is relatively higher in Dakshina Kannada and Uttara Kannada than in the other study districts. In the case of Bellary, most men live in labour colonies or near the workplace. Similarly, men who work in Bangalore also tend to live within the city limits and at the work sites.

For 19 percent of the recent male migrants, the first move was facilitated by contractors. Contractors are hired by factory owners and managers to supply labourers for their enterprises. Contractors seek workers either directly or through other people, including neighbours, family, and friends. They usually hire workers from their own areas. A higher proportion (38 percent) of recent migrants moved for the first time with the help of contractors in Mandya District than in any other study district. The majority of the male migrant workers in Mandya District are sugarcane cutters, who specialize in this semiskilled work and are usually contracted as a group.

The qualitative survey data also indicate how men enter into the contract systems and move around for work. As one respondent explained:

"I was working as an agricultural labourer in my home area, but the salary I was getting was not sufficient to provide for my family. That's why I went in search of work. Then I spoke to my friends, who told me about digging work. For this work we came to Bellary through a 


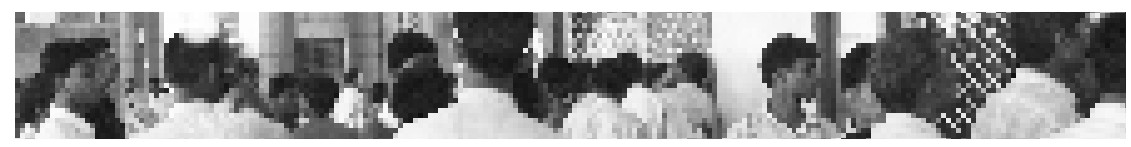

contractor. We dig into the ground for three to four feet for inserting telephone cable. I have been working at this job for six years. We used to go wherever the contractor arranged for the work, and after finishing the work, we used to return home. If we had work for many days, we used to take leave and go home, stay for two days and see all the family members. I roamed to many places in search of work and finally, for one and a half years, I've been working in KPCL. My job is loading and unloading. Now I am fine here, without any anxiety about finding work." (MMW, Bellary District, digger from Kuragod, married, 40 years old)

When asked "Have you thought of going to other places from here?", the informant said that after finishing the work, even "if we refuse, 'mestri' [the contractor] will send us to other places because we are daily wage labourers and we have to listen to whatever mestri says. So it is true that we have to go to other places where there is work. (MMW, Mangalore, construction worker, from Gadag)

Male migrants visit their places of origin with varying frequency, depending on the distances they must travel and whether their wives or families have accompanied them to their current location. Overall, more than half of migrants visit their home at no particular time. Almost 15 percent do so many times per year; about the same proportion visit a few times per year, and 2 percent only once per year.

\subsection{What drives workers' migration}

When asked why they move from place to place, men reported several reasons that include both "push" factors (reasons for moving out from the place of origin) and "pull" factors (reasons for going to the work destination).

The common reasons male workers give for migrating are expectation of a better income and better work opportunities and to escape poverty and unemployment in their home areas (see Figure 1). Other important reasons for migration include problems such as having debts at home, being fed up with work and low wages at home, drought, and family pressure. Some move because they know the place they are moving to; are being moved by the contractor; want to move to the city; or because the family intends to move to a particular place. 


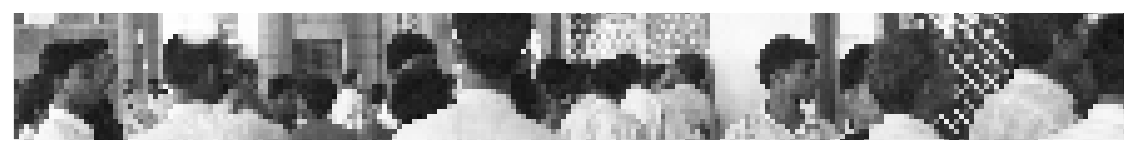

Figure 1 : Migrant workers' main reasons for moving to their current locations, Karnataka State, India, 2007

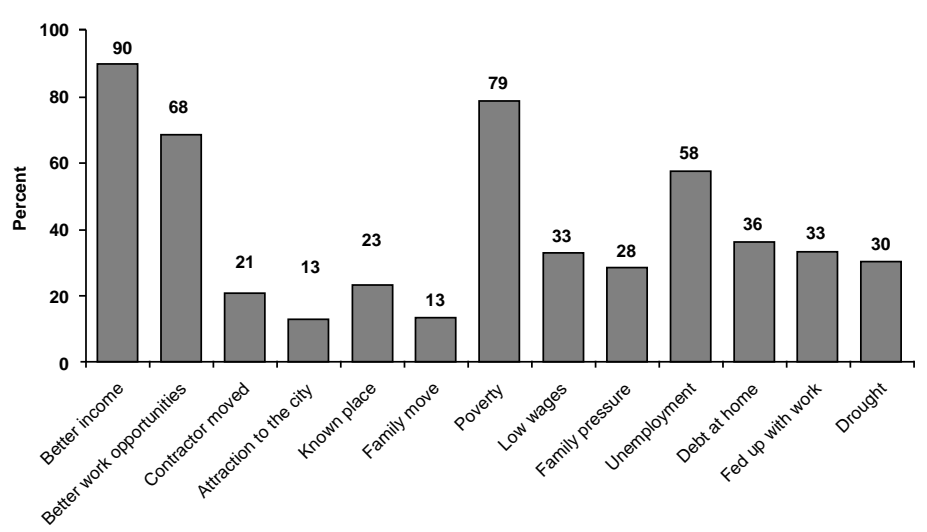

Pull factors at the migrants' curent locations

Push factors at the migrants' places of origin

Variations can be seen in workers' main reasons for migrating according to their district of origin (see Table 3). For example, men working in Bangalore are not usually working for contractors, but many move there because they like the city and because they know the area. In Bellary, drought at home is an important reason for migration, especially among people working as miners, many of whom are from Bellary District, which is dry and hot. In comparison with other districts, significantly more migrants in Dakshina Kannada and Mandya (nearly one-half) move because they have debts at home. Moreover, less than half of the men working in Mandya are there because their contractor moved them. 


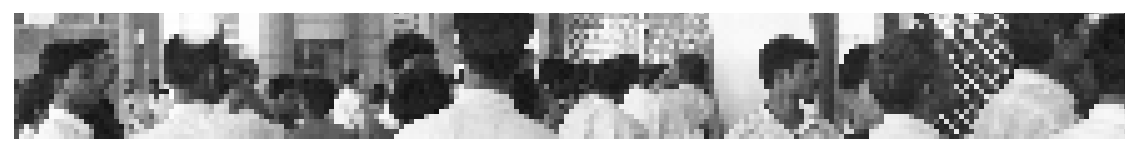

An example of the complexity and intertwining of reasons for migration comes from a male construction worker from Bijapur District who moved to Bangalore:

"I came to this place because there were no jobs in our village, the financial condition in my house had worsened, and I had the responsibility of taking care of my sister's and my brother's education. I found out that workers can make a bigger salary here. My friends had already come here before me, and there is no scarcity of jobs in this place."

A fisherman from Tamil Nadu working in Mangalore port mentions discrimination on the basis of caste as one of the reasons for migration:

Before coming here, I did fishing work at Madras, but the income was no good and the owner was not giving the wages correctly. Because we belong to the $\mathrm{SC}$ caste, the higher-caste people were troubling us, so it was very difficult to maintain the family. My friend was working at Mangalore. One day when he visited my place, he told us about this place, and then I wanted to come here..... well here we have a better income, there is no torture from the owner, and we can get work for nine months a year.

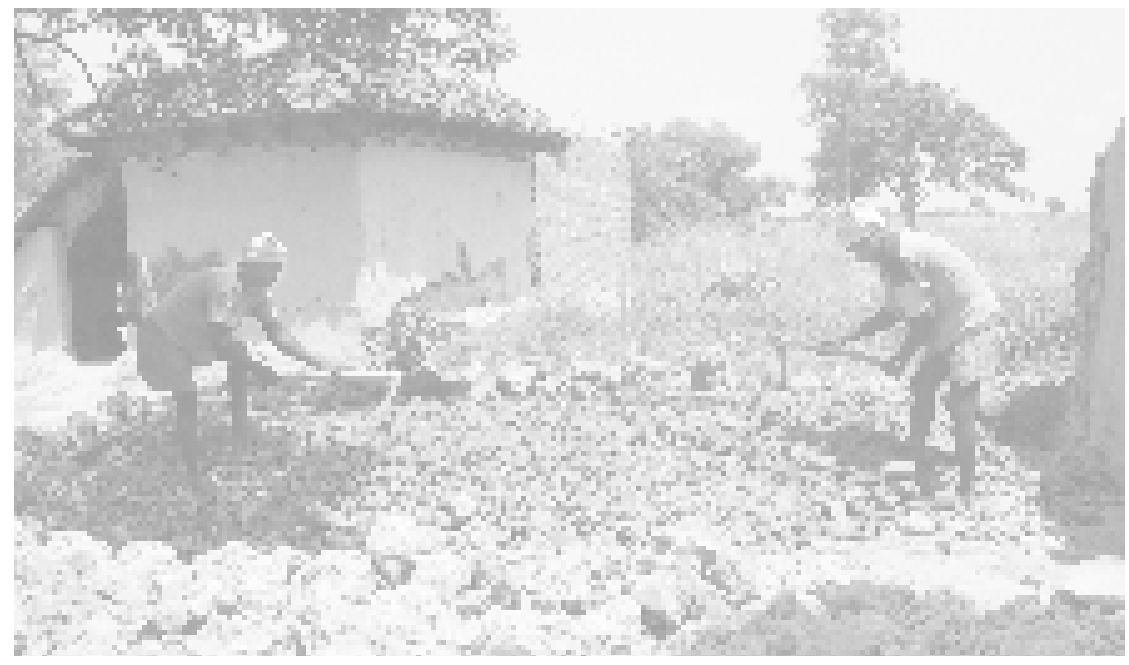




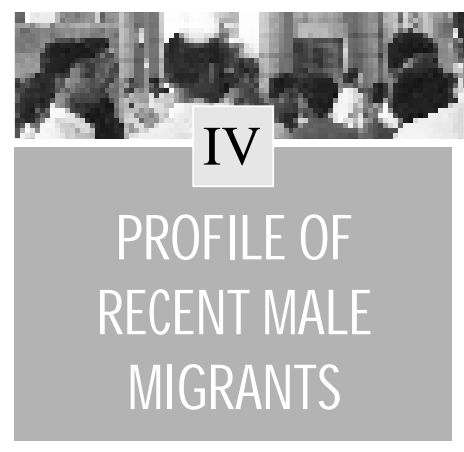

\subsection{Socioeconomic and demographic characteristics of recent male migrants}

More than 70 percent of recent male migrants surveyed were 19 to 29 years old, as shown in Figure 2. One-fifth were illiterate (see Table 4). The mean educational level among literate recent male migrants is 2.1 years (not shown). Migrant men in Uttara Kannada have the highest illiteracy among the five study districts; more than onefourth have never gone to school.

Figure 2 : Age distribution of male migrant workers, by district, Karnataka State, India, 2007

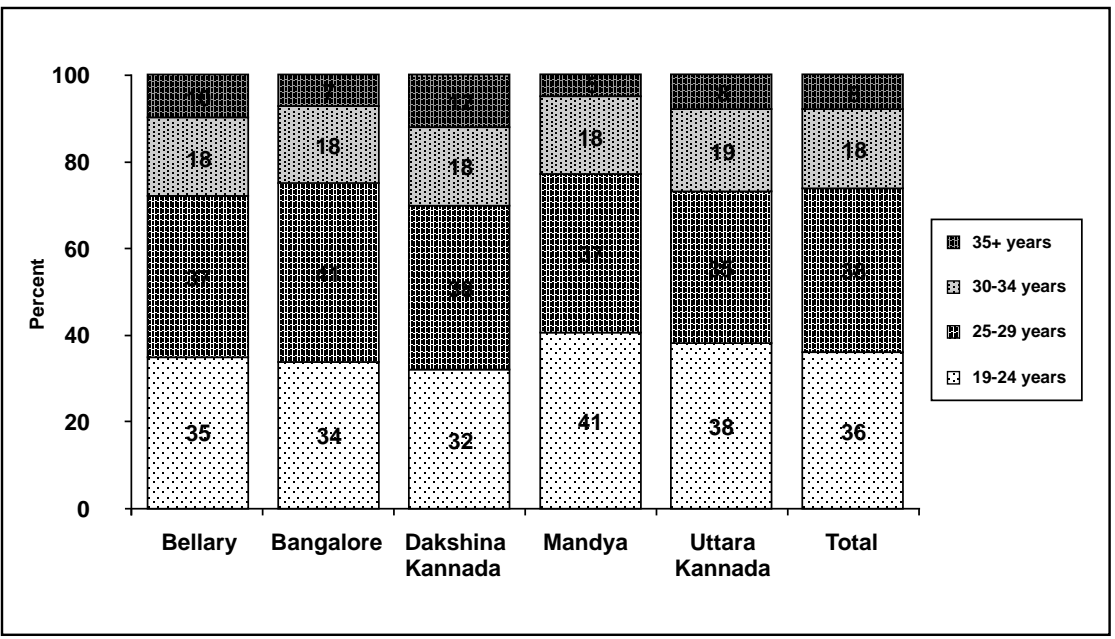

Nearly half of the recent male migrants interviewed are members of lower castes (scheduled castes or tribes: SC/ST), and another 40 percent belong to other backward castes $(\mathrm{OBC})$. The proportion of male migrants belonging to SC/ST/OBC castes is higher in Mandya and Uttara Kannada (both 93 percent), compared with those in the other study districts. 


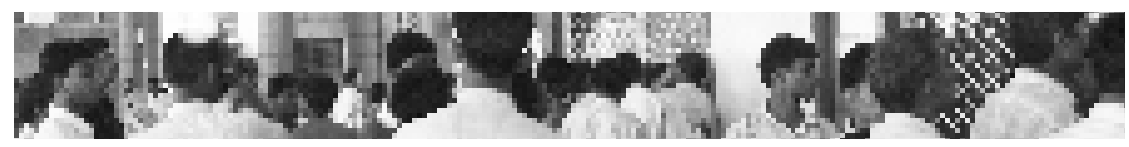

The average monthly income of recent male migrants in Karnataka is 4,485 rupees, and more than half earn less than 4,000 rupees per month. The migrants' income varies by district. For instance, men in Dakshina Kannada (especially fishermen) earn more money than others; 39 percent of them earn more than 5,000 rupees per month.

Fifty percent of the recent male migrants surveyed are currently married, and more than one-third of the married migrants are living without their wives at their current location. The proportion of these men is higher in Dakshina Kannada (53 percent) than in the other study districts (between 28 percent and 35 percent).

Regardless of their marital status, most migrants live either alone or with friends, some with their wives, and a minority with their parents and/or family. They usually live in kacha (mud and bamboo) houses or semipucca (mud and brick) houses, indicating poor living conditions.

\subsection{Occupations of recent male migrant workers}

The range of occupations of recent male migrants include construction, mining, factory work, daily wage work, brick-industry work, fishing, garment work, port/factory loading, sugarcane cutting and hamali (farmproduce warehouse work) (see Figure 3). Construction (of roads and buildings) is the main type of work available to migrant labourers in the study districts. A large majority of the study respondents worked in construction occupations, as shown in Table 5.

Variations in migrants' occupations occur by district. For example, the majority of recent male migrant workers in Bellary District are employed in the construction or mining industries. Men from these two occupations were screened and interviewed for the study. A large majority of migrant men in Dakshina Kannada District work in the fishing industry, and a large majority of the men surveyed in that district for the study worked in that industry. 


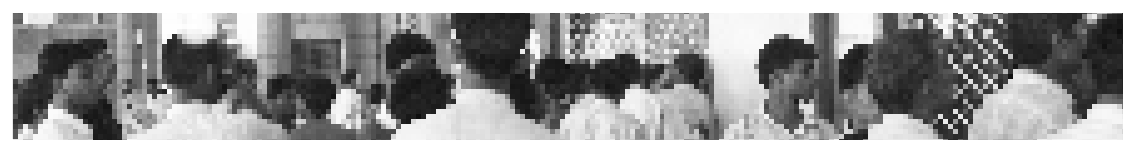

Figure 3 : Percentage of recent male migrants surveyed by their occupational category, Karnataka State, India, 2007

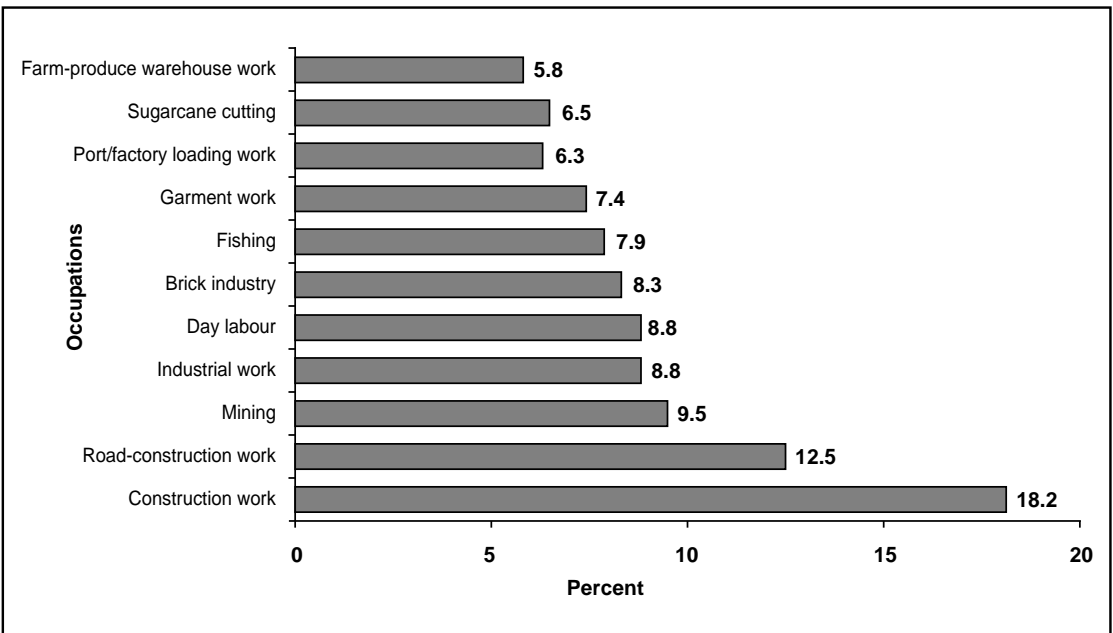

\subsection{Exposure to mass media, sex-related materials, and substance use}

In order to increase understanding of male migrants' risky sexual behaviour, the extent of their exposure to sex-related materials (for example, to photographs, magazines, and films) and their use of substances (including alcoholic beverages) must be determined, because high-risk behaviour is influenced by this exposure and use. Results from the survey show that half of the men interviewed saw sexrelated photographs or posters in the month prior to the survey, and one-third saw "adult" movies or "blue" films (see Figure 4). Altogether, two-thirds of recent male migrants have been exposed to at least one type of pornographic material.

One worker described his pastime activities, which included watching blue films, drinking, and visiting sex workers:

"I have been to all the places in Bellary. That's not new to us. I had gone to D.C. Nagar where very beautiful girls are seen. Earlier I used 


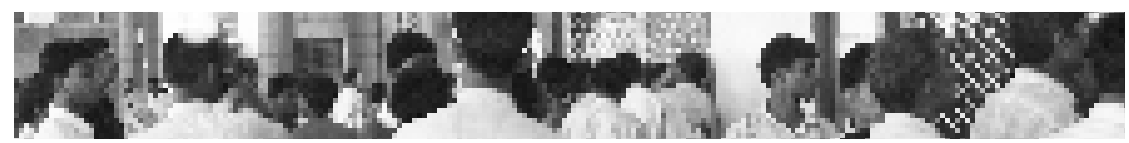

to go with my friend. He used to take me there. There we used to watch blue films and drink. In this way, we spent all our money there. Once in 15 days or once a month I used to go there." (MMW Bellary District, construction worker, from Andhra Pradesh, married, 27 years old)

Figure 4 : Percentage of recent male migrants surveyed who reported that they were exposed to sex-related materials in the month prior to the survey, Karnataka State, India, 2007

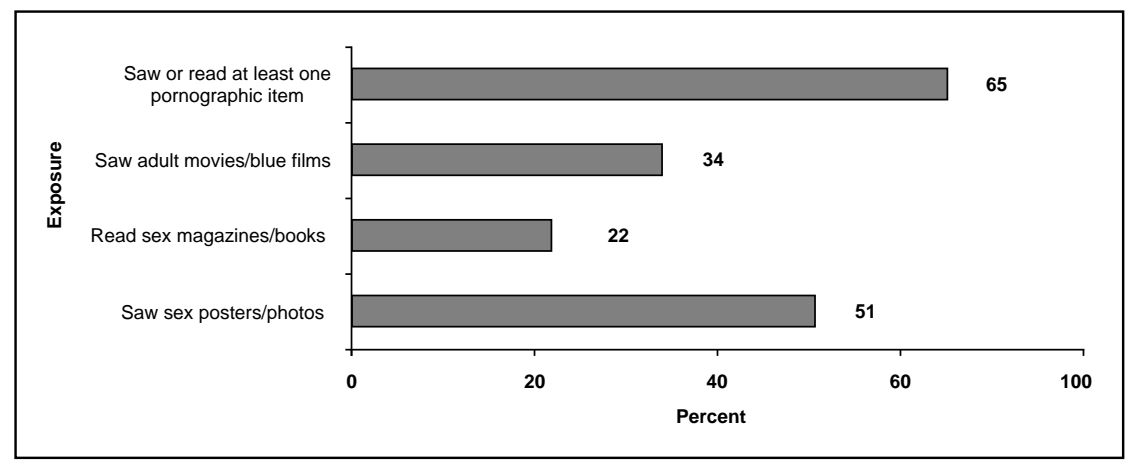

The use of alcohol is widespread among recent male migrants; a little more than two-thirds of respondents reported alcohol consumption in the month prior to the survey (see Figure 5). Alcohol consumption is

Figure 5 : Percentage of survey respondents who reported substance use, Karnataka State, India, 2007

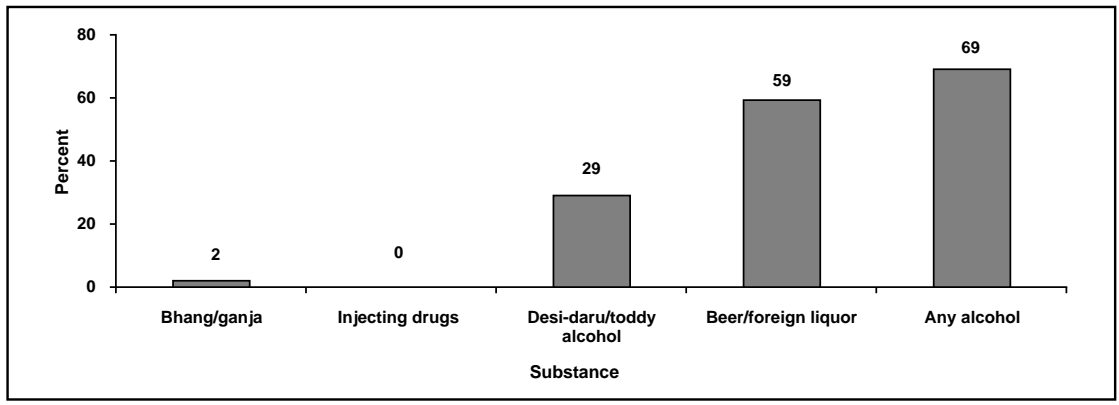




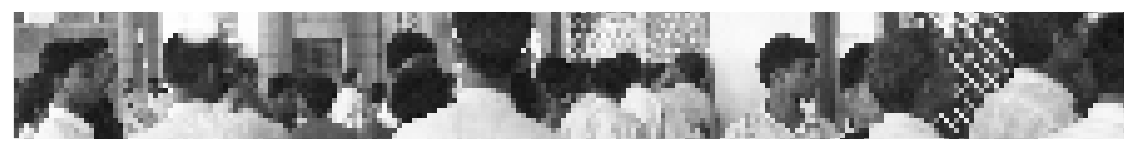

higher among migrant men in Dakshina Kannada District (78 percent) compared with the other study districts, as shown in Table 6.

These figures are supported by the qualitative data. A respondent indicated the prevalence of alcohol consumption among male migrants:

"Here most men come alone, and they work in different places, they drink and sleep late in the night. [When asked if they drink daily, he said] No, but on Sunday they drink too much." (MMW, Bellary District, construction worker, from Andhra Pradesh, unmarried, 25 years old)

A key informant reports:

"In the initial stage, they start drinking once in a while, but later they drink until they use up their wages, and they don't even care about their food. If asked, they say the company gives food, and life goes in its own way. In this way they start addicting themselves to smoking, drinking, and eating star masala. They watch movies once in a week, go to a bar, and do some "other activities." These "other activities" are always kept secret from their friend's circle. To do all these things they go to Torangal and Bellary and D.C. Nagar, but they won't tell where exactly they go. They simply go and come back. Initially they do it in secrecy, but later they do it openly. Still, they won't inform anybody, but become the victims of their own bad habits." (KI, Bellary District, referring to MMWs working in construction)

For the sake of the HIV-prevention programme, the types of mass media that male migrants are exposed to must be determined so that future media campaigns concerning safe-sex practices and HIV awareness can make use of these channels. Migrant men are particularly exposed to movies; most of them go to cinema halls and video parlours (see Table 6). Half of them listen to the radio, less than half watch television, and only one-third read newspapers or magazines. Male migrants' exposure to different types of mass media varies according to the district where they are working. More than 80 percent of migrant men in Bangalore watch movies in theatres and listen to the radio. The least exposure to the mass media was reported in Bellary (especially among migrants working as miners); less than one-fifth listened to the radio, 41 percent watched television, and onefourth read newspapers or magazines. 


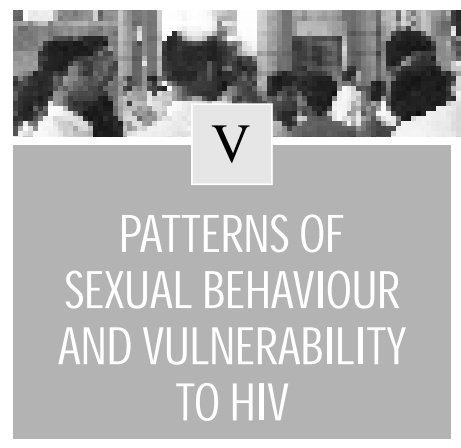

\subsection{Sexual behaviour of recent male migrants}

The data on sexual behaviour is presented here for currently married and not married (that is, unmarried and widowed/divorced/separated) migrant men separately to better understand their sex practices.

Pre- and extramarital sex is more prevalent among single male migrants than among currently married migrant men (see Figure 6). For married men, the presence of the wife at the current location is of paramount relevance. Reliance on sex workers is high among currently married men if their wives are not living with them at their work location (19 percent), compared with that of men whose wives are living with them (5 percent) (see Table 7). Moreover, married men living without their wives usually engage in transactional sex, but also have casual sex partners, whereas married men living with their wives usually engage in casual rather than commercial sex, suggesting that married men living without their wives are at the highest risk of engaging in commercial sex, compared with other men.

Figure 6 : Percentage of recent male migrant workers reporting pre-or extramarital sex by type of sex partner and current marital status, Karnataka State, India, 2007

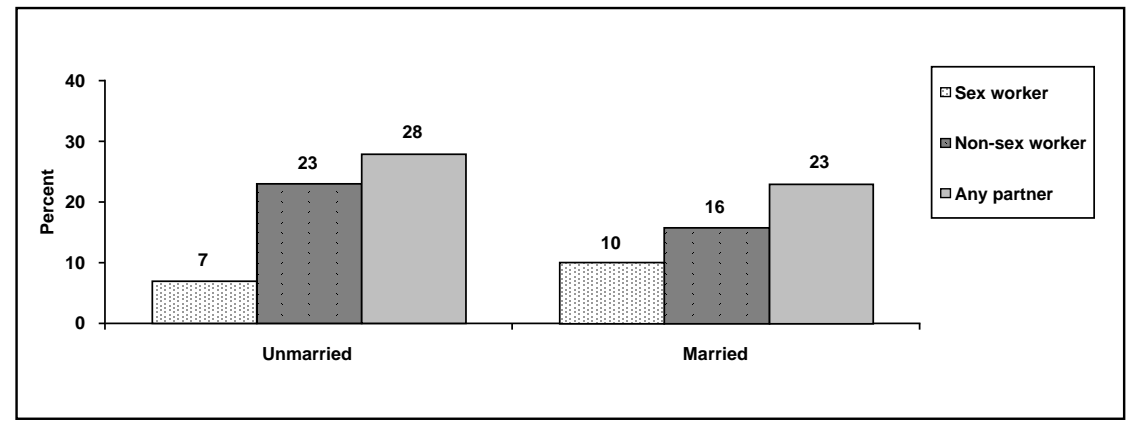




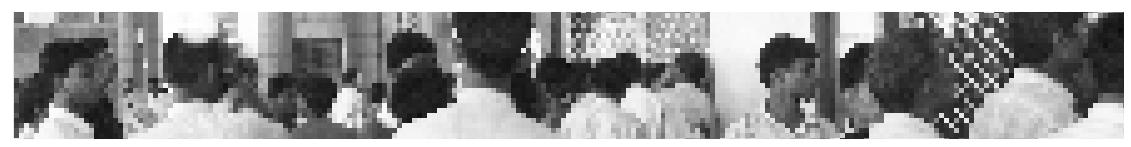

This finding is consistent with the information gathered during in-depth interviews with male migrant workers:

"It is difficult to tell how many men go to sex workers, but the unmarried, youths, and those who are married and do not have contact with their wives will go ..... Remaining youths, during a holiday, after seeing films in the night in some area where sex workers will be wandering, by seeing their behaviour they will identify and fix the rate, and if they are beautiful, then the men will pay more money, and if they are plain, they pay Rs.200. If the girl has gone to a beauty parlour or if she is a college girl, the men pay Rs.2,000 and take her to a lodge." (MMW, Mangalore District, deep-sea fisherman, from Kerala, married, 31 years old)

Among single migrants, 40 percent of men aged 25 to 29 are engaged in pre- and extramarital sex (see Table 7). Currently married migrants who engage in extramarital sex are mostly younger than 35 . These findings suggest that men in the 20-39 age group are likely to engage in high-risk sexual behaviours.

Men earning higher incomes engage in pre- and extramarital sex to a greater extent than men who earn less. Although the reasons for visiting sex workers are complex, men may also go to sex workers when they can afford to do so. A relationship between income and engaging in casual sex is also clear. However, this association is not as clear as it is for commercial sex.

The riskiest sexual behaviour among male migrants is reported by fishermen. Another high-risk group includes workers who load and unload goods at ports and factories, especially those who are unmarried. Unlike fishermen, however, these men engage more often in casual than in commercial sex. Men who cut sugarcane also reported engaging in high-risk sexual behaviours, especially married men, who engage in casual sex within their group (they migrate in various tribal groups in Bellary District and live together in tents in the sugarcane fields). Day labourers and those working in the brick industry reported engaging in the least risky sexual behaviours.

A significantly higher proportion of migrant men who drink alcohol than those who do not reported engaging in pre- and extramarital sex with 


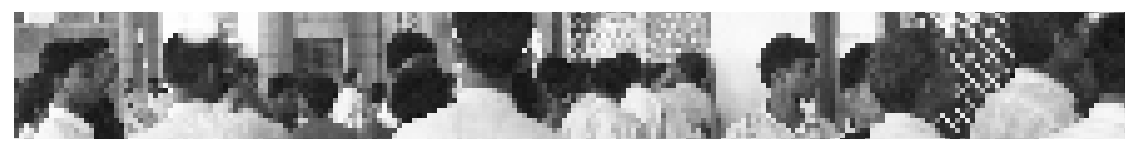

sex workers and with casual partners in the past 12 months. Higher proportions of men who were exposed to pornographic materials reported having sex with sex workers (8 percent of unmarried men and 13 percent of married men) than did those who were not exposed to such materials ( 4 percent of unmarried men and 6 percent of married men), as shown in Table 7.

During the in-depth interviews, some respondents spoke about the large number of men who drink before or during the times when they have sex with sex workers:

Do migrant men drink alcohol before having sex? Half of the men who go to sex workers drink before they go. Why do they do that? Sunday is a holiday and on that day they get their salary, so they drink. (MMW, Karwar District, day labourer, from Koppal, married, 26 years old)

\subsection{Migration/mobility characteristics and sexual behaviour}

Although all of the respondents selected for the study had migrated recently, the relationship between their mobility and sexual behaviour was examined according to their degree of mobility.

Results suggest that no relationship exists between increased mobility and pre- or extramarital sexual behaviours of recent male migrants (see Figure 7). Spending the night away from home is positively associated with the men's risky sexual behaviour, however, particularly in terms of visiting commercial sex workers (see Table 8). Having to commute between workplace and residence (without staying overnight) was expected to influence sexual behaviour. Results show the contrary: higher proportions of migrant workers who do not commute between work and residence report having had sex with a commercial sex worker, compared with those who commute, regardless of their marital status. 


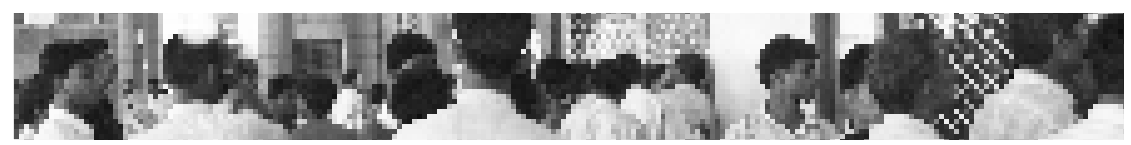

Figure 7 : Percentage of recent male migrants reporting pre- or extramarital sex according to their current marital status and degree of mobility, Karnataka State, India, 2007

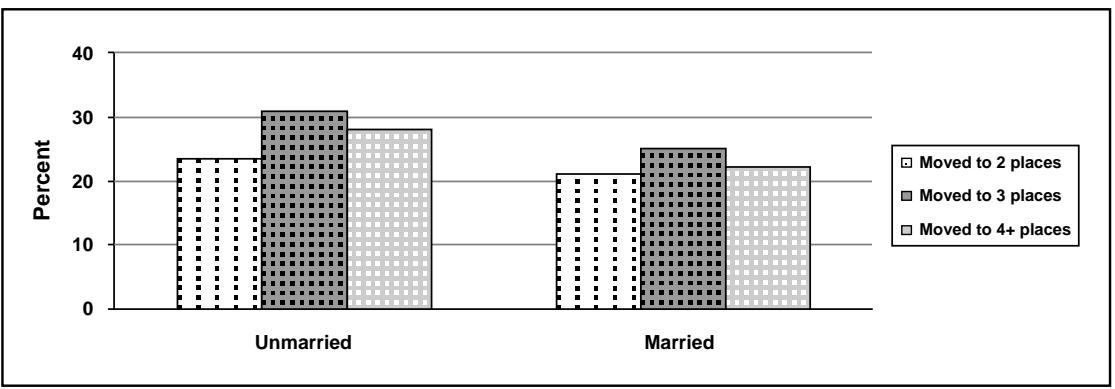

Gathering information about the sexual behaviour of male migrants working under contract is important for designing the HIV-prevention programme because contractors may represent a channel for reaching the workers. Compared with noncontracted workers, higher proportions of male migrants who were currently working under contract reported having had sex with casual partners (see Figure 8). The same pattern is observed for men whose first move in search of work was facilitated by a contractor, as shown in Table 8.

Figure 8 : Percentage of recent male migrants reporting pre- or extramarital sex, by their current marital status and contractemployment status, Karnataka State, India, 2007

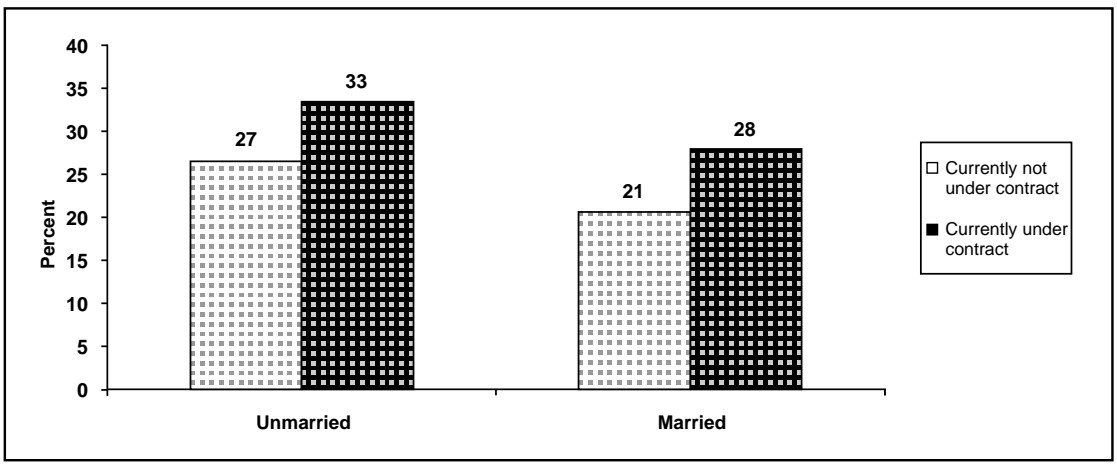




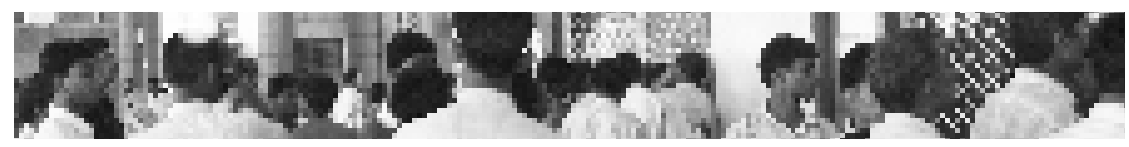

\subsection{Migrants' nonuse or incons istent use of condoms with different sexual partners}

Understanding male migrants' HIV risk requires that their level of preand extramarital sex with various partners be measured and that their level of condom use with these partners be determined.

More than three-fourths of currently unmarried and two-thirds of currently married men reported that they did not use condoms while having sex with any casual or commercial partners in the past year (see Figure 9). Their use of condoms differs substantially, however, depending on type of sexual partner, which clearly indicates the importance of the men's perception of the level of risk their partners represent. More than one-fifth of currently unmarried men and one-third of currently married men did not use condoms consistently when they had transactional sex. More than 90 percent of the men, regardless of their marital status, did not use condoms consistently when having sex with women other than sex workers. Although the proportion of male migrants who use condoms with sex workers is high, their low level of condom use with casual partners is of particular concern, given the prevalence of casual sex among these men irrespective of their marital status. Theoretically, casual partners are less risky sex partners than sex workers because they have fewer partners. Nevertheless, the sexual history and activity of male migrants' casual sex partners is not known, and in light of the men's infrequent condom use with this type of partner, their level of risk associated with casual sex may be higher than expected.

Results presented in Table 9 show the men's inconsistent condom use during sexual intercourse by their type of sex partner and according to their mobility and migration characteristics in order to assess the level of risk associated with mobility and migration. No systematic pattern is found in the relationship between condom use and degree of mobility according to type of sex partners. Unmarried men have the same level of condom use regardless of whether they are working under contract. Married men who work under contract, however, report higher nonuse of condoms with any partner than those not working under contract. 


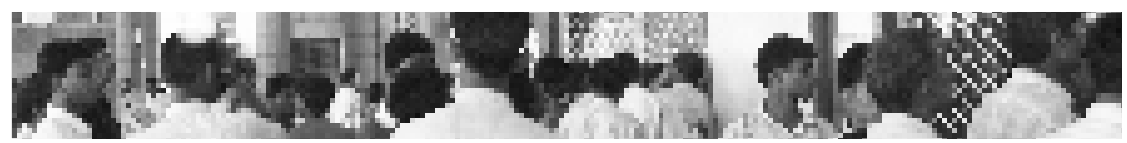

Similarly, men who reported that their first move to find work was facilitated by a contractor also report higher nonuse of condoms than their respective counterparts during sex with any partner.

\section{Figure 9 : Percentage of recent male migrants reporting inconsistent condom use, according to their type of sex partner and current marital status, Karnataka State, India, 2007}

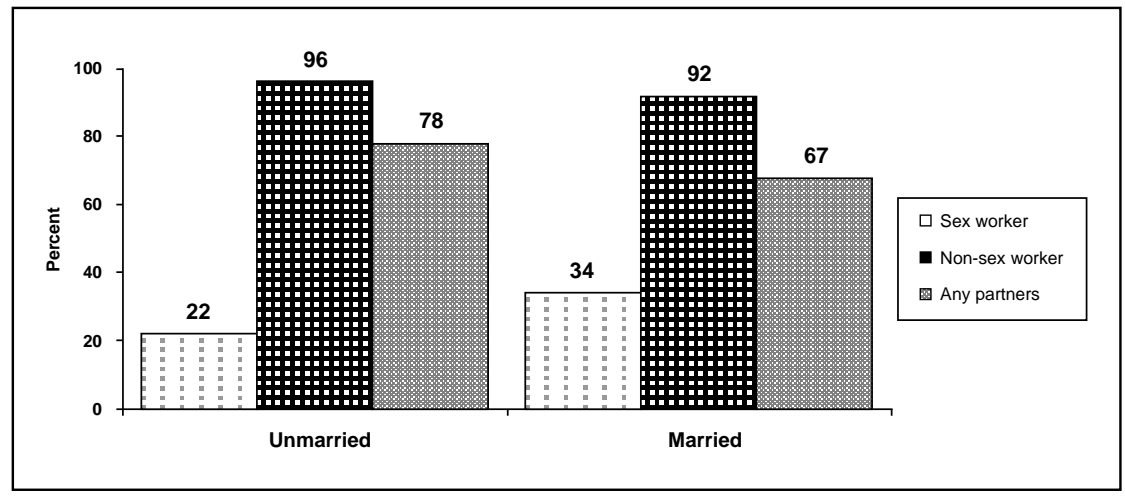

\subsection{Symptoms of STls and perception of HIV risk}

More than three-fourths of recent male migrants reported that they have experienced at least one gupt $\mathrm{rog}^{3}$ symptom in the past 12 months, as shown in Table 10. More than two-thirds reported that they have experienced at least one STI-like symptom ${ }^{4}$ (see Figure 10). Despite the high proportion of men who engage in risky sexual behaviour and who experience gupt rog symptoms, only 6 percent believe they are at high or moderate risk of acquiring HIV.

\footnotetext{
${ }^{3} \mathrm{G}$ upt rog symptoms: swapna dosh (local term for wet dreams), dhat (local term for semen ejaculation), lack of erection, bent penis, premature/early ejaculation, poor quantity of semen, garmi (local term for group of STI- related symptoms), phoda/phunsi (local term for boils), swelling in groin area, itching in genital area, frequent painful urination. ${ }^{4} \mathrm{STI}-$ like symptoms: garmi, phoda/phunsi, swelling in groin area, itching in genital area, frequent painful urination.
} 


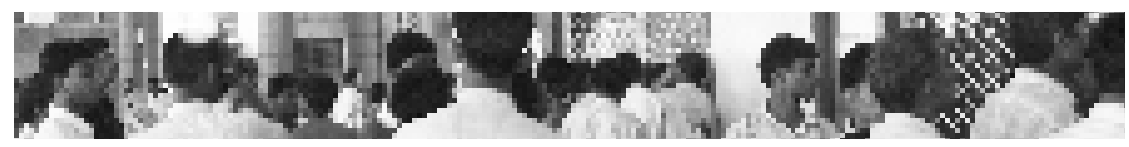

Figure 10 : Percentage of recent male migrants reporting their experience of gupt rog symptoms in the past 12 months, their experience with STI-like symptoms in the past 12 months, and their perceived high or moderate risk of acquiring HIV, Karnataka State, India, 2007

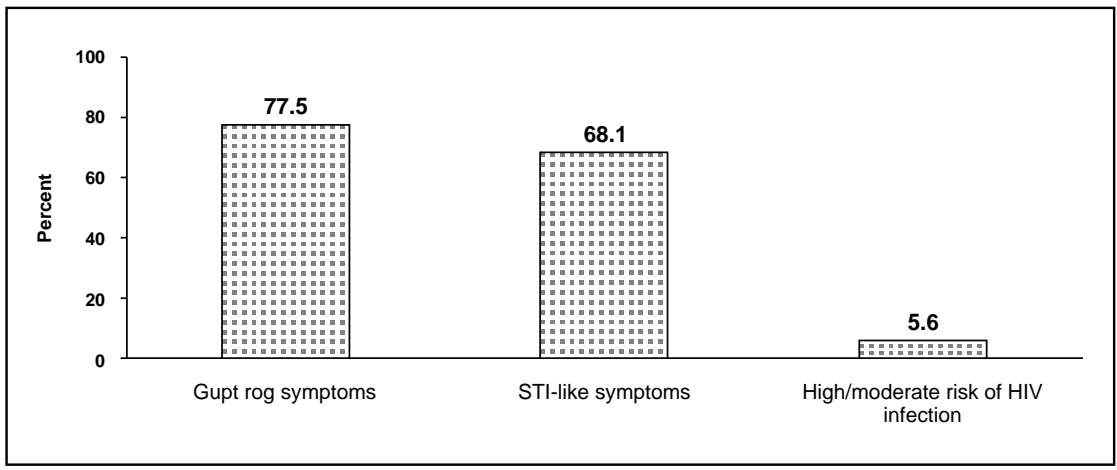

The results in Table 10 show an association between the migrants' degree of mobility and their prevalence of experiencing gupt rog and STI-like symptoms. Similarly, higher proportions of men who stay away from home overnight and who commute between their workplace and residence have experienced gupt rog and STI-like symptoms, compared with their respective counterparts.

An excerpt from an interview indicates one migrant's encounter with a sex worker and exposure to STIs:

"My friend introduced me last year to one sex worker. I was not interested, so I kept quiet. But after seeing her, I could not sleep at night. I wanted to have sex with her at least once. I also got excited by watching blue films. I couldn't control myself, and I met her on the way. While talking, I told her directly that I wanted her to come that day. ... I had so many problems after having sex with her. My skin was damaged and blood came out. ... I couldn't sleep at night because the skin became so damaged. After two days the wound didn't heal. I told my friend, and he took me to the doctor who gave me treatment. The doctor said that if I go to sex workers I should use a condom. When I asked why, he told me about HIV/AIDS. I got 


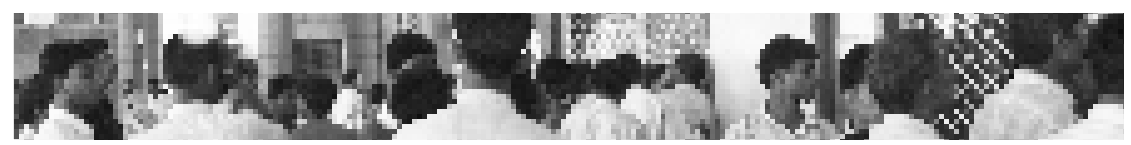

scared, but the doctor told me not to be scared. That is the last time I went to a sex worker. I am masturbating now, but I don't go to sex workers." (MMW, Bangalore District, factory worker, from Tamil Nadu, unmarried, 26 years old)

\subsection{Sexual behaviour along migration routes}

Data about migrants' pre- and extramarital sexual activity in their current location, in their previous two workplaces, and at their places of origin were used to examine their sexual behaviour along their migration routes. The number of places in which they had sex were counted and are presented in figure 11.

Figure 11 : Number of places along the migration route in which recent male migrants reported having pre- or extramarital sex, by current marital status, Karnataka State, India, 2007

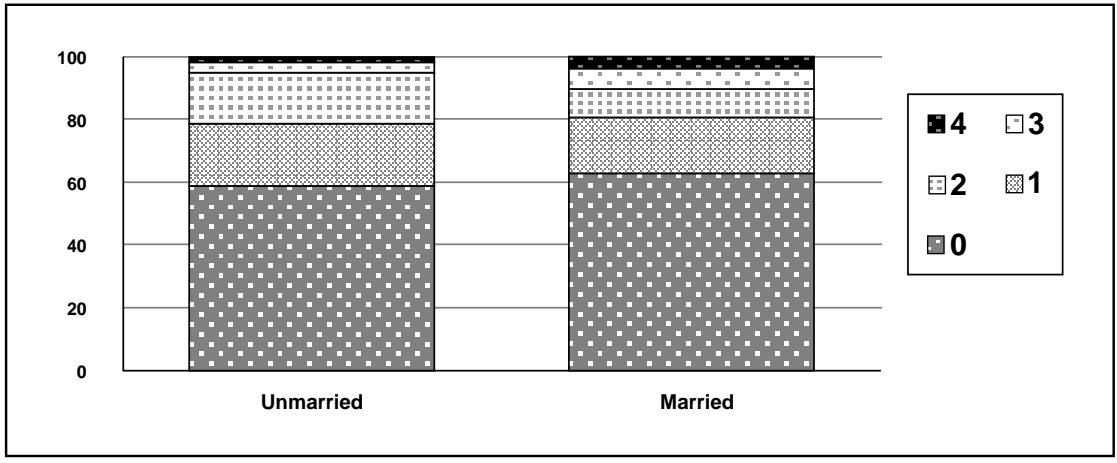

Forty percent of the survey respondents reported having had sex in at least one location along their migration routes, 20 percent had sex in at least two places, and about 7 percent had sex in at least three places in the past two years, as shown in Figure 11. These findings suggest that a significant proportion of recent male migrants engage in pre- or extramarital sexual behaviour along their migration routes, a point of concern for the designers of the HIV-prevention programme. 


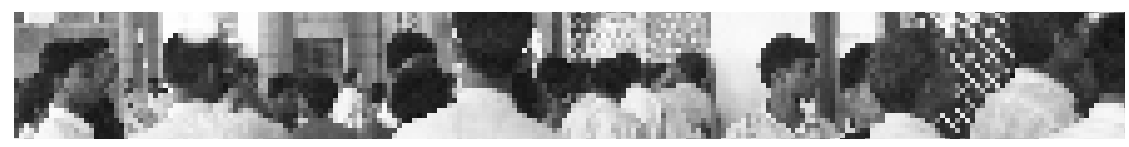

As Table 11 reveals, higher proportions of male migrants in the 25-to-29 age group engaged in these behaviours along their migration routes, compared with those in other age groups. A substantial proportion of respondents in the following occupational groups engaged in pre- and extramarital sexual activity along their migration routes: fishing, sugarcane cutting, road construction, port/factory loading/unloading and garment work.

Further analysis was carried out to determine where the migrants had engaged in pre- or extramarital sex (see Table 12). Results suggest that a substantial proportion of men (25 percent) reported having had pre- or extramarital sex at their places of origin. About 13 percent of the men who had sex in their places of origin also reported having had sex with commercial or casual partners in at least one of the three places along their migration routes in the past two years. These findings suggest that initiating HIV-prevention intervention at the men's places of origin might be appropriate. Figure 12 presents the reported pre- or extramarital sexual behaviour of migrants along their migration route by occupation. 


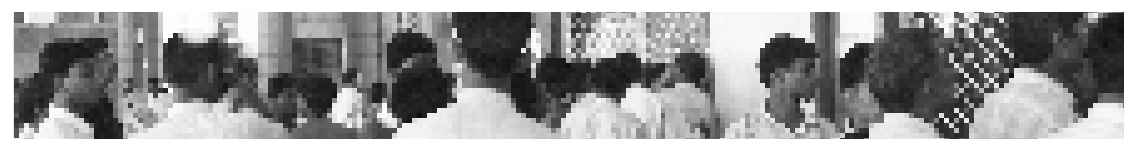

Figure 12 : Percentage of recent male migrants reporting pre- or extramarital sex, by location along their migration routes and by type of occupation, Karnataka State, India, 2007

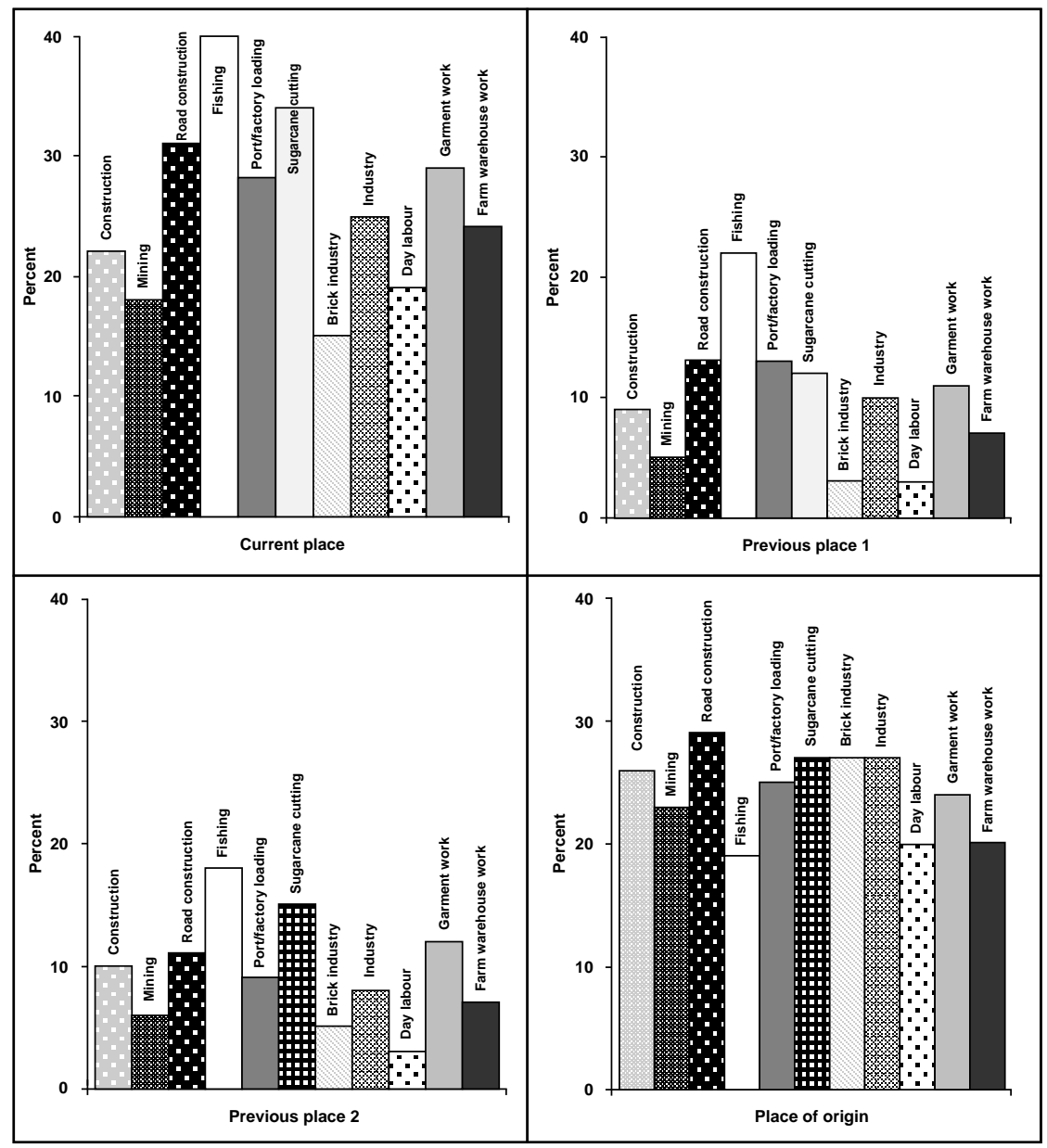




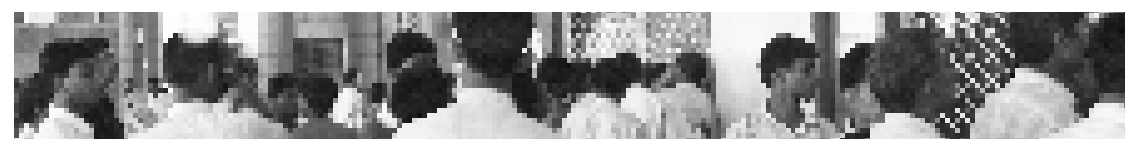

Qualitative data from the survey interviews also indicate that some men are consistent in terms of their sexual behaviour from their places of origin to their current locations. A construction worker responded to the interviewer's questions:

"You have visited so many places; did you not go for any sexual activities? Yes, I have done it in my village. ... There I had sex with our neighbour aunty. For seven months I had sex with her. . . Maybe nine to ten times I might have had sex with her. Did you use a condom? No, I used to bother only about having sex with her; I did not think about using a condom. Have you loved anybody? No. Where is love, sir? Who will love people like us who work and smoke Beda? Did you have sex with anybody else? With whom else, sir? With whom should we have sex? Here, it's only with sex worker. With how many women have you had sex? I had sex three times with one sex worker and then four times with another, and two times with another. Do you use a condom when you go for sex with sex workers? Yes, I use one every time when I go to sex workers. Who brings the condom? She keeps it with her; it is available in [the sex workers'] home, and they give it. Have you ever had sex without a condom? Yes, once I had. With whom? With that same sex worker. Do you pay her for that? Money is important for them, don't you know about that, sir? After having sex there, then you had sex here, so did you leave the aunty? No, after my brothers' marriage, after four months, I had gone to my village. At that time I had sex with her. Did you use a condom at that time? No, because aunty is not that type of woman. Did you pay the aunty? Yes, I paid her." (MMW Bangalore District, construction worker, from Raichur, unmarried, 24 years old)

Another man reported that he has a lover at home and has sex with commercial sex workers in his current location:

"If you desire to have sex, then what will you do? What we could do. Are there men having sex with men? It is there, but in our boat nobody will have that kind of sex. Who does that kind of sex? Here men who go for deep-sea fishing do it. How many men do it? I do not know. Do you have a sex partner? As I told you earlier, I loved a girl who was studying with me in school. Did you have sex with her? Yes. Did you use a condom? She is my lover and she is still fresh. She does not have sex with anyone, so I did not use one. Whenever I go to my village, I have sex with her; that is every two months. Have you ever gone to sex workers? I would not go to them anymore. How often do you go to them? Once in 15 days or a month friends will force me 


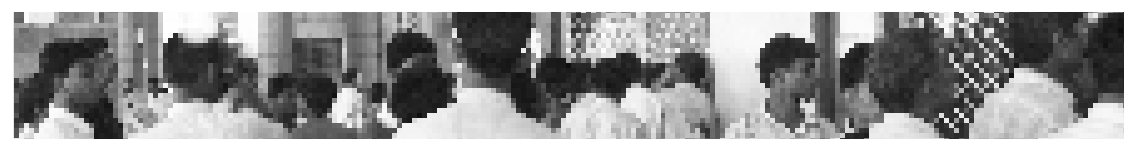

to go and take me. When did you go last time? I went one month ago. Do you use a condom while having sex with the sex worker? Yes. Who decides to use a condom? The sex worker puts on the condom first, and she does not allow you to have sex without it. Why? Because of the fear of AIDS, all of them would use a condom. What is your opinion about using a condom? If we want to be safe, then we have to use one. How do you feel when you have sex with a condom? I will not get satisfaction if I have sex with it, but just to fulfil the desire, I pay money and have sex." (MMW Mangalore District, deep-sea fisherman, from Kerala, unmarried, 26 years old)

Some men reported that they have pre- or extramarital sex only in their home areas, but not in their current workplaces. As one respondent replied:

"Apart from your wife, do you have any sex partner in your village? Sir, in my village, my uncle's daughter is devadasi, she is my keep. What does that mean? Sir, I sleep with her, and yearly I have to pay her some money. How much do you pay? I have provided her with a house to stay in, and for one year I give her Rs2,500. And I also pay for the expenses of the child born to her. Do you have sex with her? Sir, without my wife's knowledge I go to her. But currently she is kept by another person. Who is he? He is from our village. Do you use a condom with her while having sex? Sir, I do not know about a condom. Have you ever gone to sex workers? Look sir, I am a married man. Apart from my wife and devadasi in my village, I have not gone to any other women, and I will never go." (MMW, Mangalore District construction worker, from Koppal, married, 35 years old)

In addition to his wife, another man also has sex with a married woman at his place of origin and with sex workers in his work location:

"If you desire to have sex, what will you do? Here we have everything, but in the boat we do not have anything, and that desire we will fulfil after coming to shore. What do you do here? Here I would go to sex workers. Why do you go to them? To have sex. Men are born to do that. ... I have sex with a married woman in my native place. How often do you have sex with this woman? I have sex with her whenever I go to my place. Do you use a condom? I do not know when I will meet her and have sex, so how can I get a condom? So I do not use a condom. Have you ever gone to sex workers? Once in while I go to them. How often you go to them? Once in 15 days or once a month. How much money do you pay them? I pay Rs.200 to 300. Do you use 


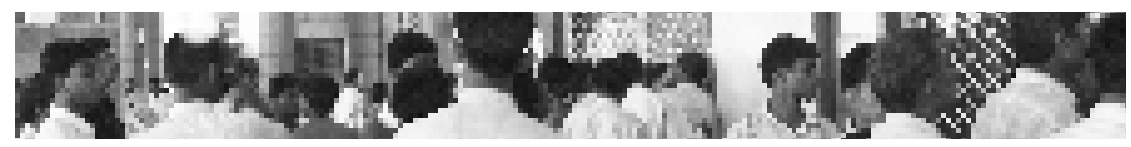

a condom with sex workers? I use a condom while having sex with them. Why? AIDS disease has arrived now, so I use a condom. Apart from when you are with sex workers, do you use a condom while having sex? I do not use one with my wife. Why? Why should I use one with my wife? I do not use one with my wife. Do you use a condom with that married woman in your home area while having sex with her? No, I do not use one with her either. Why? I do not know where the condoms are available in my home area, and I also do not know when we are going to meet and have sex. How do you feel when you have sex and are using a condom? I do not get any satisfaction, and my desire will not be fulfilled. I feel like I am wearing a bag. But what do I do? I have to protect my life from AIDS, so because of this unavoidable situation and from fear of AIDS I use a condom with sex workers." (MMW, Mangalore District, working in three-day fishing, from Karwar, married, 30 years old)

\subsection{Knowledge of HIV transmission and prevention}

The HIV-prevention programme among male migrant workers is just beginning. Therefore, determining the respondents' level of knowledge concerning the pandemic is useful. More than three-fourths of the men surveyed know that HIV can be transmitted by using infected needles and being exposed to infected blood (see Figure 13). Similarly, threefourths of the men surveyed know that HIV can be transmitted by having sex with multiple partners, and two-thirds know that having sex with an HIV-infected person can cause you to become infected. Only 10 percent, however, mentioned that having sex without using a condom is risky, and less than one-fifth mentioned the risk of having sex with commercial sex workers. Although a majority of the male migrants surveyed know that HIV is transmissible through sexual intercourse and through exposure to infected blood, a high proportion also has misconceptions about HIV. For instance, two-thirds of the men believe that one can become infected with the virus through barber-shop visits, and one-fourth mentioned kissing a HIV-positive person and being bitten by a mosquito. Table 13 shows the percentage of men surveyed by their knowledge of HIV transmission according to district.

Most male migrants know that HIV transmission can be prevented by having only one sexual partner (71 percent), by taking injections with clean needles (59 percent), and by using condoms all the time (50 percent) (see Figure 14). Almost half of the men, however, believe that 


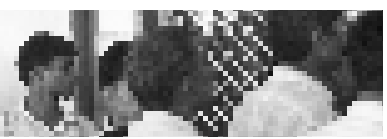

they can avoid infection by shunning the company of HIV-positive people. This finding also gives us a measure of the level of stigma against HIV-infected people. Table 13 shows the percentage of men surveyed by their perceptions of how HIV transmission can be prevented according to district.

Figure 13 : Percentage of recent male migrants surveyed, by their answers to the question How does a man become infected with HIV?, Karnataka State, India, 2007

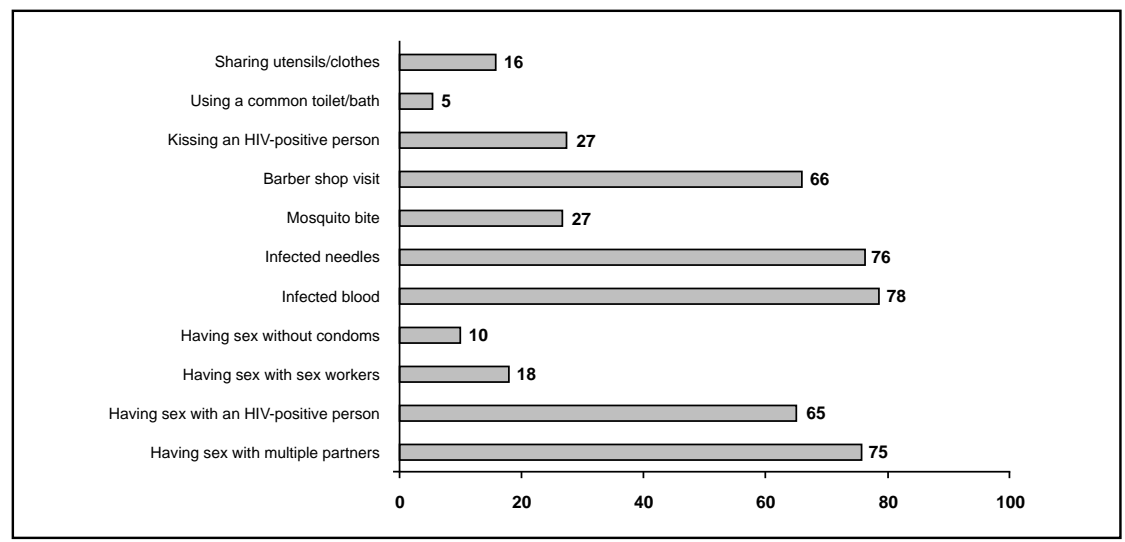

Figure 14 : Percentage of recent male migrants surveyed, by their answers to the question How can a man protect himself from acquiring HIV?, Karnataka State, India, 2007

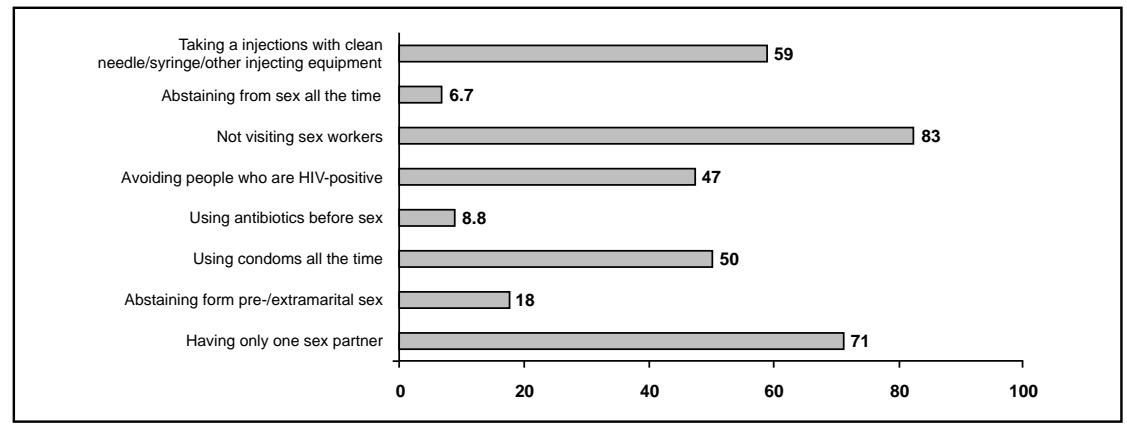




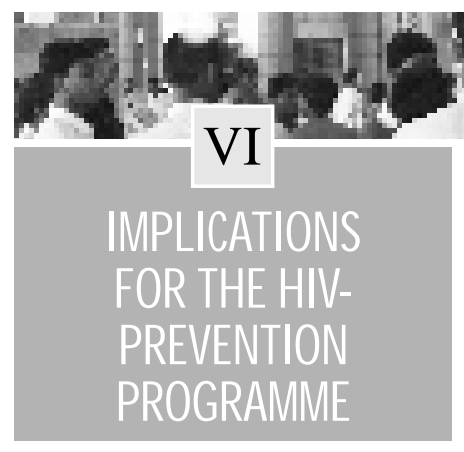

This study shows that the predominant patterns of mobility among male migrants are intradistrict and interdistrict within Karnataka State. Migrant men are involved in a variety of occupations. Migration to find work between the northern and southern districts is evident from the data.

The survey data indicate that a significant proportion of male migrants engage in sex with commercial sex workers and with other women. Men tend to use condoms consistently with sex workers, but their condom use is much lower with women they identify as "non-sex workers." (These women may include construction workers, vegetable or fruit vendors, and others.) A significant proportion of these men had sex in more than one of their work locations, as well as with women in their home areas. Other factors that were associated with increased pre- and extramarital sex are staying away from home overnight, marital status, and spouse's absence at the work location

\subsection{Role of contractors/ facilitators}

For the HIV-programme, determining which occupational groups are characterized by a large contractual labour force would be useful so as to reach the migrants working in these fields through their contractors. Table 14 shows the percentages of male migrants by occupational groups who have never worked under contract, who were not under contract during their first move from home but are currently working under contract, who worked under contract during their first move but are currently not under contract, and who have worked under contract during both their first move and their last move. The last column in Table 14 indicates the anticipated programme coverage of migrant men in each occupational group if the programme were to be implemented through the network of contractors. This coverage is calculated as a percentage representing male migrants who worked under contract in the past or who are doing so currently.

More than two-thirds of male migrants have never worked under contract, and less than 30 percent are now under contract. Therefore, a 


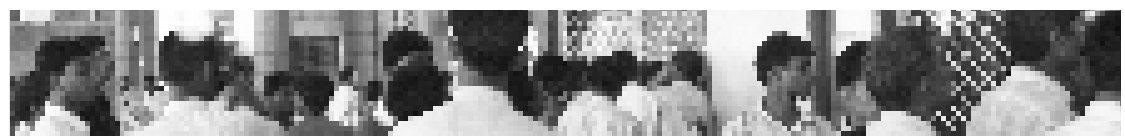

programme implemented through the contract system would cover less than one-third of male migrants. The coverage of such a programme would vary considerably by occupational group, however. Thus, the programme would be able to cover a large majority of sugarcane cutters, more than half of construction and road-construction workers, and about 40 percent of miners. A programme implemented through contractors would not be effective, however, among other occupational groups, including garment workers, farm-warehouse workers, fishermen, brick workers, factory workers, port-loading workers and day labourers.

Figure 15 illustrates the contractors' network system in the sugar industry. The contractors are hired by the sugar factories to supply the labourers needed to cut sugarcane. The contractors find workers either directly, or through other people, such as neighbours, family, and friends. In Mandya District, most sugarcane cutters come from a number of tribal groups in Bellary District, and mostly came from the same communities.

Figure 15 : Contractors' network system for sugarcane cutters, Karnataka State, India

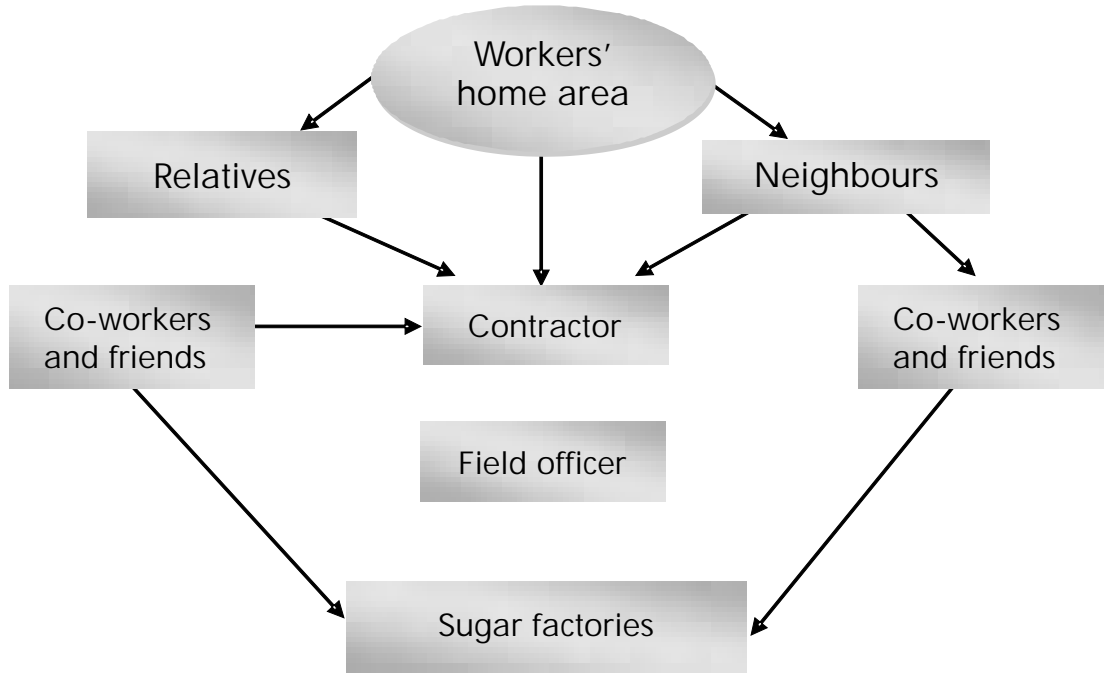




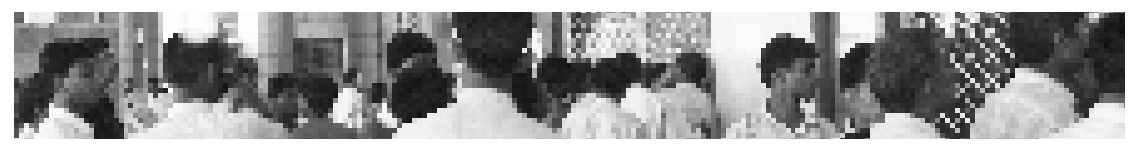

\subsection{Focus on places of origin}

A significant proportion of recent male migrants reported engaging in pre- and extramarital sex in their places of origin. The study found that most of the male migrants come to the five study districts from many sending districts and states. The states most clearly connected to Karnataka in this way are Andhra Pradesh and Tamil Nadu.

Within Karnataka, the main source districts are in the north: Koppal, Bellary, and Bagalkot (as shown in Table 2a). In the south, the main source district is Tumkur. Other districts that experience substantial male out-migration are Davanagere, Gadag, and Haveri (see Map 7). These are the main source districts for the study districts of destination and are not necessarily the main source districts in Karnataka State in terms of overall male migration. The data suggest that these migrants are consistent in their sexual behaviours from their home areas to their work locations and vice versa. Clearly a need exists for future research to determine which individuals should be targeted by HIV-prevention interventions and where the interventions should be initiated. 


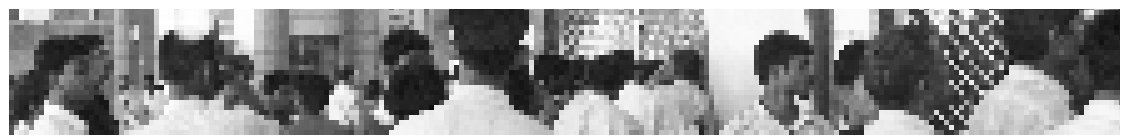

Map 7 : Main source districts for male workers' migration, Karnataka State, India, 2007
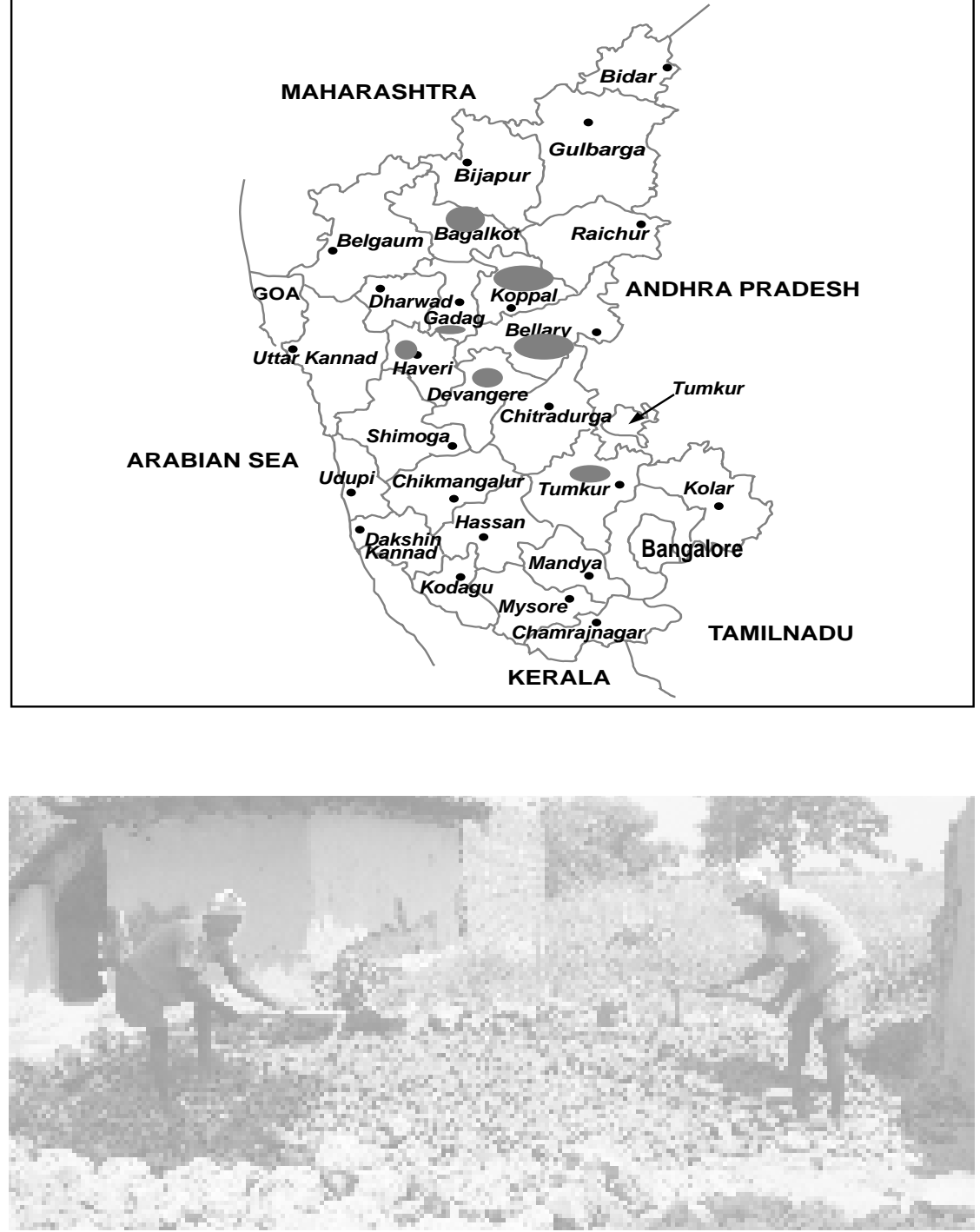


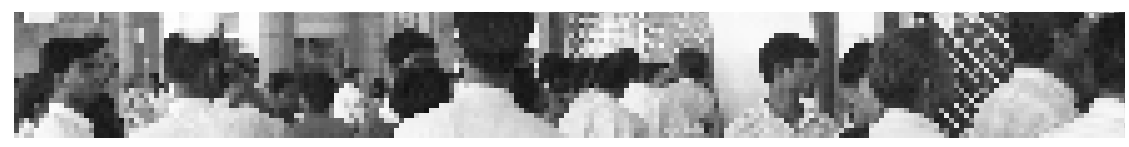

\section{REFERENCES}

Chandrasekaran, P., Dallabetta, G., Loo, V. et al. 2005. "Containing HIV/AIDS in India: the unfinished agenda." Lancet Infectious Diseases 6(8): 508-521.

Decosas, J., Kane, F., Anarfi, J.K., Sodji, K.G. and Wagner, H.U. 1995. "Migration and AIDS." Lancet 346(8,978): 826-828.

Halli, Shiva S., Blanchard, James, Satihal, D., and Moses, Stephen. 2007. "Migration and HIV transmission in rural South India: An ethnographic study." Culture, Health and Sexuality 9(1): 85-94.

IIPS and Macro International. 2007. National Family Health Survey (NFHS-3), 2005-06: India: Volume I. Mumbai: IIPS.

Menon, P. 2004. "Challenges in Karnataka." F rontline, <http://flonnet.com/fl2126/stories/20041231002209400.htm>.

Muhr, T. 2004 . Atlas.ti - The knowledge workbench. V.5.0. Berlin: Scolari Sage Publications Software.

NIHFW (National Institute of Health \& Family Welfare) and NACO (National AIDS Control Organisation). 2007. Annual HIV Sentinel Surveillance Country R eport 2006. New Delhi: NIHFW.

Saggurti, N., Verma, R.K., Achyut, P., RamaRao, S., and Jain, A. 2008. "Patterns and implications of male migration for HIV prevention strategies in Karnataka, India." Technical Brief. New Delhi: Population Council.

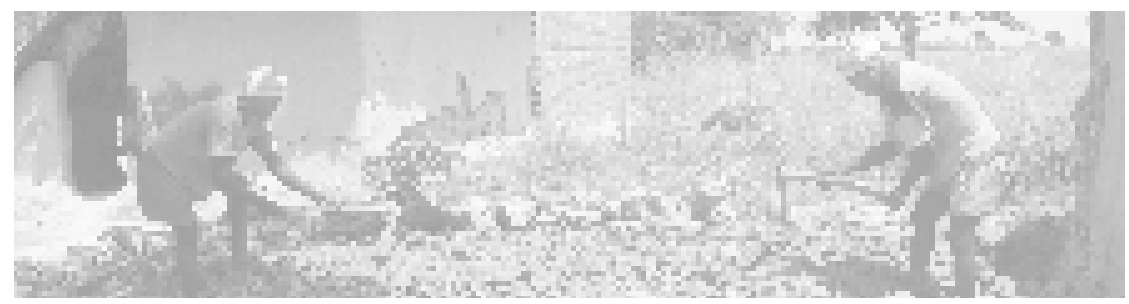




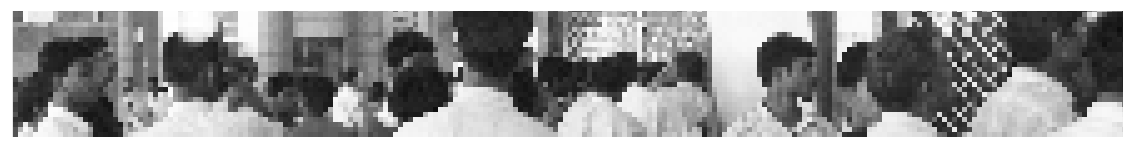

Table 1 : Percentage of migrant men, by number of locations they moved to, according to selected background characteristics, Karnataka State, India, 2007

\begin{tabular}{|c|c|c|c|c|c|}
\hline \multirow[b]{2}{*}{ Characteristic } & \multicolumn{2}{|c|}{$\begin{array}{l}\text { Number of locations respondent } \\
\text { moved to since leaving his place } \\
\text { of origin for the first time }\end{array}$} & \multicolumn{2}{|c|}{$\begin{array}{l}\text { Number of locations respondent } \\
\text { moved to in the past two years }\end{array}$} & \multirow[b]{2}{*}{ (N) } \\
\hline & $1+$ & $2+$ & $1+$ & $2+$ & \\
\hline \multicolumn{6}{|l|}{ District } \\
\hline Bellary & 77.8 & 62.6 & 77.7 & 54.5 & $(950)$ \\
\hline Bangalore & 86.1 & 71.1 & 86.0 & 62.8 & $(1,063)$ \\
\hline Dakshina Kannada & 87.0 & 57.4 & 85.9 & 42.1 & $(1,194)$ \\
\hline Mandya & 73.4 & 65.3 & 73.4 & 62.5 & (809) \\
\hline Uttara Kannada & 81.6 & 60.5 & 81.0 & 48.4 & (919) \\
\hline \multicolumn{6}{|l|}{ Residence } \\
\hline Urban & 84.0 & 61.9 & 83.4 & 50.2 & $(2,749)$ \\
\hline Rural & 79.1 & 65.1 & 78.9 & 58.0 & $(2,140)$ \\
\hline \multicolumn{6}{|l|}{ Age group } \\
\hline$\leq 19$ & 40.5 & 17.5 & 40.5 & 14.3 & $(469)$ \\
\hline $20-24$ & 90.8 & 66.8 & 90.1 & 61.5 & $(1,419)$ \\
\hline $25-29$ & 87.0 & 71.4 & 86.7 & 61.1 & $(1,634)$ \\
\hline $30-34$ & 82.4 & 68.1 & 82.0 & 55.0 & (883) \\
\hline $35+$ & 77.5 & 60.9 & 76.9 & 40.2 & $(537)$ \\
\hline Total & 81.8 & 63.1 & 81.3 & 53.3 & $(4,951)$ \\
\hline
\end{tabular}

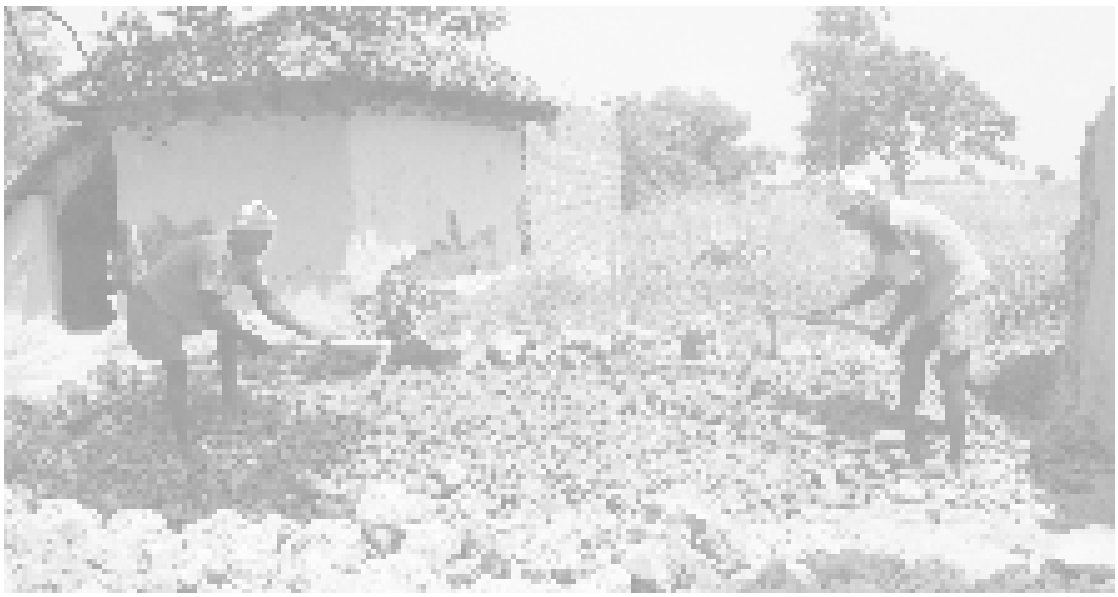




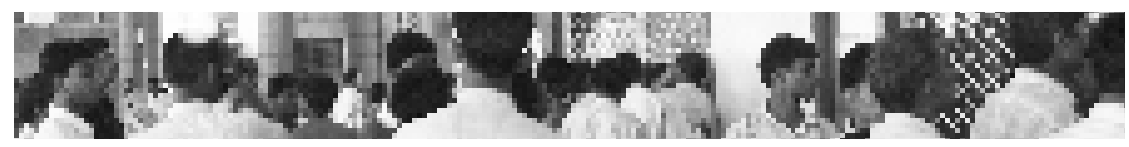

Table 2a : Percentage of recent male migrants surveyed, by their home districts, according to the study districts to which they migrated to find work, Karnataka State, India, 2007

\begin{tabular}{|c|c|c|c|c|c|c|}
\hline \multirow[b]{2}{*}{ Source districts } & \multicolumn{5}{|c|}{ Study districts } & \multirow[b]{2}{*}{ (N) } \\
\hline & Bellary & Bangalore & $\begin{array}{l}\text { Dakshina } \\
\text { Kannada }\end{array}$ & Mandya & $\begin{array}{l}\text { Uttara } \\
\text { Kannada }\end{array}$ & \\
\hline \multicolumn{7}{|l|}{ Districts in Karnataka } \\
\hline Bagalkot & 0.8 & 1.6 & 30.4 & 0.4 & 9.7 & 213 \\
\hline Bangalore & - & 2.7 & - & 1.4 & 0.7 & 28 \\
\hline Bangalore (rural) & - & - & - & - & - & - \\
\hline Belgaum & 1.4 & 1.2 & 1.0 & - & 2.9 & 33 \\
\hline Bellary & 20.8 & 6.0 & 1.2 & 32.0 & - & 316 \\
\hline Bidar & - & - & - & - & - & - \\
\hline Bijapur & 2.1 & 0.9 & 0.8 & 2.2 & 0.7 & 35 \\
\hline Chamarajanagar & 0.4 & 1.0 & - & 1.8 & - & 18 \\
\hline Chikmagalur & - & 0.9 & - & - & - & 6 \\
\hline Chitradurga & 1.7 & 5.4 & - & 2.6 & - & 58 \\
\hline Dakshina Kannada & - & - & 0.6 & 0.4 & 0.2 & 6 \\
\hline Davanagere & 14.5 & 7.2 & 1.0 & 0.2 & 0.2 & 130 \\
\hline Dharwad & 0.6 & 1.5 & 1.8 & 1.4 & 2.2 & 39 \\
\hline Gadag & 1.2 & 5.1 & 8.2 & - & 4.9 & 103 \\
\hline Gulbarga & 0.4 & 7.5 & - & - & 0.4 & 54 \\
\hline Hassan & - & 2.1 & - & 0.8 & - & 18 \\
\hline Haveri & - & 4.2 & 7.0 & 0.2 & 6.7 & 94 \\
\hline Kodagu & - & - & - & - & - & - \\
\hline Kolar & - & 2.7 & - & 2.4 & - & 30 \\
\hline Koppal & 22.2 & 2.7 & 12.3 & 1.0 & 32.4 & 344 \\
\hline Mandya & - & 0.3 & - & 3.8 & - & 21 \\
\hline Mysore & - & 0.3 & - & 1.2 & - & 8 \\
\hline Raichur & 3.5 & 3.7 & 1.2 & 3.8 & - & 68 \\
\hline Shimoga & - & 1.8 & - & - & 0.2 & 13 \\
\hline Tumkur & - & 8.7 & - & 27.5 & - & 197 \\
\hline Udupi & - & - & 2.4 & - & 0.9 & 16 \\
\hline Uttara Kannada & - & 1.3 & 4.0 & - & 11.5 & 80 \\
\hline Andhra Pradesh & 7.9 & 14.4 & 8.0 & 9.5 & 20.4 & 316 \\
\hline Tamil Nadu & 0.8 & 13.6 & 8.5 & 0.0 & 0.7 & 141 \\
\hline Other states & 21.8 & 3.0 & 11.7 & 7.7 & 5.2 & 254 \\
\hline $\begin{array}{l}\text { Total } \\
\text { (N) }\end{array}$ & $\begin{array}{l}100.0 \\
(503)\end{array}$ & $\begin{array}{l}100.0 \\
(502)\end{array}$ & $\begin{array}{l}100.0 \\
(509)\end{array}$ & $\begin{array}{l}100.0 \\
(501)\end{array}$ & $\begin{array}{l}100.0 \\
(508)\end{array}$ & $(2,63)$ \\
\hline
\end{tabular}

Note: "Recent male migrants" in this and the following tables are those men who are older than 18, whose birthplace is not where they currently reside, who moved to current location in the past two years, and who have also moved to two or more locations in the same period. 


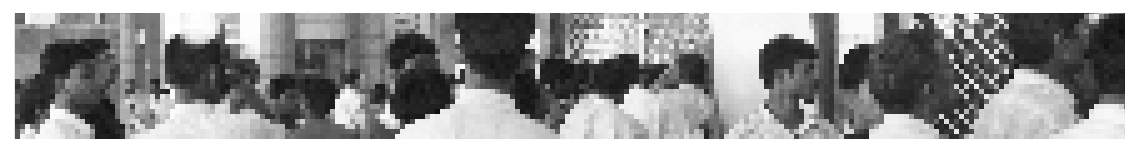

Table $2 \mathrm{~b}$ : Percentage distribution of recent male migrants surveyed by their mobility-related characteristics, according to study district, Karnataka State, India, 2007

\begin{tabular}{|c|c|c|c|c|c|c|}
\hline Characteristic & Bellary & Bangalore & $\begin{array}{l}\text { Dakshina } \\
\text { Kannada }\end{array}$ & Mandya & $\begin{array}{l}\text { Uttara } \\
\text { Kannada }\end{array}$ & Total \\
\hline \multicolumn{7}{|c|}{$\begin{array}{l}\text { Number of places moved to } \\
\text { the past two years }\end{array}$} \\
\hline 2 & 35.3 & 38.5 & 25.4 & 18.6 & 35.5 & 31.1 \\
\hline 3 & 47.5 & 46.9 & 55.9 & 46.8 & 45.6 & 48.5 \\
\hline $4+$ & 17.2 & 14.7 & 18.7 & 34.6 & 18.9 & 20.5 \\
\hline \multicolumn{7}{|c|}{$\begin{array}{l}\text { Stayed overnight away from } \\
\text { home for work in the past } \\
\text { month }\end{array}$} \\
\hline No & 92.7 & 96.1 & 77.5 & 94.5 & 91.5 & 90.8 \\
\hline At least once & 7.3 & 3.9 & 22.5 & 5.5 & 8.5 & 9.2 \\
\hline \multicolumn{7}{|l|}{$\begin{array}{l}\text { Commutes between } \\
\text { residence and work }\end{array}$} \\
\hline No & 95.7 & 97.4 & 82.4 & 87.7 & 82.9 & 89.9 \\
\hline Yes & 4.3 & 2.6 & 17.6 & 12.3 & 17.1 & 10.1 \\
\hline \multicolumn{7}{|l|}{$\begin{array}{l}\text { First-time move was } \\
\text { facilitated by contractor }\end{array}$} \\
\hline No & 77.7 & 96.3 & 86.0 & 62.4 & 78.7 & 81.2 \\
\hline Yes & 22.3 & 3.7 & 14.0 & 37.6 & 21.3 & 18.8 \\
\hline \multicolumn{7}{|c|}{$\begin{array}{l}\text { How often do you visit your } \\
\text { home location? }\end{array}$} \\
\hline Once per year & 3.1 & 2.4 & 2.6 & 1.0 & 2.5 & 2.3 \\
\hline A few times in a year & 18.1 & 13.2 & 14.3 & 11.9 & 13.5 & 14.2 \\
\hline Many times in a year & 12.5 & 14.7 & 17.7 & 14.0 & 10.1 & 13.9 \\
\hline No specific schedule & 51.0 & 47.5 & 52.3 & 58.1 & 49.0 & 51.4 \\
\hline Missing values & 15.3 & 22.3 & 13.1 & 15.0 & 24.9 & 18.2 \\
\hline $\begin{array}{l}\text { Total } \\
\text { (N) }\end{array}$ & $\begin{array}{l}100.0 \\
(518)\end{array}$ & $\begin{array}{l}100.0 \\
(668)\end{array}$ & $\begin{array}{l}100.0 \\
(503)\end{array}$ & $\begin{array}{l}100.0 \\
(506)\end{array}$ & $\begin{array}{l}100.0 \\
(445)\end{array}$ & $\begin{array}{l}100.0 \\
(2,640)\end{array}$ \\
\hline
\end{tabular}




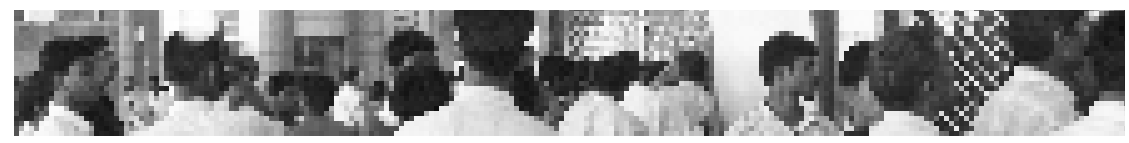

Table 3 : Percentage of recent male migrants surveyed, by reason they give for migrating, according to study district, Karnataka State, India, 2007

\begin{tabular}{lllllll}
\hline Reason & Bellary & Bangalore & $\begin{array}{l}\text { Dakshina } \\
\text { Kannada }\end{array}$ & Mandya & $\begin{array}{l}\text { Uttara } \\
\text { Kannada }\end{array}$ & Total \\
\hline $\begin{array}{l}\text { Reason for moving to current } \\
\text { location }\end{array}$ & & & & & & \\
$\quad$ Better income & 85.1 & 92.2 & 90.9 & 87.5 & 93.5 & 89.9 \\
$\quad$ Better work opportunities & 66.2 & 75.4 & 69.9 & 60.7 & 67.2 & 68.4 \\
Long-term work contract & 0.4 & 0 & 1.6 & 0.2 & 2.0 & 0.8 \\
$\quad$ Contractor moved them & 25.7 & 3.4 & 16.1 & 44.3 & 18.9 & 20.6 \\
Attraction to the city & 1.2 & 37.9 & 10.5 & 2.4 & 4.3 & 13.0 \\
Place of destination known & 28.8 & 30.8 & 11.3 & 19.2 & 22.7 & 23.1 \\
Family moved & 20.3 & 13.8 & 6.2 & 8.1 & 19.3 & 13.4 \\
$\quad$ Availability of skilled work & 8.9 & 11.5 & 4.4 & 8.3 & 2.0 & 7.4 \\
\hline Reason for leaving previous & & & & & & \\
location & & & & & & \\
Poverty & 76.8 & 76.8 & 74.4 & 78.6 & 89.4 & 78.8 \\
$\quad$ Low wages & 28.6 & 39.7 & 39.0 & 23.5 & 31.9 & 33.0 \\
Family pressure & 29.3 & 36.1 & 20.3 & 26.5 & 27.0 & 28.4 \\
$\quad$ Floods & 1.0 & 2.5 & 2.2 & 0.2 & 0.9 & 1.4 \\
$\quad$ Unemployment & 58.3 & 62.2 & 51.9 & 60.3 & 52.4 & 57.5 \\
$\quad$ Debt at home & 33.0 & 27.7 & 47.6 & 46.8 & 27.7 & 36.2 \\
Fed up with work & 36.3 & 40.0 & 34.4 & 24.3 & 29.2 & 33.4 \\
$\quad$ Drought & 39.6 & 20.7 & 32.8 & 29.8 & 31.5 & 30.3 \\
\hline (N) & $\mathbf{( 5 1 8 )}$ & $\mathbf{( 6 6 8 )}$ & $\mathbf{( 5 0 3 )}$ & $\mathbf{( 5 0 6 )}$ & $\mathbf{( 4 4 5 )}$ & $\mathbf{( 2 , 6 4 0 )}$ \\
\hline
\end{tabular}

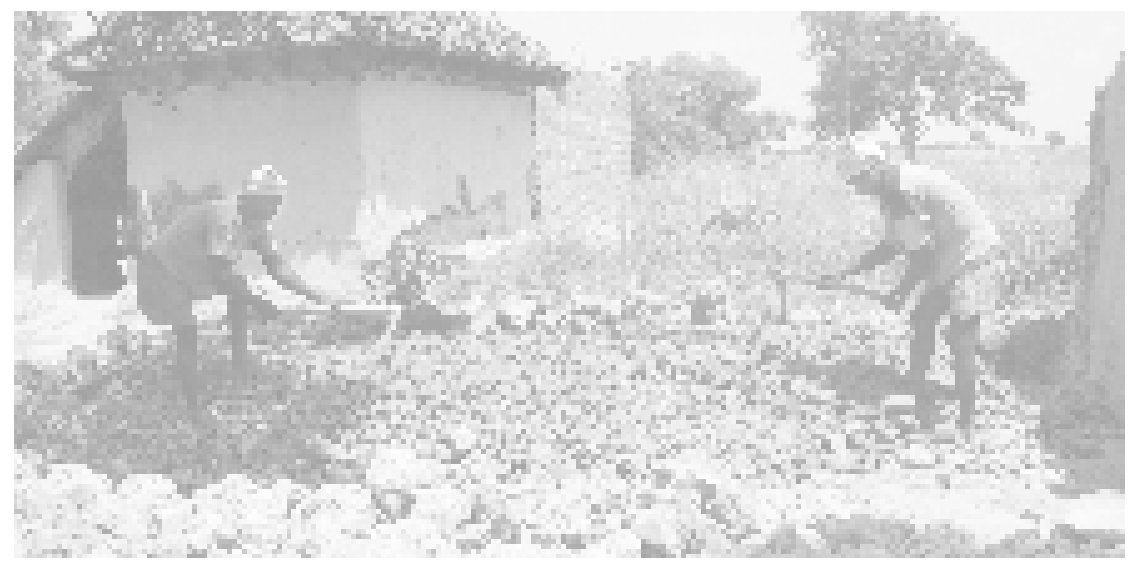




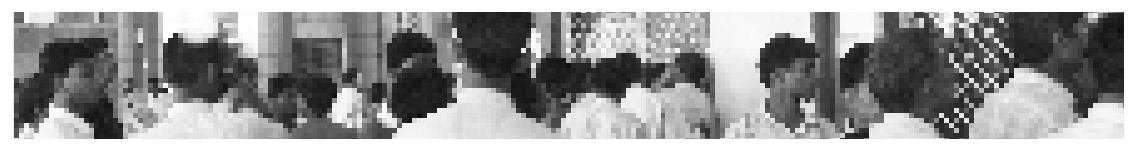

Table 4 : Percentage distribution of recent male migrants surveyed, by selected sociodemographic characteristics, Karnataka State, India, 2007

\begin{tabular}{|c|c|c|c|c|c|c|}
\hline Characteristic & Bellary & Bangalore & $\begin{array}{l}\text { Dakshina } \\
\text { Kannada }\end{array}$ & Mandya & $\begin{array}{l}\text { Uttara } \\
\text { Kannada }\end{array}$ & Total \\
\hline \multicolumn{7}{|l|}{ Age group } \\
\hline $19-24$ & 34.7 & 33.5 & 32.2 & 40.5 & 38.0 & 35.6 \\
\hline $25-29$ & 37.3 & 41.2 & 37.8 & 36.6 & 34.8 & 37.8 \\
\hline $30-34$ & 18.5 & 18.3 & 18.5 & 17.8 & 19.1 & 18.4 \\
\hline $35+$ & 9.5 & 7.0 & 11.5 & 5.1 & 8.1 & 8.2 \\
\hline \multicolumn{7}{|l|}{ Education } \\
\hline Illiterate & 21.3 & 14.6 & 16.7 & 18.0 & 28.5 & 19.3 \\
\hline Primary & 14.3 & 14.0 & 30.3 & 24.0 & 17.3 & 19.6 \\
\hline Secondary & 27.9 & 29.0 & 36.9 & 40.2 & 40.0 & 34.3 \\
\hline High school+ & 36.6 & 42.4 & 16.1 & 17.8 & 14.2 & 26.7 \\
\hline \multicolumn{7}{|l|}{ Religion } \\
\hline Hindu & 95.4 & 93.1 & 85.7 & 98.0 & 94.6 & 93.3 \\
\hline Non-Hindu & 4.6 & 6.9 & 14.3 & 2.0 & 5.4 & 6.7 \\
\hline \multicolumn{7}{|l|}{ Caste $^{a}$} \\
\hline SC/ST & 43.4 & 44.3 & 41.1 & 59.7 & 51.7 & 47.7 \\
\hline $\mathrm{OBC}$ & 40.2 & 45.7 & 44.5 & 33.4 & 41.3 & 41.3 \\
\hline Others & 16.4 & 10.0 & 14.4 & 6.9 & 7.0 & 11.0 \\
\hline \multicolumn{7}{|l|}{ Income (rupees per month) } \\
\hline$\leq 3,000$ & 26.5 & 16.2 & 9.0 & 22.6 & 15.3 & 17.9 \\
\hline $3,001-4,000$ & 31.1 & 41.7 & 26.1 & 43.8 & 48.0 & 38.1 \\
\hline $4,001-5,000$ & 21.3 & 26.9 & 25.9 & 21.8 & 27.3 & 24.7 \\
\hline $5,001+$ & 21.1 & 15.2 & 39.0 & 11.9 & 9.5 & 19.3 \\
\hline \multicolumn{7}{|l|}{ Current marital status } \\
\hline Unmarried & 46.9 & 58.4 & 46.3 & 51.5 & 46.7 & 50.5 \\
\hline Married & 53.1 & 41.6 & 53.7 & 48.5 & 53.3 & 49.5 \\
\hline \multicolumn{7}{|l|}{ If currently married, is wife staying } \\
\hline Yes & 69.4 & 72.5 & 47.0 & 65.3 & 67.1 & 64.3 \\
\hline No & 30.6 & 27.5 & 53.0 & 34.7 & 32.9 & 35.7 \\
\hline \multicolumn{7}{|l|}{ Living arrangement } \\
\hline Alone/with friends & 55.2 & 63.8 & 68.1 & 61.1 & 51.9 & 60.4 \\
\hline With parents/relatives & 7.7 & 6.7 & 6.6 & 9.5 & 11.3 & 8.2 \\
\hline With wife & 37.1 & 29.5 & 25.3 & 29.4 & 36.7 & 31.4 \\
\hline \multicolumn{7}{|l|}{ Type of house } \\
\hline Pucca (brink and cement hut) & 4.2 & 10.1 & 7.0 & 3.8 & $1.1^{\mathrm{b}}$ & 5.6 \\
\hline $\begin{array}{l}\text { Semi-pucca (brick and mud hut) } \\
\text { Kacha (bamboo and mud. }\end{array}$ & 29.7 & 60.8 & 22.5 & 23.9 & 15.1 & 32.6 \\
\hline thatched-roof hut) & 66.0 & 29.1 & 70.6 & 72.3 & 83.7 & 61.8 \\
\hline Total & 100.0 & 100.0 & 100.0 & 100.0 & 100.0 & 100.0 \\
\hline (N) & (518) & (668) & (503) & (506) & (445) & $(2,640)$ \\
\hline
\end{tabular}

${ }^{\mathrm{a}} \mathrm{SC} / \mathrm{ST}=$ Scheduled classes/scheduled tribes. OBC $=$ Other backward classes. ${ }^{\mathrm{b}}$ Based on fewer than 10 cases. 


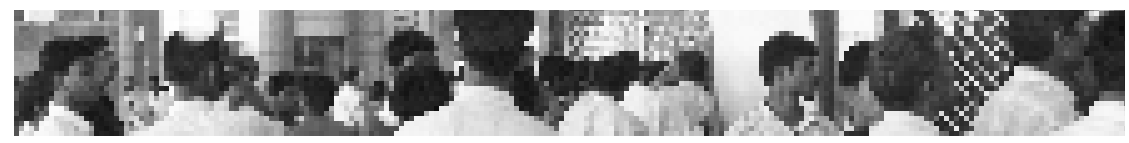

Table 5 : Percentage distribution of recent male migrants surveyed, by their occupational category, according to study district, Karnataka State, India, 2007

\begin{tabular}{lllllll}
\hline Occupation & Bellary & Bangalore & $\begin{array}{l}\text { Dakshina } \\
\text { Kannada }\end{array}$ & Mandya & $\begin{array}{l}\text { Uttara } \\
\text { Kannada }\end{array}$ & Total \\
\hline Construction & 51.5 & 11.2 & - & - & 31.2 & 18.2 \\
Road construction & - & - & 40.0 & 25.3 & - & 12.5 \\
Mining & 48.5 & - & - & - & - & 9.5 \\
Industry & - & 24.4 & - & 13.4 & - & 8.8 \\
Day labour & - & - & - & - & 52.4 & 8.8 \\
Brick industry & - & 12.1 & - & 27.3 & - & 8.3 \\
Fishing & - & - & 29.4 & - & 13.7 & 7.9 \\
Garment work & - & 29.2 & - & - & - & 7.4 \\
$\begin{array}{l}\text { Port/factory loading } \\
\text { Sugarcane cutting }\end{array}$ & - & - & 30.6 & - & 2.7 & 6.3 \\
$\begin{array}{l}\text { Farm-produce warehouse } \\
\text { work }\end{array}$ & - & - & - & 34.0 & - & 6.5 \\
\hline $\begin{array}{l}\text { Total } \\
\text { (N) }\end{array}$ & - & $\mathbf{2 3 . 1}$ & - & - & - & 5.8 \\
\hline
\end{tabular}

- $=$ Not applicable.

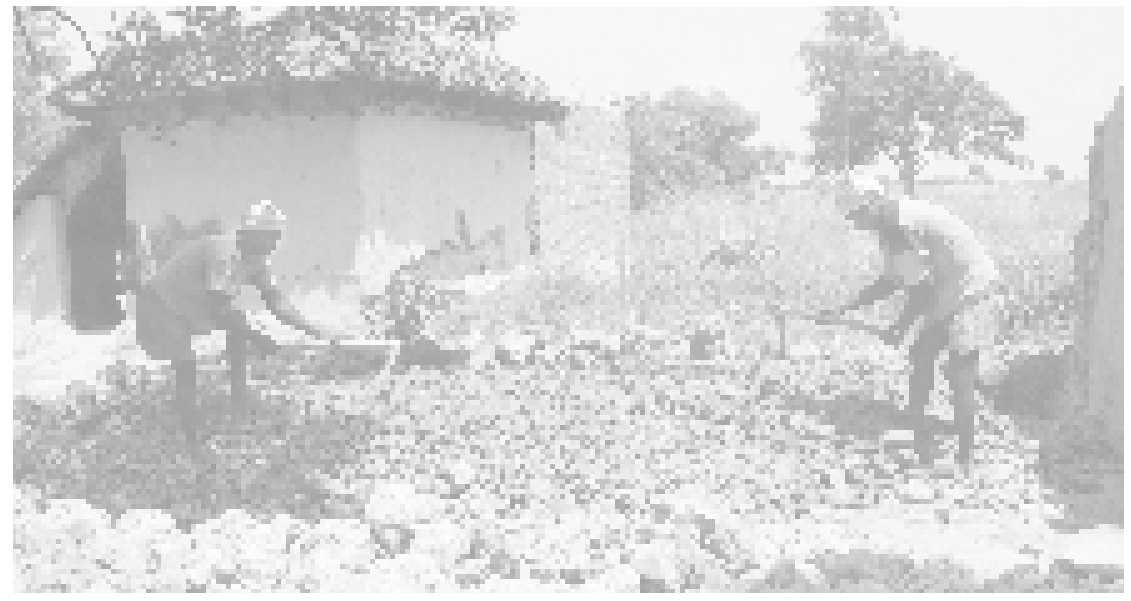




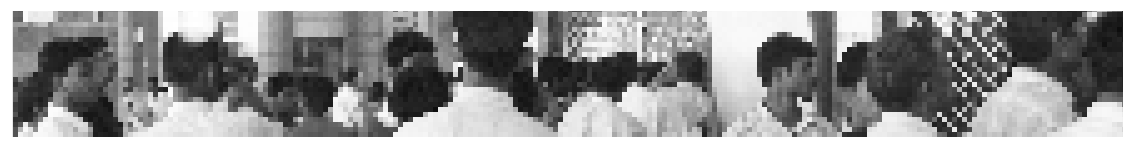

Tabe 6 : Percentage of recent male migrants surveyed, by their exposure to mass media, sex-related materials, and their substance use, according to study district, Karnataka State, India, 2007

\begin{tabular}{lllllll}
\hline Type of exposure & Bellary & Bangalore & $\begin{array}{l}\text { Dakshina } \\
\text { Kannada }\end{array}$ & Mandya & $\begin{array}{l}\text { Uttara } \\
\text { Kannada }\end{array}$ & Total \\
\hline $\begin{array}{l}\text { Media exposure } \\
\quad \text { Newspaper/magazines }\end{array}$ & 25.7 & 40.4 & 40.6 & 31.4 & 21.1 & 32.6 \\
$\quad \begin{array}{l}\text { Movie in cinema halls/ } \\
\quad \text { video parlours }\end{array}$ & 79.0 & 87.4 & 78.3 & 79.2 & 75.5 & 80.5 \\
$\quad \begin{array}{l}\text { Television } \\
\quad \text { Radio/ FM }\end{array}$ & 41.3 & 50.3 & 45.4 & 42.7 & 42.7 & 44.9 \\
\hline $\begin{array}{l}\text { Sex-related materials } \\
\quad \text { Poster/photographs }\end{array}$ & 17.0 & 81.7 & 53.1 & 59.9 & 32.4 & 51.1 \\
$\quad$ Magazines/books & 49.9 & 55.7 & 47.4 & 46.5 & 52.6 & 50.7 \\
$\quad$ Adult movies/blue films & 22.8 & 32.2 & 15.5 & 17.1 & 17.5 & 21.8 \\
$\quad$ Any pornographic materials & 31.5 & 37.7 & 41.6 & 30.8 & 25.8 & 33.9 \\
\hline Substance use & 66.0 & 68.7 & 69.9 & 58.0 & 62.0 & 65.2 \\
$\quad$ Bhang/ganja & & & & & & \\
$\quad$ Injecting drugs & 0.8 & 2.2 & 3.8 & 1.0 & 1.8 & 1.9 \\
$\quad \begin{array}{l}\text { Desi-daru/toddy alcohol } \\
\quad \text { Beer/foreign liquor }\end{array}$ & 0.2 & 0.1 & 0 & 0 & 0.2 & 0.1 \\
$\quad$ Any alcohol & 27.2 & 18.4 & 37.3 & 33.8 & 32.8 & 29.1 \\
\hline (N) & 53.9 & 64.5 & 65.0 & 56.5 & 53.3 & 59.1 \\
\hline
\end{tabular}

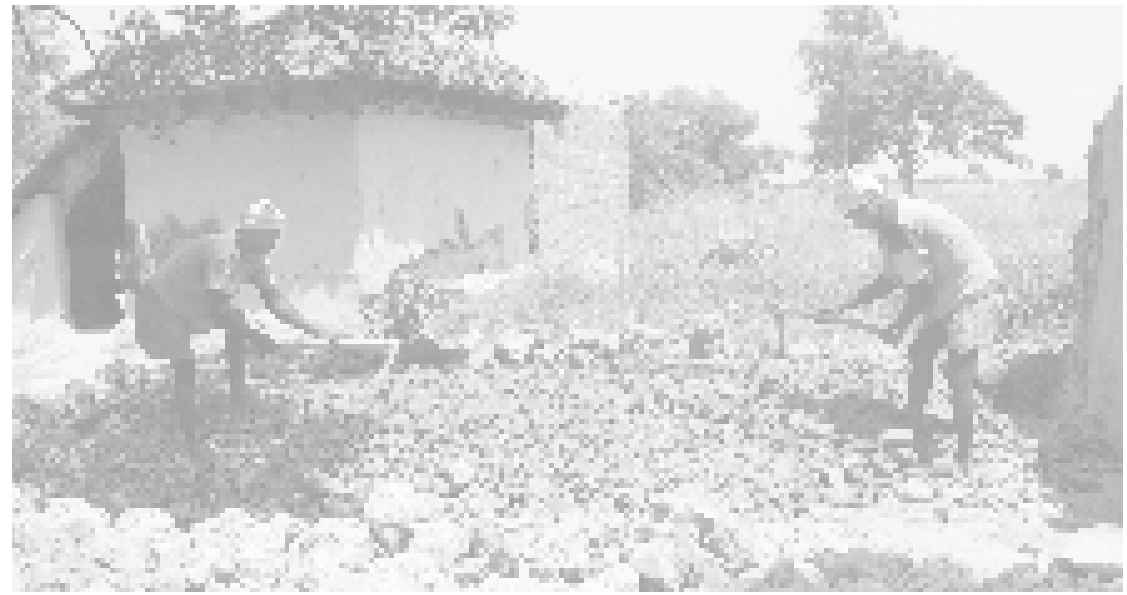




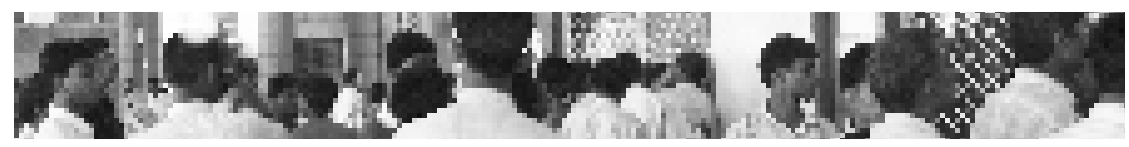

Table 7 : Percentage of recent male migrants surveyed, by their type of sex partner, according to selected background characteristics and current marital status, Karnataka State, India, 2007

\begin{tabular}{|c|c|c|c|c|c|c|c|c|}
\hline \multirow[b]{2}{*}{ Characteristic } & \multicolumn{4}{|c|}{ Unmarried } & \multicolumn{4}{|c|}{ Married } \\
\hline & sw & NSW & $\begin{array}{l}\text { Any } \\
\text { partner }\end{array}$ & (N) & sw & NSW & $\begin{array}{l}\text { Any } \\
\text { partner }\end{array}$ & (N) \\
\hline \multicolumn{9}{|l|}{ Age group } \\
\hline $19-24$ & 3.1 & 19.2 & 21.9 & (873) & & & & \\
\hline $25-29$ & 12.9 & 31.0 & 40.3 & (419) & & & & \\
\hline $30+$ & 22.0 & 26.8 & 36.6 & (41) & & & & \\
\hline $19-29$ & & & & & 9.8 & 17.2 & 25.0 & $(644)$ \\
\hline $30-34$ & & & & & 10.1 & 15.6 & 23.3 & (455) \\
\hline $35+$ & & & & & 10.7 & 11.2 & 16.1 & (205) \\
\hline \multicolumn{9}{|l|}{ Education } \\
\hline Illiterate & 7.7 & 20.4 & 27.1 & $(181)$ & 4.3 & 8.8 & 12.5 & (328) \\
\hline Primary & 6.3 & 26.4 & 28.8 & (208) & 12.1 & 21.5 & 29.0 & (307) \\
\hline Secondary & 5.2 & 20.7 & 25.1 & (502) & 11.8 & 18.5 & 27.3 & (399) \\
\hline High school+ & 8.4 & 25.8 & 32.0 & (438) & 12.0 & 13.5 & 22.6 & (266) \\
\hline \multicolumn{9}{|l|}{ Income level } \\
\hline$\leq 3,000$ & 2.1 & 19.7 & 20.7 & $(290)$ & 6.6 & 7.7 & 12.6 & $(182)$ \\
\hline $3,001-4,000$ & 4.1 & 19.3 & 22.5 & (559) & 5.6 & 14.4 & 19.4 & (443) \\
\hline $4,001-5,000$ & 8.8 & 28.5 & 35.6 & (295) & 7.3 & 16.9 & 22.0 & (354) \\
\hline $5,001+$ & 19.0 & 32.6 & 45.7 & (184) & 21.0 & 20.7 & 34.9 & (324) \\
\hline \multicolumn{9}{|l|}{ District } \\
\hline Bellary & 4.1 & 23.5 & 26.7 & $(243)$ & 4.4 & 11.6 & 14.5 & $(275)$ \\
\hline Bangalore & 7.7 & 20.8 & 26.7 & $(390)$ & 13.7 & 12.6 & 23.7 & (278) \\
\hline Dakshina Kannada & 13.7 & 28.3 & 37.3 & (233) & 21.5 & 19.6 & 33.7 & (270) \\
\hline Mandya & 5.4 & 23.8 & 27.7 & (260) & 6.5 & 22.4 & 26.9 & (245) \\
\hline Uttara Kannada & 1.9 & 20.8 & 22.7 & (207) & 3.0 & 12.7 & 15.7 & (236) \\
\hline \multicolumn{9}{|l|}{ Occupation } \\
\hline Construction & 5.3 & 23.2 & 27.2 & $(246)$ & 7.2 & 11.9 & 17.0 & (235) \\
\hline Mining & 1.1 & 26.3 & 27.4 & (95) & 0 & 12.8 & 12.8 & (156) \\
\hline Road construction & 7.3 & 27.0 & 32.6 & (178) & 19.3 & 15.3 & 30.0 & (150) \\
\hline Fishing & 24.7 & 19.1 & 34.8 & (89) & 32.8 & 24.4 & 44.5 & (119) \\
\hline Port/factory loading & 6.2 & 33.3 & 38.3 & (81) & 3.5 & 15.3 & 18.8 & (85) \\
\hline Sugarcane cutting & 3.4 & 25.9 & 27.6 & (58) & 2.6 & 37.7 & 37.7 & (114) \\
\hline Brick industry & 0.8 & 19.3 & 19.3 & (119) & 3.0 & 8.0 & 10.0 & (100) \\
\hline Industry & 8.7 & 15.3 & 23.3 & (150) & 18.5 & 12.3 & 28.4 & (81) \\
\hline Day labour & 0.9 & 23.4 & 24.3 & (111) & 3.3 & 10.7 & 14.0 & (121) \\
\hline Garment work & 8.1 & 26.0 & 30.9 & (123) & 12.5 & 16.7 & 26.4 & $(72)$ \\
\hline Farm-produce warehouse work & 10.8 & 19.3 & 27.7 & $(83)$ & 12.7 & 8.5 & 19.7 & (71) \\
\hline \multicolumn{9}{|c|}{ Exposure to pornography } \\
\hline No & 3.7 & 25.2 & 28.5 & $(326)$ & 5.9 & 13.6 & 18.7 & (589) \\
\hline Yes & 7.7 & 22.5 & 28.0 & $(1,007)$ & 13.2 & 17.6 & 26.4 & $(712)$ \\
\hline \multicolumn{9}{|l|}{ Alcohol consumption } \\
\hline No & 1.2 & 13.1 & 13.9 & $(581)$ & 2.5 & 10.6 & 12.3 & $(236)$ \\
\hline Yes & 11.0 & 31.0 & 39.1 & (752) & 11.7 & 16.9 & 25.4 & $(1,067)$ \\
\hline \multicolumn{9}{|l|}{$\begin{array}{l}\text { If married, is wife staying with } \\
\text { you at current location? }\end{array}$} \\
\hline Yes & - & - & - & - & 5.1 & 14.5 & 18.7 & $(825)$ \\
\hline No & - & - & - & 一 & 19.0 & 17.6 & 30.5 & $(459)$ \\
\hline Total & 6.8 & 23.2 & 28.1 & $(1,333)$ & 10.0 & 15.7 & 23.0 & $(1,304)$ \\
\hline
\end{tabular}

$\mathrm{SW}=$ Sex worker. $\quad \mathrm{NSW}=$ Non-sex worker. Any partner $=$ Either sex worker or non-sex worker. $-=$ Not applicable. 


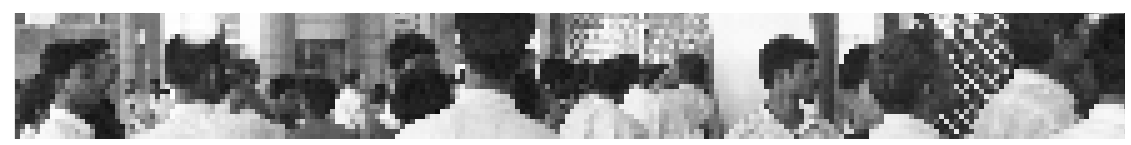

Table 8 : Percentage of recent male migrants surveyed, by their reported sexual behaviour, according to their migration/mobility characteristics and current marital status, Karnataka State, India, 2007

\begin{tabular}{|c|c|c|c|c|c|c|c|c|}
\hline \multirow[b]{2}{*}{ Characteristic } & \multicolumn{4}{|c|}{ Unmarried } & \multicolumn{4}{|c|}{ Married } \\
\hline & sw & NSW & $\begin{array}{l}\text { Any } \\
\text { partner }\end{array}$ & (N) & sw & NSW & $\begin{array}{l}\text { Any } \\
\text { partner }\end{array}$ & (N) \\
\hline \multicolumn{9}{|c|}{$\begin{array}{l}\text { Moved for work during past } \\
\text { two years to }\end{array}$} \\
\hline 2 places & 5.5 & 19.4 & 23.5 & $(345)$ & 9.1 & 14.6 & 21.1 & $(474)$ \\
\hline 3 places & 8.4 & 24.6 & 30.6 & $(670)$ & 11.2 & 16.9 & 24.8 & (609) \\
\hline $4+$ places & 4.7 & 24.2 & 28.0 & (318) & 9.0 & 14.9 & 22.2 & (221) \\
\hline \multicolumn{9}{|c|}{$\begin{array}{l}\text { Stayed overnight away from } \\
\text { home while at current } \\
\text { location in the past month }\end{array}$} \\
\hline No & 5.7 & 23.8 & 27.8 & $(1,202)$ & 9.0 & 15.9 & 22.4 & $(1,192)$ \\
\hline Yes & 16.8 & 17.6 & 31.3 & $(131)$ & 21.4 & 14.3 & 29.5 & (112) \\
\hline \multicolumn{9}{|c|}{$\begin{array}{l}\text { Commuted between } \\
\text { workplace and residence but } \\
\text { did not stay overnight }\end{array}$} \\
\hline No & 7.4 & 24.1 & 29.6 & $(1,176)$ & 10.4 & 15.9 & 23.6 & $(1,188)$ \\
\hline Yes & 2.0 & 15.2 & 15.9 & $(151)$ & 5.3 & 14.2 & 16.8 & $(113)$ \\
\hline \multicolumn{9}{|c|}{ Currently under contract } \\
\hline No & 6.5 & 21.9 & 26.5 & $(1,015)$ & 10.6 & 12.8 & 20.6 & $(874)$ \\
\hline Yes & 7.5 & 27.4 & 33.3 & $(318)$ & 8.8 & 21.6 & 27.9 & $(430)$ \\
\hline \multicolumn{9}{|c|}{$\begin{array}{l}\text { First-time move facilitated } \\
\text { by contractor }\end{array}$} \\
\hline No & 6.9 & 21.6 & 26.6 & $(1,116)$ & 10.5 & 13.9 & 21.5 & $(1,019)$ \\
\hline Yes & 6.1 & 30.8 & 35.5 & $(214)$ & 7.5 & 21.5 & 27.6 & $(279)$ \\
\hline Total & 6.8 & 23.2 & 28.1 & $(1,333)$ & 10.0 & 15.7 & 23.0 & $(1,304)$ \\
\hline
\end{tabular}

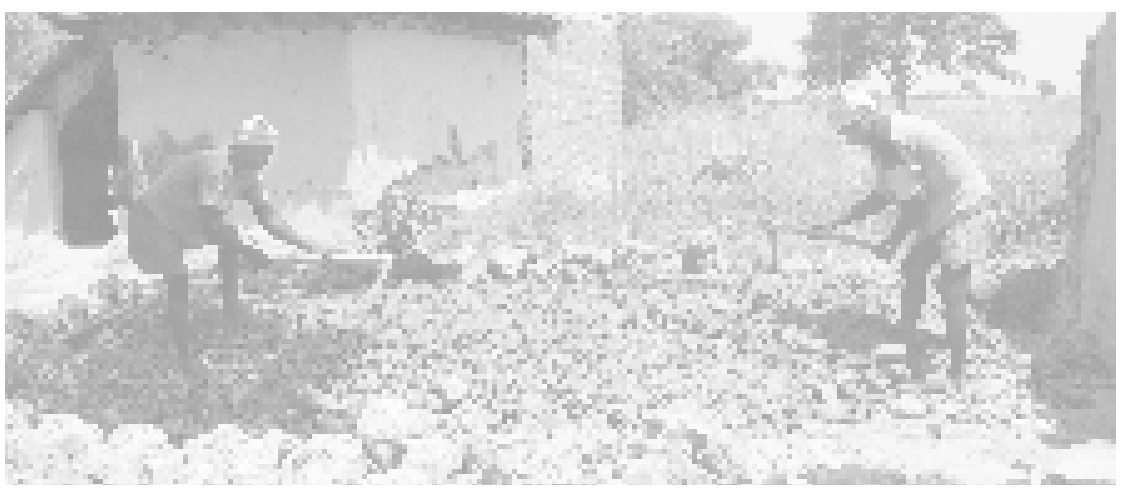



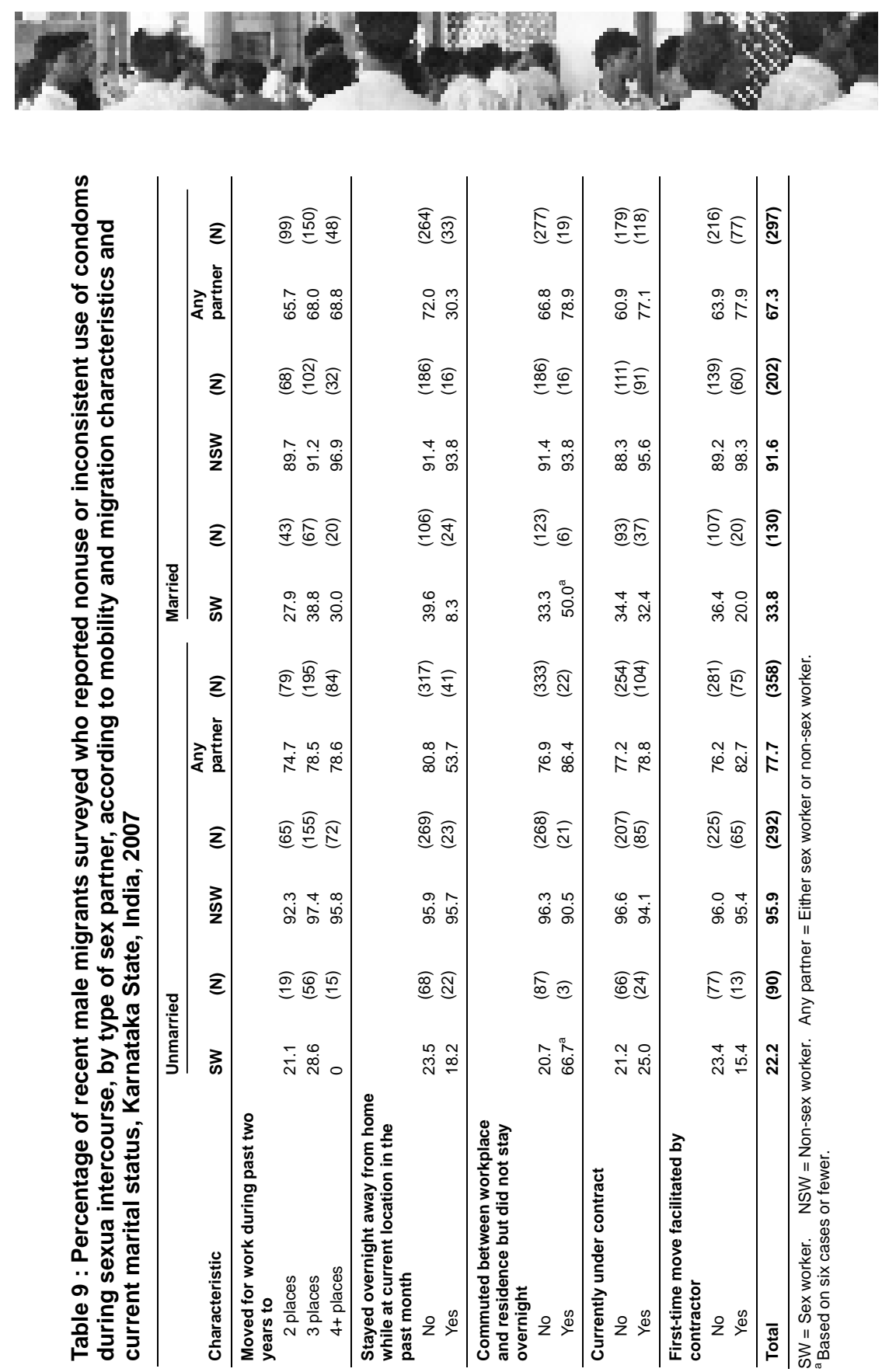


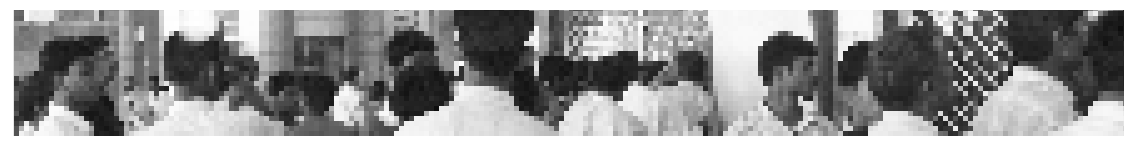

Table 10 : Percentage of recent male migrants reporting their experience with gupt rog in the past 12 months, their experience with STI-like symptoms in the past 12 months, and their perceived high or moderate risk of acquiring HIV, Karnataka State, India, 2007

\begin{tabular}{|c|c|c|c|c|}
\hline Characteristic & $\begin{array}{l}\text { Reported } \\
\text { gupt rog } \\
\text { symptoms }\end{array}$ & $\begin{array}{l}\text { Reported } \\
\text { STI-like } \\
\text { symptoms }^{\text {b }}\end{array}$ & $\begin{array}{l}\text { Perceive high } \\
\text { or moderate } \\
\text { risk of HIV } \\
\text { infection }\end{array}$ & (N) \\
\hline \multicolumn{5}{|c|}{ Moved for work during past two years to } \\
\hline 2 places & 72.0 & 64.1 & 3.8 & $(820)$ \\
\hline 3 places & 79.4 & 70.0 & 5.4 & $(1,280)$ \\
\hline $4+$ places & 81.3 & 69.6 & 8.7 & $(540)$ \\
\hline \multicolumn{5}{|c|}{$\begin{array}{l}\text { Stayed overnight away from home while at } \\
\text { current location in the past month }\end{array}$} \\
\hline No & 76.4 & 67.4 & 5.9 & $(2,397)$ \\
\hline Yes & 87.7 & 75.3 & 2.1 & $(243)$ \\
\hline \multicolumn{5}{|c|}{$\begin{array}{l}\text { Commuted between workplace and } \\
\text { residence but did not stay overnight }\end{array}$} \\
\hline No & 76.5 & 67.8 & 6.1 & $(2,366)$ \\
\hline Yes & 86.8 & 70.9 & 1.2 & $(265)$ \\
\hline \multicolumn{5}{|c|}{ Currently under contract } \\
\hline No & 77.0 & 67.9 & 6.6 & $(1,891)$ \\
\hline Yes & 78.5 & 68.6 & 3.2 & $(749)$ \\
\hline \multicolumn{5}{|c|}{ First-time move facilitated by contractor } \\
\hline No & 78.1 & 68.9 & 6.4 & $(2,137)$ \\
\hline Yes & 74.7 & 64.4 & 1.7 & $(494)$ \\
\hline Total & 77.5 & 68.1 & 5.6 & $\left(2^{\prime} 640\right)$ \\
\hline
\end{tabular}

${ }^{a}$ Gupt rog symptoms: swapna dosh, dhat, lack of erection, bent penis, premature/early ejaculation, poor quantity of semen, poor quality of semen, garmi, phoda/phunsi, swelling in groin area, itching in genital area, frequent painful urination.

${ }^{b}$ STI-like symptoms: garmi, phoda/phunsi, swelling in groin area, itching in genital area, frequent painful urination

${ }^{c}$ Data available for 2,631 respondents for this variable.

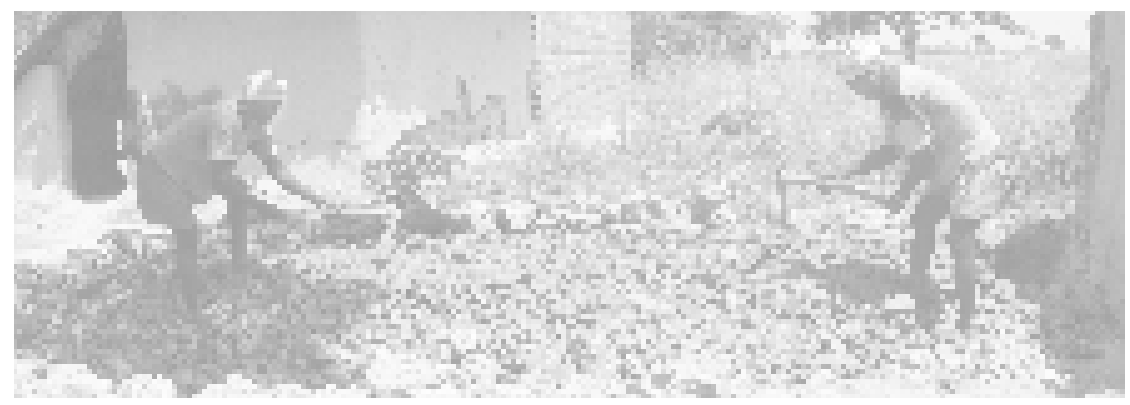




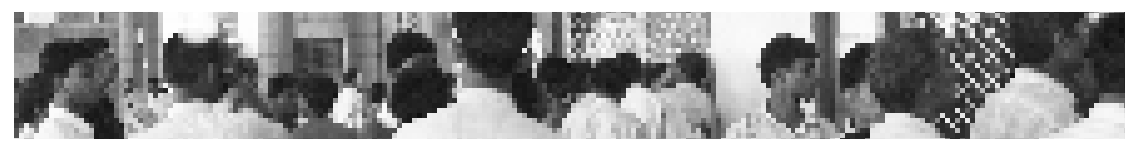

Table 11 : Percentage distribution of recent male migrants surveyed, by number of locations along their migration routes where they had pre-or extramarital sex in the past two years, according to selected characteristics, Karnataka State, India, 2007

\begin{tabular}{|c|c|c|c|c|c|c|c|}
\hline \multirow[b]{2}{*}{ Characteristic } & \multicolumn{5}{|c|}{ Number of locations $^{a}$} & \multirow[b]{2}{*}{ Total } & \multirow[b]{2}{*}{ (N) } \\
\hline & None & 1 place & 2 places & 3 places & 4 places & & \\
\hline \multicolumn{8}{|l|}{ Age group } \\
\hline $19-24$ & 66.0 & 20.0 & 12.2 & 1.4 & 0.4 & 100.0 & $(940)$ \\
\hline $25-29$ & 52.4 & 21.3 & 15.4 & 8.1 & 2.7 & 100.0 & (998) \\
\hline $30-34$ & 63.6 & 15.4 & 10.7 & 7.4 & 2.9 & 100.0 & $(486)$ \\
\hline $35+$ & 69.0 & 16.7 & 6.0 & 3.7 & 4.6 & 100.0 & $(216)$ \\
\hline \multicolumn{8}{|l|}{ Current marital status } \\
\hline Unmarried & 58.7 & 20.6 & 15.8 & 4.0 & 1.0 & 100.0 & $(1,333)$ \\
\hline Married & 62.7 & 18.2 & 9.4 & 6.5 & 3.2 & 100.0 & $(1,304)$ \\
\hline \multicolumn{8}{|l|}{$\begin{array}{l}\text { If married, is wife staying with you at } \\
\text { current location? }\end{array}$} \\
\hline Yes & 67.6 & 17.0 & 8.2 & 4.8 & 2.3 & 100.0 & $(825)$ \\
\hline No & 54.9 & 19.2 & 11.3 & 9.8 & 4.8 & 100.0 & (459) \\
\hline \multicolumn{8}{|l|}{ Type of occupation } \\
\hline Construction & 61.3 & 20.0 & 11.9 & 5.2 & 1.7 & 100.0 & $(481)$ \\
\hline Mining & 65.3 & 22.7 & 8.4 & 2.0 & 1.6 & 100.0 & (251) \\
\hline Road construction & 56.2 & 17.3 & 16.4 & 6.4 & 3.6 & 100.0 & (329) \\
\hline Fishing & 52.2 & 17.7 & 14.4 & 12.0 & 3.8 & 100.0 & (209) \\
\hline Port/factory loading & 57.8 & 15.7 & 21.1 & 4.8 & 0.6 & 100.0 & (166) \\
\hline Sugarcane cutting & 55.8 & 17.4 & 15.7 & 5.2 & 5.8 & 100.0 & (172) \\
\hline Brick industry & 66.7 & 20.5 & 9.1 & 3.2 & 0.5 & 100.0 & (219) \\
\hline Industry & 58.9 & 23.4 & 9.1 & 6.9 & 1.7 & 100.0 & (231) \\
\hline Day labour & 69.1 & 19.7 & 9.0 & 1.7 & 0.4 & 100.0 & (233) \\
\hline Garment work & 58.5 & 18.5 & 13.8 & 7.2 & 2.1 & 100.0 & (195) \\
\hline Farm-produce warehouse work & 64.3 & 18.2 & 13.6 & 2.6 & 1.3 & 100.0 & $(154)$ \\
\hline \multicolumn{8}{|l|}{ Contract status $^{b}$} \\
\hline $\begin{array}{l}\text { Never under contract } \\
\text { Worked under contract at first but }\end{array}$ & 61.8 & 19.3 & 12.9 & 4.8 & 1.3 & 100.0 & $(1,820)$ \\
\hline not now & 57.1 & 15.8 & 12.6 & 9.8 & 4.7 & 100.0 & $(317)$ \\
\hline $\begin{array}{l}\text { First worked without contract but } \\
\text { now under contract } \\
\text { Under contract in both first and }\end{array}$ & 67.7 & 18.5 & 7.7 & 3.1 & 3.1 & 100.0 & $(65)$ \\
\hline current job & 58.3 & 22.6 & 12.1 & 4.0 & 3.0 & 100.0 & $(429)$ \\
\hline Total & 60.6 & 19.4 & 12.7 & 5.2 & 2.1 & 100.0 & $(2,640)$ \\
\hline
\end{tabular}

${ }^{a}$ Based on the men's reports of their sexual behaviour at their current locations, at their previous two locations, and at their place of origin. ${ }^{\mathrm{b}}$ Data available for 2,631 respondents on this variable. 


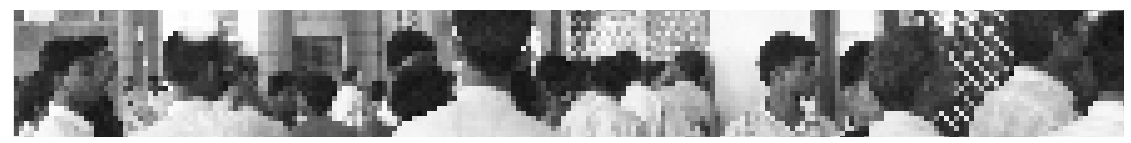

Table 12 : Percentage of recent male migrants surveyed who reported engaging in pre - or extramarital sex in places along their migration routes in the past two years, by selected characteristics, Karnataka State, India, 2007

\begin{tabular}{|c|c|c|c|c|c|c|}
\hline Characteristic & $\begin{array}{l}\text { Current } \\
\text { location }\end{array}$ & $\begin{array}{l}\text { Previous } \\
\text { location } 1\end{array}$ & $\begin{array}{l}\text { Previous } \\
\text { location } 2\end{array}$ & $\begin{array}{l}\text { Place of } \\
\text { origin }\end{array}$ & $\begin{array}{l}\text { Had sex in place of } \\
\text { origin and one of } \\
\text { the other three } \\
\text { places }\end{array}$ & (N) \\
\hline \multicolumn{7}{|l|}{ Age group } \\
\hline $19-24$ & 21.5 & 4.5 & 4.5 & 20.0 & 8.4 & $(940)$ \\
\hline $25-29$ & 32.0 & 13.0 & 13.1 & 29.9 & 16.6 & (998) \\
\hline $30-34$ & 24.1 & 11.8 & 11.1 & 23.7 & 14.4 & $(486)$ \\
\hline $35+$ & 17.1 & 10.7 & 8.8 & 22.1 & 9.3 & $(216)$ \\
\hline \multicolumn{7}{|l|}{ Income (rupees per month) } \\
\hline$\leq 3,000$ & 17.6 & 5.1 & 5.7 & 21.2 & 8.3 & $(472)$ \\
\hline $3,001-4,000$ & 21.1 & 7.0 & 7.1 & 25.2 & 12.4 & $(1,004)$ \\
\hline $4,001-5,000$ & 28.2 & 9.3 & 9.3 & 25.9 & 14.2 & $(650)$ \\
\hline $5,001+$ & 38.8 & 19.2 & 17.1 & 25.3 & 15.7 & $(508)$ \\
\hline \multicolumn{7}{|l|}{ Occupation } \\
\hline Construction & 22.2 & 8.8 & 9.9 & 25.6 & 12.3 & $(481)$ \\
\hline Mining & 18.3 & 4.8 & 5.6 & 23.1 & 8.4 & $(251)$ \\
\hline Road construction & 31.3 & 12.8 & 10.6 & 29.2 & 19.1 & $(329)$ \\
\hline Fishing & 40.2 & 22.2 & 17.9 & 18.5 & 12.4 & $(209)$ \\
\hline Port/factory loading & 28.3 & 12.9 & 9.2 & 25.0 & 13.9 & $(166)$ \\
\hline Sugarcane cutting & 34.3 & 11.6 & 15.1 & 26.7 & 18.6 & $(172)$ \\
\hline Brick industry & 15.1 & 2.7 & 5.0 & 27.4 & 10.0 & (219) \\
\hline Industry & 25.1 & 10.0 & 7.9 & 26.5 & 11.7 & $(231)$ \\
\hline Day labour & 18.9 & 2.6 & 3.0 & 20.3 & 9.9 & $(233)$ \\
\hline Garment work & 29.2 & 11.3 & 11.8 & 23.6 & 13.3 & (195) \\
\hline \multicolumn{7}{|l|}{ Farm-produce warehouse } \\
\hline work & 24.0 & 7.1 & 7.1 & 20.1 & 8.4 & $(154)$ \\
\hline \multicolumn{7}{|l|}{ Current marital status } \\
\hline Unmarried & 28.1 & 7.4 & 7.3 & 25.5 & 13.3 & $(1,333)$ \\
\hline Married & 23.0 & 11.8 & 11.3 & 23.6 & 12.1 & $(1,304)$ \\
\hline \multicolumn{7}{|c|}{$\begin{array}{l}\text { If married, is wife staying } \\
\text { with you in current location? }\end{array}$} \\
\hline Yes & 18.7 & $8 . .4$ & 8.7 & 21.7 & 10.4 & $(825)$ \\
\hline No & 30.5 & 17.9 & 16.2 & 26.3 & 15.3 & $(459)$ \\
\hline \multicolumn{7}{|l|}{ Contract status $^{\mathrm{a}}$} \\
\hline Never under contract & 23.9 & 8.4 & 8.1 & 24.4 & 11.6 & $(1,820)$ \\
\hline \multicolumn{7}{|c|}{$\begin{array}{l}\text { First time worked under } \\
\text { contract but is not under }\end{array}$} \\
\hline contract now & 25.9 & 15.6 & 15.9 & 32.6 & 19.9 & $(317)$ \\
\hline \multicolumn{7}{|l|}{ First time did not work } \\
\hline $\begin{array}{l}\text { under contract but is } \\
\text { under contract now }\end{array}$ & 18.5 & 10.9 & 9.2 & 16.9 & 4.6 & $(65)$ \\
\hline \multicolumn{7}{|c|}{ Under contract in both first } \\
\hline and current job & 32.9 & 9.1 & 8.7 & 20.3 & 12.6 & (429) \\
\hline Total & 25.6 & 9.6 & 9.3 & 24.6 & 12.7 & $(2,640)$ \\
\hline
\end{tabular}

${ }^{\mathrm{a}}$ Data available for 2,631 respondents on this variable. 


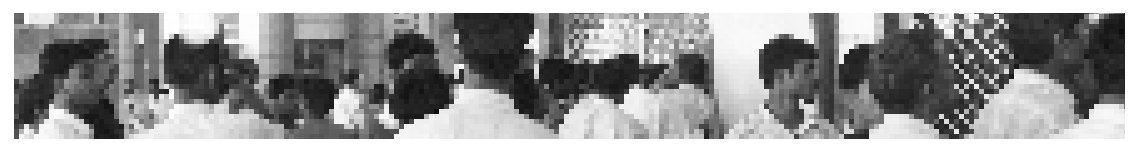

Table 13 : Percentage of recent male migrants surveyed, by their knowledge of HIV transmission and prevention, according to study district, Karnataka State, India, 2007

\begin{tabular}{|c|c|c|c|c|c|c|}
\hline Knowledge of HIV & Bellary & Bangalore & $\begin{array}{l}\text { Dakshina } \\
\text { Kannada }\end{array}$ & Mandya & $\begin{array}{l}\text { Uttara } \\
\text { Kannada }\end{array}$ & Total \\
\hline \multicolumn{7}{|l|}{$\begin{array}{l}\text { How does a man become infected with } \\
\text { HIV? }\end{array}$} \\
\hline Sex with multiple partners & 69.9 & 75.7 & 80.1 & 74.3 & 77.3 & 75.4 \\
\hline Sex with HIV-positive person & 64.3 & 65.8 & 62.4 & 66.1 & 66.1 & 64.9 \\
\hline Sex with sex workers & 16.8 & 16.0 & 20.1 & 21.0 & 15.0 & 17.7 \\
\hline Sex without condoms & 10.4 & 13.3 & 5.6 & 9.4 & 9.3 & 9.8 \\
\hline Infected needles & 76.0 & 84.0 & 68.1 & 76.0 & 73.2 & 76.0 \\
\hline Infected blood & 81.8 & 82.2 & 69.5 & 80.4 & 76.1 & 78.3 \\
\hline Using common toilet/bath & 4.7 & 4.2 & 5.2 & 6.0 & 5.9 & 5.1 \\
\hline Sharing utensils/clothes & 21.5 & 17.7 & 9.4 & 12.8 & 15.7 & 15.6 \\
\hline Kissing an HIV-positive person & 23.2 & 21.7 & 35.1 & 28.5 & 30.9 & 27.4 \\
\hline Mosquito bite & 27.7 & 25.0 & 35.7 & 23.4 & 21.6 & 26.7 \\
\hline Barber shop visit & 60.7 & 71.9 & 72.9 & 64.7 & 55.6 & 65.8 \\
\hline \multicolumn{7}{|l|}{ How can HIV infection be prevented? } \\
\hline Having only one sex partner & 68.2 & 67.2 & 74.5 & 70.3 & 78.0 & 71.2 \\
\hline $\begin{array}{l}\text { Abstaining from pre - and extramarital } \\
\text { sex }\end{array}$ & 19.9 & 19.5 & 13.4 & 14.8 & 20.0 & 17.6 \\
\hline Using condoms all the time & 49.4 & 56.4 & 55.7 & 43.9 & 42.6 & 50.2 \\
\hline Using antibiotics before sex & 9.6 & 10.9 & 7.0 & 7.0 & 9.1 & 8.8 \\
\hline Abstaining from sex all the time & 9.4 & 10.2 & 2.0 & 5.6 & 5.2 & 6.7 \\
\hline $\begin{array}{l}\text { Taking injections with a clean needle/ } \\
\text { syringe/other injecting equipment }\end{array}$ & 67.8 & 69.2 & 39.9 & 54.6 & 59.6 & 58.9 \\
\hline Having a good diet & 25.8 & 24.7 & 7.8 & 7.4 & 13.2 & 16.4 \\
\hline Avoiding people who are HIV-positive & 55.5 & 58.8 & 37.7 & 39.8 & 39.5 & 47.3 \\
\hline Not visiting sex workers & 84.2 & 88.6 & 75.6 & 80.0 & 82.5 & 82.6 \\
\hline
\end{tabular}

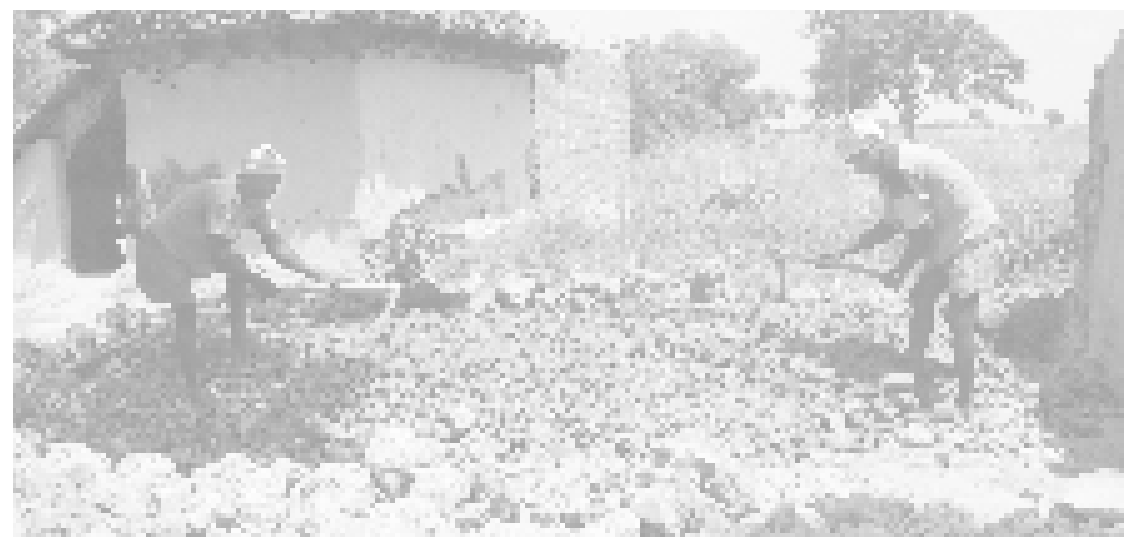




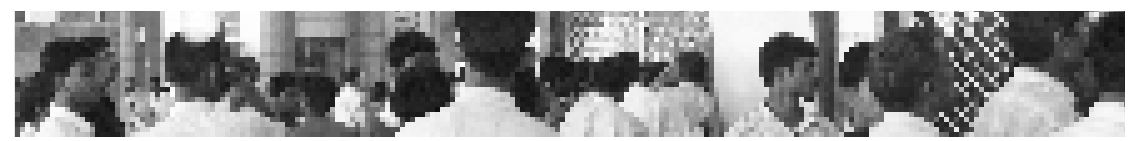

Table 14 : Percentage of recent male migrants surveyed who reported that they were working under a contract either for the first time for work or currently, at the first time they moved from home to find work, or never, by occupation, Karnataka State, India, 2007

\begin{tabular}{|c|c|c|c|c|c|c|}
\hline Occupation & $\begin{array}{l}\text { Never } \\
\text { worked } \\
\text { under } \\
\text { contract }\end{array}$ & $\begin{array}{l}\text { Not under } \\
\text { contract first } \\
\text { time moved } \\
\text { for work but is } \\
\text { now under } \\
\text { contract }\end{array}$ & $\begin{array}{l}\text { Under } \\
\text { contract first } \\
\text { time moved } \\
\text { for work but not } \\
\text { now under } \\
\text { contract }\end{array}$ & $\begin{array}{l}\text { Under } \\
\text { contract first } \\
\text { time moved } \\
\text { for work } \\
\text { and currently }\end{array}$ & $\begin{array}{l}\text { Anticipated HIV- } \\
\text { prevention } \\
\text { programme coverage } \\
\text { of migrant men if } \\
\text { programme } \\
\text { implemented through } \\
\text { contract system }\end{array}$ & (N) \\
\hline Construction & 44.8 & 28.1 & 2.3 & 24.8 & 55.2 & $(480)$ \\
\hline Mining & 59.6 & 23.2 & 3.6 & 13.6 & 40.4 & (250) \\
\hline Road construction & 46.2 & 19.7 & 0.6 & 33.5 & 53.8 & (325) \\
\hline Fishing & 96.7 & 1.4 & 0.0 & 1.9 & 3.3 & (209) \\
\hline Port/factory loading & 89.8 & 1.2 & 8.4 & 0.6 & 10.2 & (166) \\
\hline Sugarcane cutting & 6.4 & 29.8 & 1.2 & 62.6 & 93.6 & (171) \\
\hline Brick industry & 93.6 & 0.5 & 4.1 & 1.8 & 6.4 & (219) \\
\hline Industry & 93.0 & 0.9 & 2.2 & 3.9 & 7.0 & (230) \\
\hline Day labour & 78.1 & 0.4 & 3.4 & 18.0 & 21.9 & (233) \\
\hline Garment work & 98.5 & 0.0 & 1.5 & 0.0 & 1.5 & (194) \\
\hline warehouse work & 98.7 & 0.0 & 1.3 & 0.0 & 1.3 & $(154)$ \\
\hline Total & 69.2 & 12.0 & 2.5 & 16.3 & 30.8 & $(2,631)$ \\
\hline
\end{tabular}

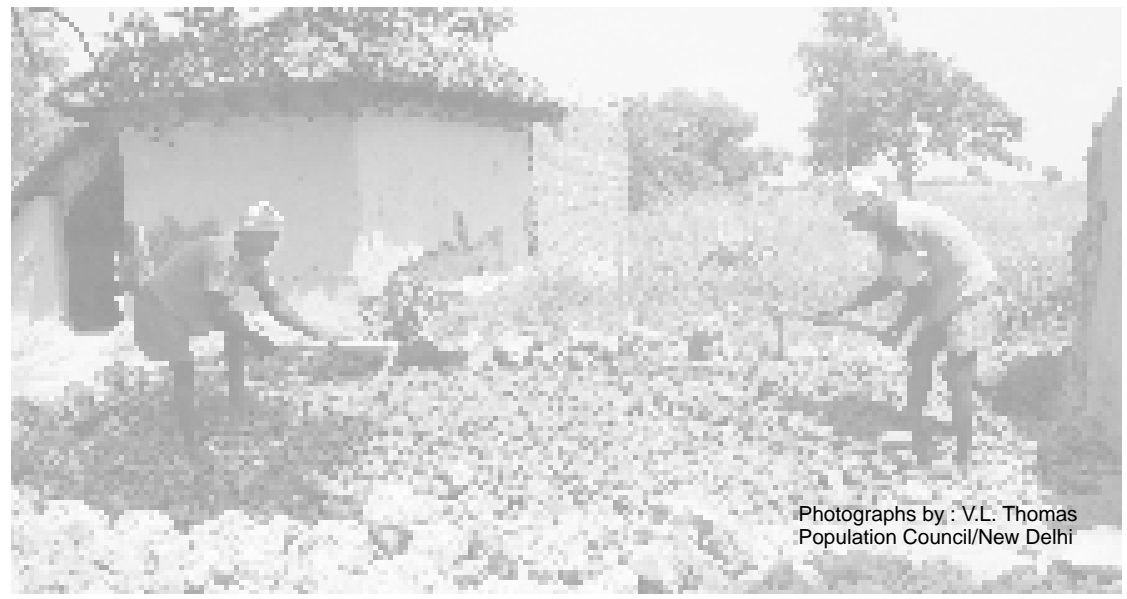




\section{Population Council}

www.popcouncil.org

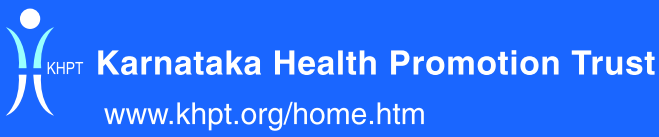

